Cochrane Database of Systematic Reviews

\title{
Consultation liaison in primary care for people with mental disorders (Review)
}

Gillies D, Buykx P, Parker AG, Hetrick SE

Gillies D, Buykx P, Parker AG, Hetrick SE.

Consultation liaison in primary care for people with mental disorders.

Cochrane Database of Systematic Reviews 2015, Issue 9. Art. No.: CD007193.

DOI: 10.1002/14651858.CD007193.pub2.

www.cochranelibrary.com 
TABLE OF CONTENTS

ABSTRAC

PLAIN LANGUAGE SUMMARY

SUMMARY OF FINDINGS

BACKGROUND

OBJECTIVES

METHODS

RESULTS

Figure 1.

Figure 2.

DISCUSSION

AUTHORS' CONCLUSIONS

ACKNOWLEDGEMENTS

REFERENCES

CHARACTERISTICS OF STUDIES

DATA AND ANALYSES

Analysis 1.1. Comparison 1 Consultation liaison versus control, Outcome 1 Improvement.

Analysis 1.2. Comparison 1 Consultation liaison versus control, Outcome 2 Symptoms.

Analysis 1.3. Comparison 1 Consultation liaison versus control, Outcome 3 Consumer satisfaction.

Analysis 1.4. Comparison 1 Consultation liaison versus control, Outcome 4 Consumer adherence.

Analysis 1.5. Comparison 1 Consultation liaison versus control, Outcome 5 Disability.

Analysis 1.6. Comparison 1 Consultation liaison versus control, Outcome 6 Healthcare visits.

Analysis 1.7. Comparison 1 Consultation liaison versus control, Outcome 7 People lost to follow-up.

Analysis 1.8. Comparison 1 Consultation liaison versus control, Outcome 8 Diagnosis.

Analysis 1.9. Comparison 1 Consultation liaison versus control, Outcome 9 Received any treatment.

Analysis 1.10. Comparison 1 Consultation liaison versus control, Outcome 10 Received adequate treatment.

Analysis 1.11. Comparison 1 Consultation liaison versus control, Outcome 11 Specialist treatment.

Analysis 1.12. Comparison 1 Consultation liaison versus control, Outcome 12 Prescribing.

Analysis 1.13. Comparison 1 Consultation liaison versus control, Outcome 13 Primary care provider adherence.

Analysis 2.1. Comparison 2 Consultation liaison versus collaborative care, Outcome 1 Improvement.

Analysis 2.2. Comparison 2 Consultation liaison versus collaborative care, Outcome 2 Symptoms.

Analysis 2.3. Comparison 2 Consultation liaison versus collaborative care, Outcome 3 Consumer satisfaction. .......................

Analysis 2.4. Comparison 2 Consultation liaison versus collaborative care, Outcome 4 Disability.

Analysis 2.5. Comparison 2 Consultation liaison versus collaborative care, Outcome 5 General health.

Analysis 2.6. Comparison 2 Consultation liaison versus collaborative care, Outcome 6 Loss to follow-up.

Analysis 2.7. Comparison 2 Consultation liaison versus collaborative care, Outcome 7 Received adequate treatment. ............

Analysis 2.8. Comparison 2 Consultation liaison versus collaborative care, Outcome 8 Prescribing. ADDITIONAL TABLES

APPENDICES

WHAT'S NEW

CONTRIBUTIONS OF AUTHORS

DECLARATIONS OF INTEREST

SOURCES OF SUPPORT

DIFFERENCES BETWEEN PROTOCOL AND REVIEW

INDEX TERMS 
[Intervention Review]

\title{
Consultation liaison in primary care for people with mental disorders
}

\author{
Donna Gillies ${ }^{1}$, Penny Buykx²,3, Alexandra G Parker ${ }^{4}$, Sarah E Hetrick 5
}

1Western Sydney Local Health District - Mental Health, Parramatta, Australia. ${ }^{2}$ School of Health and Related Research (ScHARR), University of Sheffield, Sheffield, UK. ${ }^{3}$ Monash University School of Rural Health, Bendigo, Australia. ${ }^{4}$ Orygen Youth Health Research Centre, Centre for Youth Mental Health, University of Melbourne, Melbourne, Australia. ${ }^{5}$ Orygen, The National Centre of Excellence in Youth Mental Health and The Centre of Youth Mental Health, University of Melbourne, Melbourne, Australia

Contact: Donna Gillies, Western Sydney Local Health District - Mental Health, Cumberland Hospital, Locked Bag 7118, Parramatta, NSW, 2124, Australia. donna.gillies1@health.nsw.gov.au.

Editorial group: Cochrane Effective Practice and Organisation of Care Group.

Publication status and date: Edited (no change to conclusions), published in Issue 12, 2016.

Citation: Gillies D, Buykx P, Parker AG, Hetrick SE. Consultation liaison in primary care for people with mental disorders. Cochrane Database of Systematic Reviews 2015, Issue 9. Art. No.: CD007193. DOI: 10.1002/14651858.CD007193.pub2.

Copyright @ 2016 The Cochrane Collaboration. Published by John Wiley \& Sons, Ltd.

\section{A B S T R A C T}

\section{Background}

Approximately $25 \%$ of people will be affected by a mental disorder at some stage in their life. Despite the prevalence and negative impacts of mental disorders, many people are not diagnosed or do not receive adequate treatment. Therefore primary health care has been identified as essential to improving the delivery of mental health care. Consultation liaison is a model of mental health care where the primary care provider maintains the central role in the delivery of mental health care with a mental health specialist providing consultative support. Consultation liaison has the potential to enhance the delivery of mental health care in the primary care setting and in turn improve outcomes for people with a mental disorder.

\section{Objectives}

To identify whether consultation liaison can have beneficial effects for people with a mental disorder by improving the ability of primary care providers to provide mental health care.

\section{Search methods}

We searched the EPOC Specialised Register, Cochrane Central Register of Controlled Trials (CENTRAL), and bibliographic databases: MEDLINE, EMBASE, CINAHL and PsycINFO, in March 2014. We also searched reference lists of relevant studies and reviews to identify any potentially relevant studies.

\section{Selection criteria}

We included randomised controlled trials (RCTs) which compared consultation liaison to standard care or other service models of mental health care in the primary setting. Included participants were people attending primary care practices who required mental health care or had a mental disorder, and primary care providers who had direct contact with people in need of mental health care.

\section{Data collection and analysis}

Two review authors independently screened the titles and abstracts of identified studies against the inclusion criteria and extracted details including the study design, participants and setting, intervention, outcomes and any risk of bias. We resolved any disagreements by discussion or referral to a third author. We contacted trial authors to obtain any missing information.

We collected and analysed data for all follow-up periods: up to and including three months following the start of treatment; between three and 12 months; and more than 12 months following the start of therapy. 
We used a random-effects model to calculate the risk difference (RD) for binary data and number needed to treat for an additional beneficial outcome (NNTB), if differences between groups were significant. The mean difference (MD) or standardised mean difference (SMD) was calculated for continuous data.

\section{Main results}

There were 8203 citations identified from database searches and reference lists. We included 12 trials with 2605 consumer participants and more than 905 primary care practitioner participants. Eleven trials compared consultation liaison to standard care and one compared consultation liaison to collaborative care, with a case manager co-ordinating mental health care. People with depression were included in eight trials; and one trial each included people with a variety of disorders: depression, anxiety and somatoform disorders; medically unexplained symptoms; and drinking problems. None of the included trials reported separate data for children or older people.

There was some evidence that consultation liaison improved mental health up to three months following the start of treatment (two trials, $\mathrm{n}=445$, NNTB $8,95 \% \mathrm{Cl} 5$ to 25 ) but there was no evidence of its effectiveness between three and 12 months. Consultation liaison also appeared to improve consumer satisfaction (up to three months: one trial, $\mathrm{n}=228$, NNTB 3,95\% $\mathrm{Cl} 3$ to $5 ; 3$ to 12 months: two trials, $\mathrm{n}=$ 445, NNTB 8, 95\% Cl 5 to 17 ) and adherence ( 3 to 12 months: seven trials, $\mathrm{n}=1251$, NNTB $6,95 \% \mathrm{Cl} 4$ to 13 ) up to 12 months. There was also an improvement in the primary care provider outcomes of providing adequate treatment between three to 12 months (three trials, $\mathrm{n}=797$, NNTB $7,95 \% \mathrm{Cl} 4$ to 17 ) and prescribing pharmacological treatment up to 12 months (four trials, $\mathrm{n}=796, \mathrm{NNTB} 13,95 \% \mathrm{Cl} 7$ to 50). There was also some evidence that consultation liaison may not be as effective as collaborative care in regards to symptoms of mental disorder, disability, general health status, and provision of treatment.

The quality of these findings were low for all outcomes however, apart from consumer adherence from three to 12 months, which was of moderate quality. Eight trials were rated a high risk of performance bias because consumer participants were likely to have known whether or not they were allocated to the intervention group and most outcomes were self reported. Bias due to attrition was rated high in eight trials and reporting bias was rated high in six.

\section{Authors' conclusions}

There is evidence that consultation liaison improves mental health for up to three months; and satisfaction and adherence for up to 12 months in people with mental disorders, particularly those who are depressed. Primary care providers were also more likely to provide adequate treatment and prescribe pharmacological therapy for up to 12 months. There was also some evidence that consultation liaison may not be as effective as collaborative care in terms of mental disorder symptoms, disability, general health status, and provision of treatment. However, the overall quality of trials was low particularly in regards to performance and attrition bias and may have resulted in an overestimation of effectiveness. More evidence is needed to determine the effectiveness of consultation liaison for people with mental disorders particularly for those with mental disorders other than depression.

\section{PLAIN LANGUAGE SUMMARY}

\section{Consultation liaison in primary care appears to improve mental health practice and outcomes for people with a mental disorder}

Despite the prevalence and negative impacts of mental disorders, many people are not diagnosed or do not receive adequate treatment. Consultation liaison is one way of providing mental health care to people in the primary care setting. In consultation liaison, a mental health specialist works with the primary care provider to deliver appropriate care for people with mental health needs. In this review of studies published up till March 2014, the effectiveness of consultation liaison was compared to standard primary care and other types of mental health care. We included 12 trials with 2605 consumers and more than 905 primary care providers. Consultation liaison was compared to standard care in 11 trials, and compared to collaborative care in one trial. Collaborative care is mental health care co-ordinated by a primary care case manager. There was some evidence that consultation liaison improved mental health, satisfaction with care and adherence to treatment in people with some mental disorders, particularly those with depression, and improved mental health care by primary care providers. There was also some evidence suggesting consultation liaison may not be as effective as collaborative care. However, as the overall quality of trials was low, the effectiveness of these ways of delivering care may have been overestimated. No conclusions can be made regarding the use of consultation liaison with people who have other mental disorders such as schizophrenia or bipolar disorder. There was also no data which could inform practice with specific groups of people such as children and adolescents, and the elderly. More high quality trials of consultation liaison are needed. 


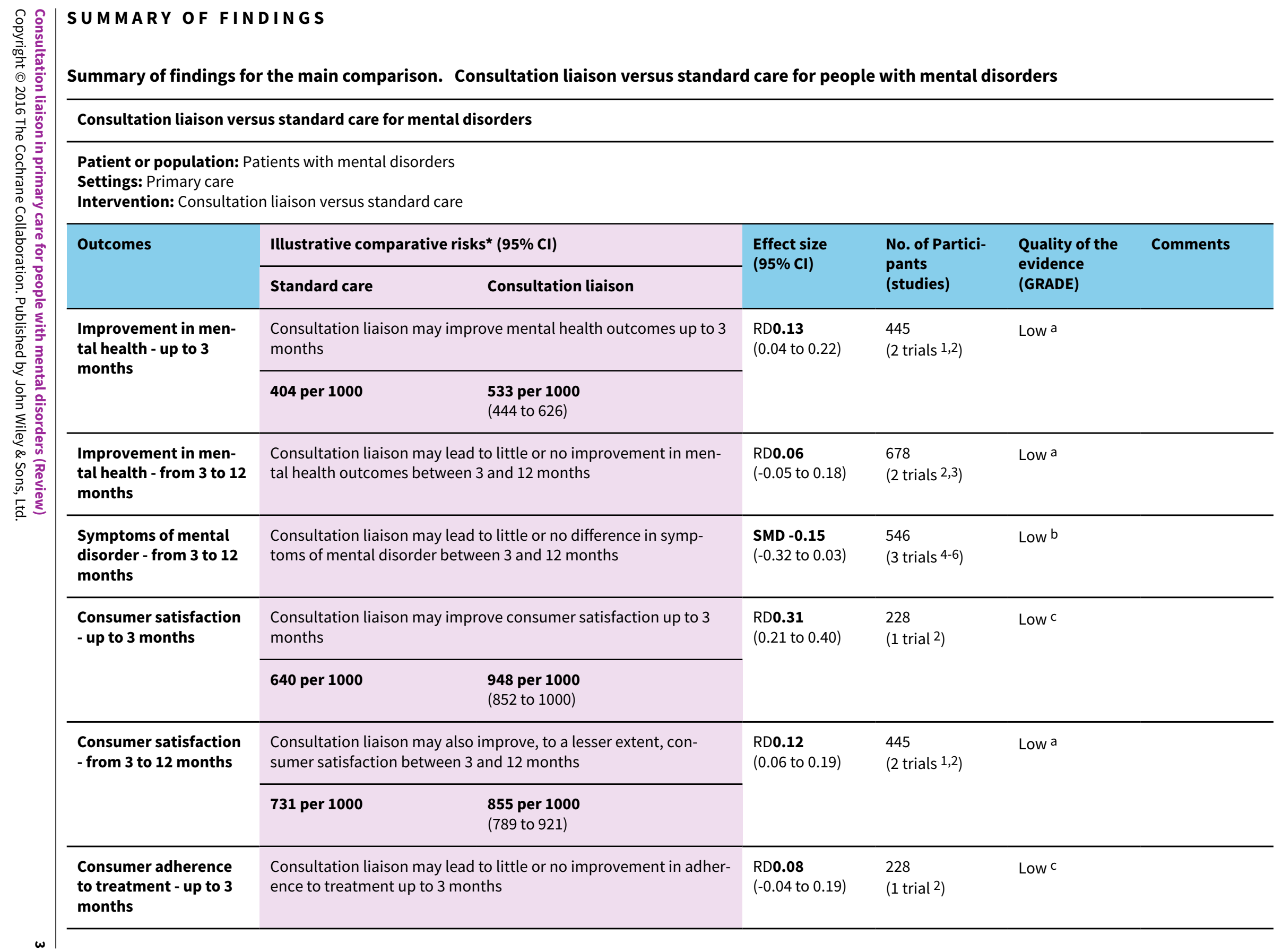

Settings: Primary care

Outcomes

Illustrative comparative risks* $(95 \% \mathrm{CI})$

Effect siz

No. of Partici-

lity of the

Consultation liaison may improve mental health outcomes up to 3

RD0.13

445

tal health - up to 3

533 per 1000

(444 to 626 )

Improvement in men-

Consultation liaison may lead to little or no improvement in men-

RD0.06

678

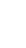

months

Consultation liaison may lead to little or no difference in symp-

SMD -0.15

546

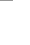

months

Consumer satisfaction month 


\section{B A C K G R O U N D}

\section{Description of the condition}

Up to $25 \%$ of people across the world will be affected by a mental disorder at some stage in their life. The most prevalent of these are mood and anxiety disorders which affect $10 \%$ and $8 \%$ of people respectively at any time (WHO 2001). A number of mental disorders rank among the leading causes of disability, particularly among 15 to 44 year olds, where depressive disorders are the second most common cause of disability-adjusted life years (DALYs), with schizophrenia 8th and bipolar affective disorder 9th (WHO 2001). In addition, alcohol use disorders and self-inflicted injuries, both of which are commonly associated with mental disorders, are ranked as 4th and 5th most common cause of DALYs amongst this age group (WHO 2001). Mental disorders account for approximately $12 \%$ of total DALYs lost due to all diseases and illnesses (Patel 2007; WHO 2001) and increase the risk of ill health, earlier death, and attempted and completed suicide (Marttunen 2000; Van Heeringen 2000).

\section{Description of the intervention}

Consultation liaison, in its broadest sense, is a model of mental health care in which there is an interface between mental health specialists and other health care providers. There is a strong history of consultation liaison within the hospital setting (Huyse 2000; Ilchef 2006) but the consultation liaison services required by hospital patients can be quite different from those in primary care (Ruddy 2005). Hospital patients are more likely to be acutely physically unwell and more likely to receive short-term interventions compared to patients in primary care (Ruddy 2005).

In more recent years, the potential advantages of consultation liaison in the primary care setting have been recognised (Harmon 2000; Sved Williams 2006), and the World Health Organization (WHO 2001; Kohn 2004) identified primary care as essential to improving the delivery of mental health care because of its greater accessibility (Parslow 2000; WHO 2001). Primary care, such as general or family physician practices, provides general community-based health care which links people to specialist services for specific health needs. In mental health consultation liaison, the primary care provider maintains a central role in the delivery of mental health care with the mental health care specialist typically assessing the person with a mental disorder and providing consultation to the primary care provider (Berardi 2002; Bower 2005; Ruddy 2005). The mental health specialist may also directly treat and refer consumers (Berardi 2002; Ruddy 2005). The mental health specialist is often a psychiatrist, but can also be a mental health nurse, psychologist, social worker, or a team of mental health care providers (Gunn 2009; Kisely 2007; McNamara 2008). Consultation liaison has the potential to improve the ability of primary care providers to recognise and treat mental disorders (Kisely 2007; Sved-Williams 2010; Younes 2008), enhance communication between services (Bambling 2007; Sved Williams 2006), increase effective use of mental health resources (Mitchell 2002; Sved Williams 2006), and decrease mental health admissions (Sved Williams 2006).

Consultation Liaison also lends itself readily to e-health technologies such as videoconferencing to provide mental health support in areas with limited access to resources, such as rural areas (Hilty 2006), and in resource-poor settings (Vythilingum 2011).

\section{How the intervention might work}

A high proportion of people attending primary care have mental disorders, with estimates of between 20\% and 50\% (Copty 2005; Hickie 2007; Kisely 2007; Reilly 2012). The most common disorders in people attending primary care are affective, anxiety and somatoform disorders (Bourgeois 2005; Rodrigo 2013; Sarries 2008). Most people with mental disorders are identified and treated in primary care settings (Copty 2005; Kessler 2012; Van Rijswijk 2007) and often prefer to be managed by primary care professionals (Harmon 2000; Mitchell 2002). However, although people with mental disorders are more likely to access primary care than mental health services (Chew-Graham 2007; Sved Williams 2006), many are not correctly diagnosed or do not receive adequate treatment (Hickie 2007; Kohn 2004; Trude 2003), or are diagnosed some time after onset (Andrews 2001; Wang 2005). Consultation liaison between primary care providers and mental health specialists has the potential to improve outcomes for people with a mental disorder by enhancing the ability of primary care providers to diagnose and correctly treat mental disorders (Emmanuel 2002; Gilbody 2003; Kisely 2007; Younes 2008), provide an opportunity for early intervention (Broome 2005; Tovey 2004), and ensure that the relationship between the primary care provider and consumer is not disrupted (Mitchell 2002).

\section{Why it is important to do this review}

A previous Cochrane review (Bower 2000) examined the effectiveness of onsite mental health workers in primary care. Due to increasing research in this area this original review has now been split into separate reviews on collaborative care and consultation liaison. Two Cochrane reviews of collaborative care for people with mental disorders have now been published (Archer 2012; Reilly 2013). No meta-analytic review of consultation liaison services in primary care settings for people with mental disorders has yet been published.

\section{O B JECTIVES}

To identify whether consultation liaison can have beneficial effects for people with a mental disorder by improving the ability of primary care providers to provide mental health care.

\section{METHODS}

\section{Criteria for considering studies for this review}

\section{Types of studies}

Given the findings of the original review by Bower 2000, we believed that there would be few RCTs in this area and therefore RCTs, non-randomised controlled trials, controlled before and after studies, and interrupted time series which met the Effective Practice and Organisation of Care (EPOC) criteria would have been included (EPOC 2013a). However, all identified studies which met the inclusion criteria were RCTs. Therefore all future updates of this review will include RCTs only.

We included both published and unpublished studies and applied no language restrictions. 


\section{Types of participants}

\section{People with a mental disorder}

We included people with a mental disorder presenting to primary care practices and who the primary care provider regarded as needing mental health care, or had been diagnosed with a mental disorder using any diagnostic system, such as the WHO International Classification of Diseases (ICD) or Diagnostic and Statistical Manual (DSM) of Mental Disorders criteria or a scale based on these criteria. The mental disorder may or may not have been comorbid with other physical conditions. Consumer participants could be any age or gender, and could be hospitalised for a mental disorder during an episode of care.

We excluded studies which focused on people with disorders listed in the DSM or ICD Mental and Behavioural Disorders which are considered predominantly physical or behavioural disorders. Examples include studies of people with an intellectual or learning disability, Alzheimer's disease, dementia associated with HIV/AIDs, for management of overweight or obesity, or nicotine withdrawal.

\section{Primary care providers}

We included primary care providers who were healthcare professionals providing general health care to consumers in need of mental health care. This included general practitioners and physicians and other health professionals such as nurses.

\section{Types of interventions}

\section{Consultation Liaison}

We included consultation liaison as a specific service delivery model, or as a component of a broader service delivery model (for example, consultation liaison in conjunction with psychoeducation for consumers).There had to be at least one session where a mental health specialist consulted with the primary care provider to be defined as consultation liaison although the amount of contact and method of interaction could vary. Consultation liaison could include education, problem solving, and formal feedback from mental health specialists on diagnosis and prescribing or other strategies designed to enhance the primary care provider's management of mental health.There did not have to be direct contact between the mental health specialist and the consumer. If there was direct contact, this could be done separately or undertaken jointly with the primary care provider. The amount of direct care provided to consumers by primary care clinicians and mental health specialists could vary.

We excluded time-limited educational interventions which focused on providing generic information about mental disorders but included consumer-specific educational materials which were included as part of the consultation liaison process. We also excluded technology-based mental health interventions such as screening tools, computerised aids or self-help interventions unless the technology was used to support a consultation liaison role.

As it is often difficult to differentiate between collaborative care and consultation liaison in the literature, we defined collaborative care as involving at least three types of healthcare professional, that is the primary care provider, mental health specialist and case manager (Katon 2001). In contrast, we defined the consultation liaison model as one where only two types of health professionals (the primary care provider and mental health specialist) are involved, with the primary care provider maintaining responsibility for managing care (Katon 2001). The mental health specialist could differ in terms of speciality, qualifications, training and experience.

\section{Comparator interventions}

- Standard care e.g. primary care care providers continuing to provide mental health careand referreing to specialist mental health services where needed

- Other models of mental health care e.g. collaborative care

\section{Types of outcome measures}

\section{Primary outcomes}

Consumer

- Improvement in mental health: for example, no longer meeting diagnostic criteria for a mental disorder or clinical cut-off score, or a prespecified improvement on a symptom scale for mental disorders.

- Mental disorder symptoms: scores on validated measures of mental disorder symptoms.

- Adverse events: any adverse events reported by study authors.

\section{Secondary outcomes}

Consumer

- Relapse: recurrence of mental disorder following improvement.

- Satisfaction: with treatment.

- Adherence: to prescribed medication or referral to treatment.

- Disability: scores on a validated disability scale.

- General health status: scores on general health questionnaires or scales.

- Healthcare visits: visits to either general health or specialist mental health practitioners or services.

- Number of people lost to follow-up.

Provider

- Diagnosis: number and accuracy of diagnoses of mental disorders.

- Treatment: number of consumers receiving mental health treatment and adequacy of treatment.

- Specialist treatment: number and appropriateness of referrals to, or treatment by, mental health services.

- Prescribing: rate and appropriateness of prescribing psychotropic medications.

- Adherence: to treatment guidelines or algorithms.

- Knowledge: in diagnosing or treating mental disorders.

- Confidence: in diagnosing or treating mental disorders.

- Cost of treatment.

\section{Search methods for identification of studies}

\section{Electronic searches}

We searched the following electronic databases for primary studies in March 2014.

The EPOC Specialised Register (and the database of studies awaiting assessment), using a broad search to capture the range 
of health service delivery models relevant to mental health care in general practice (Appendix 1).

The search terms were:

(psychiatri $^{\star}$ or psycho* or mental or depress* ${ }^{\star}$ or anxiet* or disorder ${ }^{\star}$ or therap* or counsel ${ }^{\star}$ ) and ("primary care" or "family practi*" or "general practi*" or "family medicine" or "family physician*" or "gp" or "gps") and (consult* or liais* or refer ${ }^{\star}$ or collaborat $\left.^{\star}\right)$ )

The Cochrane Central Register of Controlled Trials (CENTRAL) (The Cochrane Library) (Issue 3, 2014). (Appendix 1)

Ovid MEDLINE (1946 to March 2014)

Ovid EMBASE (1974 to March 2014)

EBSCO CINAHL (1982 to March 2014)

OVID PsycINFO (1806 to March 2014)

We searched electronic databases using a strategy developed incorporating the methodological component of the EPOC search strategy combined with selected MeSH terms and free text terms relating to consultation liaison (EPOC 2014) The MEDLINE search strategywas translated into the other databases using the appropriate controlled vocabulary as applicable.

The Database of Abstracts of Reviews of Effectiveness (DARE) was also searched for related reviews.

\section{Searching other resources}

We also searched reference lists of studies and relevant reviews to identify any other potential studies.

\section{Data collection and analysis}

\section{Selection of studies}

Two review authors independently screened the titles and abstracts of studies identified from the search for references which appeared to meet the inclusion criteria. We then compared these potentially relevant studies and any discrepancies were resolved by discussion. The full text of all potentially relevant studies were then obtained and also screened to identify those that met the inclusion criteria for the review.

\section{Data extraction and management}

We developed and piloted a data extraction form for this review based on the Cochrane Effective Practice and Organisation of Care (EPOC) Group data collection checklist s(EPOC 2013b). Two review authors independently extracted methodological and outcome data from each study independently. Each pair then compared their results. If we identified any differences, they were resolved by consensus or referral to a third author. Where further clarification or missing data were needed from study authors, we made all reasonable attempts to contact study authors.

We extracted the following information from all included studies.

- Study: the type of study and whether it met the inclusion criteria.
- Participants

- consumers: number of participants enrolled and lost to follow-up, age, gender, diagnoses and other mental health or demographic information.

- primary care providers and mental health specialists: number of participants, age, gender, profession, speciality, clinical experience and training.

- Intervention: a description of interactions between i) mental health specialists and consumers, ii) primary care providers and mental health specialists, and iii) primary care providers and consumers; as well as the frequency of contacts, study setting, and length of the intervention.

- Outcomes: consumer and provider outcomes which were included in the review, how they were defined or measured, when they were measured, types of data and values.

- Quality criteria - these are described in Assessment of risk of bias in included studies.

\section{Assessment of risk of bias in included studies}

Because all identified studies which met the inclusion criteria were RCTs they were independently assessed according to the following risk of bias criteria (Higgins 2011).

Adequate sequence generation (selection bias)

Low risk: a random sequence generation process is clearly described by the study authors; high risk: a non-random sequence generation process is described; unclear risk: insufficient information

\section{Allocation concealment (selection bias)}

Low risk: participants and investigators enrolling participants could not identify allocation; high risk: participants or investigators enrolling participants could identify allocation; unclear risk: insufficient information

\section{Blinding of participants (performance bias)}

Low risk: blinding of participants ensured, or incomplete blinding but the outcome is unlikely to be influenced by lack of blinding; high risk: no blinding and the outcome is likely to be influenced by lack of blinding; unclear risk: insufficient information.

Blinding of outcome assessment (detection bias)

Low risk: adequate blinding of outcome assessment is described or outcome measurement is unlikely to be influenced by lack of blinding; high risk: no blinding of outcome assessment and measurement likely to be influenced by lack of blinding; unclear risk: insufficient information

\section{Incomplete outcome data (attrition bias)}

Low risk: no missing outcome data or the amount of missing data is small (up to $5 \%$ ) and the appropriate imputation methods were used; high risk: loss to follow-up was more than $25 \%$ or more than $5 \%$ if imputation was not used; unclear risk: insufficient information about attrition or if attrition was between $0 \%$ and $5 \%$ and imputation was not used or if attrition was between 6 and $25 \%$ but appropriate imputation methods were used.

Free of selective reporting (selective reporting)

Low risk: the study protocol is available and all of the study's prespecified outcomes, which are included in the review as primary outcomes, have been reported; high risk: not all of the study outcomes, which were primary outcomes in the review, 
were reported or data were only reported for a subgroup of participants; unclear risk: insufficient information or a secondary review outcome was collected but not reported in a study.

\section{Free of any other bias}

Low risk: the study appears to be free of other sources of bias; high risk: there is at least one important risk of bias such as markedly different characteristics of participants in each group; unclear risk: there is insufficient information to assess whether an additional risk of bias exists, e.g. inadequate description of the demographic characteristics for each intervention and standard care group.

Two review authors independently extracted risk of bias criteria data from each study. If there was any disagreement about whether or not a trial fulfilled a particular risk of bias criterion, these differences were resolved by consensus or referral to a third author.

\section{Measures of treatment effect}

\section{Binary data}

We extracted data from the included studies for the binary outcomes of improvement in mental health, consumer satisfaction and adherence, practitioner adherence, diagnosis, treatment, prescribing, and loss to follow-up. For binary outcomes we calculated the risk difference (RD) and 95\% confidence intervals (Cls) using a a random-effects model. The choice of RD was based on three criteria (Deeks 2011): i) consistency - there was less heterogeneity for RD than than for risk ratio for our data; ii) mathematical properties - it is used to calculate the NNTB; and iii) ease of interpretation - absolute measures are considered more interpretable than relative measures.

\section{Continuous dato}

We extracted data for the continuous outcomes of mental disorder symptoms, general health status, disability and healthcare visits from included studies. However, we only included data if the scale or questionnaire used to measure these outcomes had been reported as valid and reliable in a peer-reviewed journal. Because a number of different scales were used for symptoms, we calculated the standardised mean difference (SMD); however for all other outcomes which used similar scales or were only reported by individual studies, we used the mean difference (MD). If change data had been reported for the same outcome, these values would have been included in a meta-analysis using an unstandardised mean difference. Where SMD was calculated we considered less than 0.40 as a small effect size, 0.40 to 0.70 as moderate, and more than 0.70 as large (Deeks 2011).

\section{Skewed data}

As a meta-analysis is based on assumptions of normality, we checked all continuous data for skew before inclusion. For a scale which starts from zero, a standard deviation which is more than half the mean suggests skew, while a standard deviation which is more than the mean is considered strong evidence of a skewed distribution (Deeks 2011). Therefore, if the standard deviation was greater than the mean for both groups we did not include these data in a meta-analysis and reported them separately.

\section{Unit of analysis issues}

We did not identify any crossover trials. If they had been identified, only first interval data would have been used as there was a high likelihood of a carryover effect in the intervention groups.

If corrected data were reported for cluster-randomised trials, we planned to use these data for meta-analysis. If corrected data were not reported, we intended to estimate corrections if adequate data were available; however, these data were also not reported. Also, we had intended to conduct a sensitivity analysis of these trials on meta-analytic findings but there was not enough data to be able to do this.

\section{Dealing with missing data}

We used intention-to-treat data and imputed values such as last observation carried forward values where these were reported. We had intended to conduct sensitivity analyses to test for any effects of loss to follow-up on the stability of results but there were not enough trials reporting primary outcome data for this to be done.

\section{Assessment of heterogeneity}

We used a Mantel-Haenszel Chi ${ }^{2}$ test and the $\mathrm{I}^{2}$ statistic to test for heterogeneity (Higgins 2003). We considered a $\mathrm{Chi}^{2}$ value of less than 0.10 or an 12 value of greater than $50 \%$, or both, as substantial heterogeneity. We conducted a sensitivity analysis to investigate the potential effects of substantial heterogeneity as well as investigating possible reasons for this heterogeneity.

\section{Assessment of reporting biases}

We had intended that primary outcome data from all included studies would be entered into a funnel plot (trial effect against trial size) to investigate the possibility of publication bias; however there were too few studies reporting primary outcomes to be able to do this.

\section{Data synthesis}

As we collected data for all follow-up periods, we analysed data as up to and including three months from the start of therapy, from three to 12 months follow-up, and follow-up for more than 12 months. If more than one set of useable data was reported for any of these periods (e.g. data at six and nine months follow-up), because these data could not be pooled, we used the first data set, as earlier intervals were more likely to have the best rates of follow-up.

All data were meta-analysed using Review Manager 5.3 (RevMan 2014). We used a random-effects model to synthesise all data as we considered it unlikely that the same effect was being measured across studies of such diversity. However, because random-effects gives more weight to smaller studies than a fixed-effect analysis, we also compared fixed and random-effects analyses to identify whether there were any differences (Sensitivity analysis).

\section{Subgroup analysis and investigation of heterogeneity}

We had intended to conduct the following subgroup analyses.

- Type of intervention, e.g. consultation liaison only or consultation liaison within an integrated model.

- Nature of the mental disorder, e.g. types of mental disorder.

- Nature of primary health care setting, e.g. youth-focused primary health care service versus generalist 
- Single versus multiple contacts: between primary care provider and mental health specialist; and between mental health specialist and consumer.

However, because of limited data these analyses were not possible.

\section{Sensitivity analysis}

We had proposed to conduct sensitivity analyses to assess the effect of risk of selection, performance and detection, attrition and reporting but we were unable to do so with the current data because of the limited number of studies available for meta-analysis. We were able to compare fixed and randomeffects models but there were no differences except that the 95\% confidence interval was slightly smaller when a fixed-effect model was used.

\section{RES U L T S}

\section{Description of studies}

\section{Results of the search}

We identified 8191 studies in the database searches, as well as 12 studies from reference lists of other publications. After screening these 8203 citations we identified 32 studies (48 citations) as potentially relevant and obtained full copies of study publications. After screening these full texts, we included 12 and excluded 20 studies. See PRISMA study flow diagram (Figure 1).

Figure 1. PRISMA Study flow diagram.

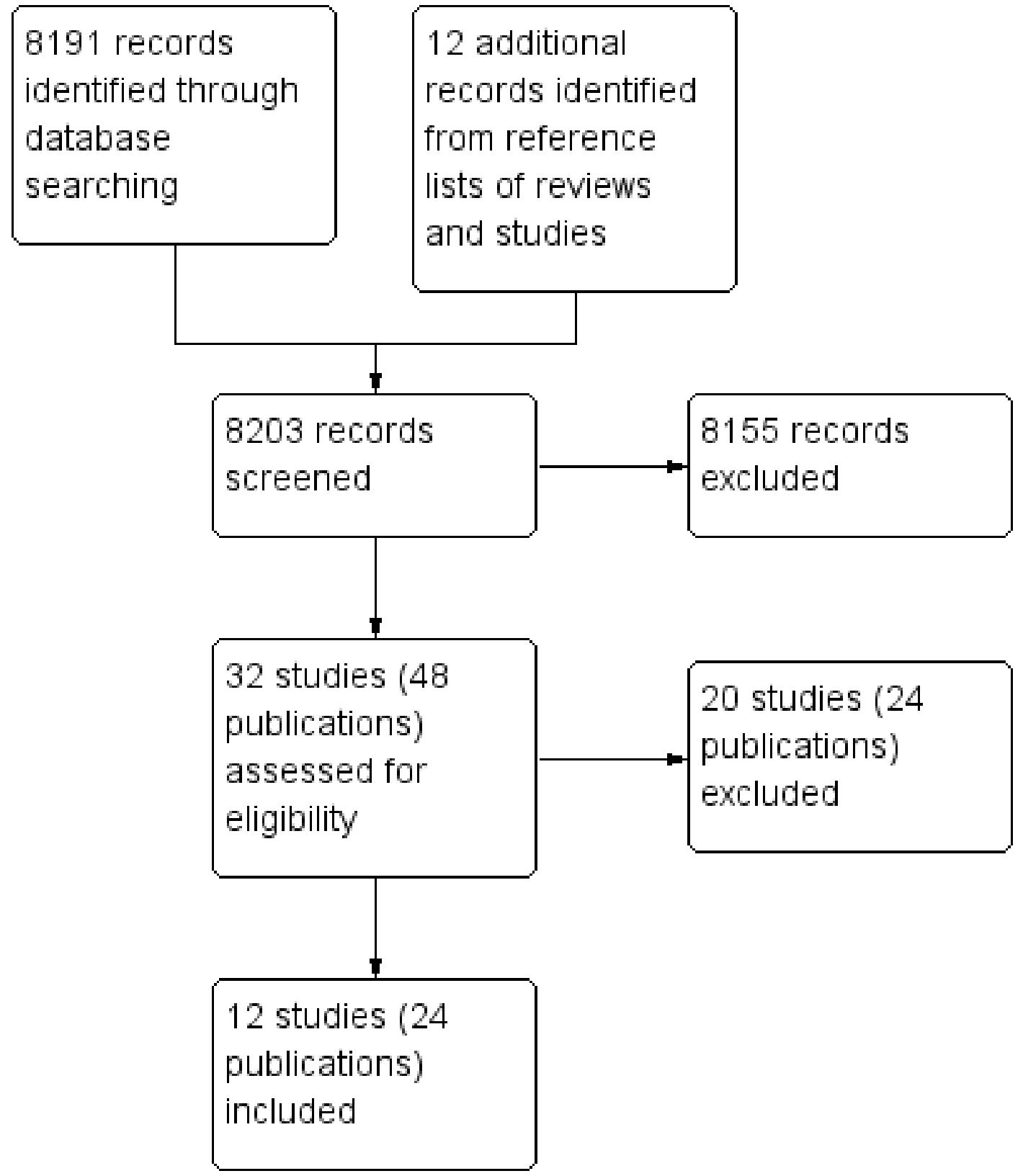




\section{Included studies}

We included 12 studies with 2605 consumer participants and more than 905 primary care providers.

Eleven trials with 2251 consumer participants and more than 838 primary care providers compared consultation liaison to a standard care group. Five trials randomised consumers to consultation liaison and standard care groups (De Cruppe 2005; Drummond 1990; Katon 1992; Katon 1995; Katon 1999), four randomised primary care clinicians (Berti Ceroni 2002; Dobscha 2006; Schrader 2005; Worrall 1999) and two randomised practices (Datto 2003; Van der Feltz 2006).

One trial with 354 consumer participants and 67 primary care providers randomised consumers to consultation liaison or collaborative care groups (Hedrick 2003).

Six trials were undertaken in the USA (Datto 2003; Dobscha 2006; Hedrick 2003; Katon 1992; Katon 1995; Katon 1999) and one each in Australia (Schrader 2005), Canada (Worrall 1999), Germany (De Cruppe 2005), Italy (Berti Ceroni 2002), the Netherlands (Van der Feltz 2006) and the United Kingdom (Drummond 1990). Apart from Dobscha 2006 and Hedrick 2003 which were set in Veterans' Affairs clinics, and Schrader 2005 which enrolled participants in urban hospitals and delivered consultation liaison with their GP, all other studies were described as being conducted in a general practice or primary care setting. The number of sites involved in each trial ranged from one (Katon 1995) to 42 (Worrall 1999).

Most trials reported consumer and provider outcomes except Drummond 1990, Katon 1995, Schrader 2005 and Van der Feltz 2006 which did not compare provider outcomes.

\section{Participants}

\section{Consumers}

The number of consumer participants included in each trial ranged from 40 (Drummond 1990) to 669 (Schrader 2005). The average age of participants was reported in all but two trials (Schrader 2005; Worrall 1999) and ranged from 39 to 57 years. The majority of consumer participants were female in seven trials (Berti Ceroni 2002; Datto 2003; De Cruppe 2005; Katon 1992; Katon 1995; Katon 1999; Van der Feltz 2006) and male in four trials, two of which were set in Veteran's Affairs clinics (Dobscha 2006; Hedrick 2003) and one aimed at problem drinkers (Drummond 1990). Gender was not reported in Worrall 1999.

The most common mental health condition for which participants were included in trials was depression or dysthymia (Berti Ceroni 2002; Datto 2003; Dobscha 2006; Hedrick 2003; Katon 1995; Katon 1999; Schrader 2005; Worrall 1999). Katon 1992 also included consumers with anxiety or somatoform disorders. One trial included people with a range of disorders (De Cruppe 2005); one with persistent medically unexplained symptoms (Van der Feltz 2006), and one included people with problem drinking (Drummond 1990).

A wide range of consumer exclusion criteria applied across studies. These included:

- recent (Dobscha 2006; Hedrick 2003) or ongoing (Berti Ceroni 2002; Hedrick 2003; Katon 1999; Van der Feltz 2006) mental health treatment ;
- active suicidal ideation/risk or very high depression score, or both (Datto 2003; Dobscha 2006; Hedrick 2003; Katon 1992; Katon 1995; Van der Feltz 2006);

- having only mild depression (Berti Ceroni 2002);

- psychotic disorder or symptoms (Berti Ceroni 2002;Datto 2003; De Cruppe 2005; Dobscha 2006; Hedrick 2003; Katon 1992; Katon 1995; Katon 1999; Van der Feltz 2006);

- bipolar disorder (Datto 2003; Dobscha 2006;

- dementia (Dobscha 2006; Katon 1992; Katon 1995; Van der Feltz 2006);

- current alcohol or other substance use problems (Datto 2003; Hedrick 2003; Katon 1992; Katon 1995; Katon 1999; Van der Feltz 2006);

- requiring treatment for post-traumatic stress disorder (PTSD) (Hedrick 2003);

- cognitive impairment (Berti Ceroni 2002; Schrader 2005);

- life threatening or terminal illness (Berti Ceroni 2002;De Cruppe 2005; Dobscha 2006);

- physical impairment (Schrader 2005);

- pregnant or breastfeeding Katon 1999);

- older than 65 (Berti Ceroni 2002) or less than 18 years (Van der Feltz 2006);

- limited study language (De Cruppe 2005; Katon 1992; Katon 1995; Katon 1999; Schrader 2005) or being unable to complete questionnaire (Van der Feltz 2006);

- planning to discontinue health insurance (Katon 1992; Katon 1995; Katon 1999); and

- being a participant in another trial (Schrader 2005).

\section{Primary care providers}

The number of primary care providers was reported in all but two trials (De Cruppe 2005; Drummond 1990) and ranged from 18 (Katon 1992) to 480 (Schrader 2005). All trials included doctors; described as general practitioners (GPs) (Berti Ceroni 2002; De Cruppe 2005; Drummond 1990;Schrader 2005; Van der Feltz 2006), family physicians (Datto 2003; Dobscha 2006; Katon 1992; Katon 1995; Katon 1999; Worrall 1999); internal medicine specialists (Datto 2003); residents or internists (Hedrick 2003; Katon 1992); or fellows (Hedrick 2003). Three trials also included nurse practitioners (Datto 2003; Dobscha 2006; Hedrick 2003) and one included physician assistants (Dobscha 2006).

\section{Mental health specialists}

Most trials included only one or two mental health specialists (Berti Ceroni 2002; Datto 2003; Dobscha 2006; Katon 1992; Katon 1995; Van der Feltz 2006; Worrall 1999), although one trial involved more than 10 mental health specialists (Hedrick 2003). Two trials did not report the number of mental health specialists involved (Katon 1999; Schrader 2005). The most common profession among mental health specialists was psychiatry, either working within a single discipline (Berti Ceroni 2002; Katon 1992; Katon 1995; Katon 1999; Van der Feltz 2006) or cross-disciplinary team (Datto 2003; Dobscha 2006; Drummond 1990; Hedrick 2003; Schrader 2005; Worrall 1999). One trial involved psychosomatic consultants trained in internal medicine and psychotherapy (De Cruppe 2005). Other mental health specialists working in teams with psychiatrists included specialist nurses (Datto 2003; Dobscha 2006; Drummond 1990; Schrader 2005), psychologists (Hedrick 2003), social workers (Hedrick 2003) and an academic family physician (Worrall 1999). 


\section{Interventions}

\section{Consultation liaison}

Consultation liaison interventions could involve three levels of interaction: i) between the mental health specialist and consumer; ii) between the mental health specialist and primary care provider; and iii) between the primary care provider and consumer. All trials except Berti Ceroni 2002 and Worrall 1999 reported on the nature of interaction between mental health specialists and consumers.

These interactions included:

- assessment interview (Datto 2003; De Cruppe 2005; Drummond 1990; Katon 1992; Schrader 2005; Van der Feltz 2006);

- referral to specialist mental health care (De Cruppe 2005; Hedrick 2003; Katon 1995);

- provision of psycho-educational materials such as booklets and DVDs (Datto 2003; Dobscha 2006; Katon 1995);

- counselling, structured advice or treatment monitoring (Datto 2003; Dobscha 2006; Drummond 1990; Hedrick 2003; Katon 1995; Katon 1999); and

- an education session (Dobscha 2006).

Most interactions were face-to-face, but some trials included contact by telephone (Datto 2003; Dobscha 2006; Katon 1999). The degree of interaction varied from a single session, which was usually an initial assessment and formulation of a treatment plan (De Cruppe 2005; Drummond 1990; Katon 1992; Schrader 2005; Van der Feltz 2006), through to those which included several occasions of contact, either face-to-face or by phone (Datto 2003; Dobscha 2006; Katon 1995; Katon 1999).

In the case of Hedrick 2003, which compared consultation liaison to collaborative care, mental health specialists provided treatment if deemed appropriate in the consultation liaison groups.

All trials reported on the nature of interaction between mental health specialists and primary care providers, with the nature and extent of this interaction varying greatly between trials.

The types of interaction reported included:

- meetings to discuss the consumer's diagnosis, treatment planning or progress, or both, either face-to-face (Berti Ceroni 2002; Drummond 1990; Katon 1992; Katon 1995; Katon 1999) or by telephone (De Cruppe 2005; Schrader 2005);

- provision of written reports from the mental health specialist to the primary care provider concerning assessment, treatment recommendations or progress, or both (Datto 2003; Dobscha 2006; Hedrick 2003; Katon 1992; Katon 1995; Schrader 2005; Van der Feltz 2006);

- availability of ongoing consultation advice and support as needed (Datto 2003; Drummond 1990; Hedrick 2003; Worrall 1999);

- facilitated referral (Dobscha 2006; Hedrick 2003);

- provision of face-to-face professional development training (Dobscha 2006; Katon 1995; Van der Feltz 2006; Worrall 1999); and

- educational material, such as treatment guidelines (Drummond 1990; Katon 1992; Schrader 2005).
The amount of contact between mental health specialists and primary care providers ranged from a single contact (De Cruppe 2005; Schrader 2005), a single contact with the option of further contact if required (Datto 2003; Drummond 1990; Hedrick 2003; Katon 1999; Worrall 1999), and between two and 12 contacts with more needed if required (Berti Ceroni 2002; Dobscha 2006; Katon 1992; Katon 1995; Van der Feltz 2006).

Most trials did not specify the type of interaction between the primary care provider and consumer that occurred in the consultation liaison intervention (Berti Ceroni 2002; Datto 2003; Dobscha 2006; Drummond 1990; Katon 1992; Katon 1995; Katon 1999; Schrader 2005; Van der Feltz 2006; Worrall 1999). Of the two trials which reported the interaction between the primary care provider and consumer, one stated that the primary care providers were responsible for initiating treatment and co-ordinating care (Hedrick 2003) while the other noted that it was recommended to primary care providers that they specifically discuss the consumer's symptoms with the consumer every four to six weeks (De Cruppe 2005).

\section{Collaborative care}

One trial compared consultation liaison with collaborative care (Hedrick 2003). The collaborative care team included a clinical psychologist, a psychiatrist, social workers and a "psychology technician". The mental health team informed the primary care provider of the consumer's diagnosis, provided a treatment plan, and communicated with the primary care provider regarding adherence and progress. Primary care providers were also able to refer to psychologists and social workers working at the clinic. The social worker or students also provided psychoeducation to consumers and contacted them on a regular basis to encourage adherence, address treatment barriers and assess response. All consumers received a video and workbook.

\section{Standard care controls}

Four studies did not describe what constituted standard care in detail (Berti Ceroni 2002; Datto 2003; Katon 1992; Schrader 2005). Most studies included assessment of consumers by the mental health specialist (De Cruppe 2005; Drummond 1990), initial counselling (Drummond 1990), continuing specialist treatment (Drummond 1990) and referral (De Cruppe 2005; Dobscha 2006; Katon 1995; Katon 1999) or admission (Drummond 1990) to other services if required. Primary care providers in the standard care groups also received training in mental health care (Dobscha 2006; Van der Feltz 2006), copies of clinical practice guidelines (Worrall 1999), and consumer's symptom scores (Dobscha 2006).

\section{Outcomes}

\section{Primary outcomes}

\section{Improvement in mental health}

Improvement in mental health was defined by a $50 \%$ reduction in the Symptom Checklist (SCL)-90 depression score at four months in Katon 1995 which compared consultation liaison to standard care, and at at three and nine months in Hedrick 2003 which compared consultation liaison to collaborative care. In the other trials which compared consultation liaison to standard care, improvement was defined as asymptomatic ( 0 to 1 symptoms) on the nine-symptom Structured Clinical Interview for DSM-IV at three and six months (Katon 1999); and no longer categorised as depressed by Centre 
for Epidemiologic Studies Depression (CES-D) scores at 12 months (Schrader 2005). Other improvement data were reported which could not be used in a meta-analysis. Improvement was defined as remission of diagnosis using the Composite International Diagnostic Interview (CIDI) at 12 months by Berti Ceroni 2002 but these data were not reported, and Datto 2003 defined improvement by a score of less than 11 on CES-D scores at 16 weeks, but data were reported as odds ratio.

\section{Symptoms of mental disorder}

Depression symptom scores were measured using the Hamilton Depression Rating Scale (Berti Ceroni 2002), Allgemeine Depressionskala (De Cruppe 2005), the CES-D (Datto 2003; Schrader 2005; Worrall 1999), the SCL-90 (Dobscha 2006; Hedrick 2003; Katon 1995; Katon 1999; Van der Feltz 2006), and Veterans Short Form (SF)-36 (Hedrick 2003; Schrader 2005). Depression scores were measured at one (Dobscha 2006; Katon 1995; Katon 1999; Van der Feltz 2006), three (Dobscha 2006; Hedrick 2003; Katon 1999), four (Katon 1995), six (De Cruppe 2005; Dobscha 2006; Katon 1999; Van der Feltz 2006; Worrall 1999), seven (Katon 1995), nine (Dobscha 2006; Hedrick 2003), twelve (Berti Ceroni 2002; Dobscha 2006), and 42 months (De Cruppe 2005). Depression scores could not be used from three studies. Data were reported graphically in Katon 1995 and could not be estimated because of the resolution of the graph; symptom scores were estimated from graphs in Katon 1999 but data were skewed; and Van der Feltz 2006 did not report depression scores because 'changes -- were not significant'.

In Drummond 1990, symptoms were measured using the Alcohol Problems Questionnaire at six months but data were skewed and could not be included in a meta-analysis of symptoms.

\section{Adverse events}

No adverse events were reported.

Secondary outcomes: consumer

\section{Relapse}

Relapse was not reported.

\section{Consumer satisfaction}

Consumer satisfaction with treatment was assessed in three studies comparing consultation liaison to a control: at four months in Katon 1995; three and six months in Katon 1999, and six and 12 months in Dobscha 2006; and at three and nine months in Hedrick 2003 which compared consultation liaison to collaborative care. All defined satisfaction as a rating of good or excellent on a five-point consumer satisfaction rating scale except for Dobscha 2006 which reported mean scores.

\section{Consumer adherence}

Consumer adherence was assessed using a wide range of outcomes. Adherence to treatment was measured at 16 weeks (Datto 2003); by the use of recommended psychotherapy treatments at six and 42 months (De Cruppe 2005); attending at least three mental health appointments (Dobscha 2006); filling one or more prescriptions over 12 months (Katon 1992); obtaining adequate medications for at least 90 days through automated pharmacy records (Katon 1995); self-reported adherence to antidepressant therapy for 25 of the previous 30 days at one, three, and six months (Katon 1999); and taking antidepressants for six months (Worrall 1999). Adherence in Drummond 1990 was defined as complete abstinence from alcohol over six months.

\section{Disability scores}

Two studies used disability scores. Van der Feltz 2006 used the Sickness Impact Profile at six weeks and six months, when consultation liaison was compared with treatment as usual. Hedrick 2003 used the Sheehan Disability Scale at three and nine months when comparing consultation liaison to collaborative care.

\section{General health status}

Two studies which compared consultation liaison with treatment as usual reported general health status; the General Health Questionnaire at six months was used by Drummond 1990 and the SF-36 physical health subscale scores at 12 months were reported by Schrader 2005 . Hedrick 2003 also reported SF-36 physical health scores at three and nine months for consultation liaison and collaborative care groups.

\section{Healthcare visits}

Six studies reported healthcare visits. Drummond 1990 reported visits to the GP over six months; Katon 1999 reported visits to the primary care provider at three and six months; Katon 1995 reported the mean number of healthcare visits over 12 months; Van der Feltz 2006 reported visits to doctors and other health care services at six weeks and six months; and Worrall 1999 reported healthcare visits over six months. However, data from Drummond 1990; Katon 1999; Van der Feltz 2006; and Worrall 1999 were skewed and could not be included in a meta-analysis. Dobscha 2006 also reported on the number in each group who attended more than three primary care appointments over 12 months.

\section{People lost to follow-up}

Loss to follow-up per group was reported or could be calculated from data in Datto 2003; De Cruppe 2005; Dobscha 2006; Drummond 1990; Katon 1999; Schrader 2005; and Van der Feltz 2006, and were therefore included in a meta-analysis.

\section{Secondary outcomes: provider \\ Diagnosis}

The number of correct diagnoses of depression over six months per primary care provider group was reported by Worrall 1999.

\section{Received any treatment}

One trial reported whether participants in either the consultation liaison or standard care group received any treatment, including pharmacological treatment, psychological treatment (e.g. psychotherapy), or any other treatment (e.g. specialist treatment) at three to 12 months (Berti Ceroni 2002).

\section{Received adequate treatment}

All definitions of adequate treatment were based on the prescription of 'adequate', 'therapeutic', or 'minimum' dose of antidepressants. These outcomes were reported when consultation liaison was compared to standard care by Dobscha 2006; Katon 1995 and Katon 1999 and to collaborative care by Hedrick 2003. Across these studies adequate treatment was reported for several time intervals but because all these studies reported adequate treatment for 90 days, these data were used for meta-analysis. 


\section{Specialist treatment}

Specialist treatment was defined by seeing psychotherapists over 12 months (Berti Ceroni 2002) and referrals to mental health professionals over six months (Worrall 1999). Hedrick 2003 also reported the number of people receiving cognitive behavioural therapy but as this was only available to the collaborative care group it was not included.

\section{Prescribing}

Worrall 1999 reported whether pharmacological treatment was prescribed at the first visit to the primary care provider; three studies reported on whether it was prescribed over 12 months ((Berti Ceroni 2002; Dobscha 2006; Katon 1992); and one over more than 12 months (De Cruppe 2005). Hedrick 2003 reported prescribing over the nine months of the trial.

\section{Primary Care Provider adherence}

Provider adherence was assessed in Datto 2003 by asking consumers whether primary care providers had made treatment recommendations up to 12 weeks and in De Cruppe 2005 by whether GPs had followed through with consultation liaison recommendations at six months.

\section{Knowledge}

No measures of improving knowledge in diagnosing or treating mental disorders were reported.

\section{Confidence}

No measures of confidence in diagnosing or treating mental disorders were reported.

\section{Cost}

Total cost per person in the collaborative care and consultation liaison groups over nine months was reported by Hedrick 2003.

\section{Excluded studies}

Twenty studies were excluded, six were studies of collaborative care (Bauer 2011; Bogner 2012; Dietrich 2004; Horner 2005; LlewellynJones 1999; Serrano 2011); five were implementation studies of another quality improvement intervention (Arora 2011; Baker 2001; Chung 2011; Sinnema 2011; Tello-Bernabe 2011); and three were controlled before and after studies that did not meet the EPOC inclusion criteria (Carr 1997; Harvey 2012; Wiener 2006). In addition, the decision for treatment to be delivered by primary care providers, the consultant psychiatrist, community mental health centre, or a combination of these was based on a treatment algorithm in Menchetti 2007; Liu 2007 was set in a hospital general medical outpatient clinic; consumer participants in Stiefel 2008 did not necessarily have a mental disorder; Su 2011 was an audit of a hospital consultation liaison service; Sherbourne 2001 was a trial of treatment recommendations; and in Wells 1999 the interaction between the mental health specialist and primary care provider was focused on education only.

\section{Risk of bias in included studies}

Selection bias due to random sequence generation was rated as low in six studies and unclear in the remaining six. The potential for selection bias due to allocation concealment was rated unclear in 11 studies and low in one study. Eight studies were considered a high risk of performance bias with only one trial rated low and the remainder rated unclear. Eight studies were also rated a high risk of attrition bias, with two rated as low, and two unclear. Six studies were considered a high risk of attrition bias with the reminder rated as unclear. Six were also rated as a high risk of reporting bias with none rated as low. Three studies were rated a high risk of other potential biases, seven as unclear and two as a low risk of other bias. See 'Risk of bias' summary Figure 2 and details below. 
Figure 2. Risk of bias summary: review authors' judgements about each risk of bias item for each included study.

\begin{tabular}{|c|c|c|c|c|c|c|}
\hline & 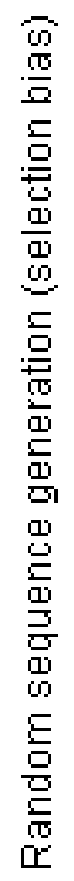 & 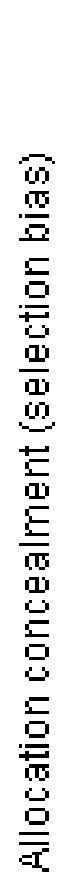 & 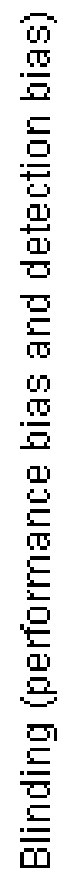 & 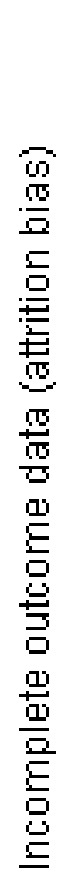 & 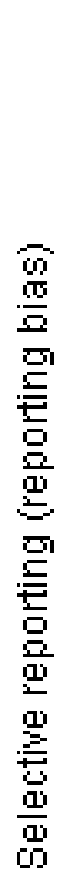 & 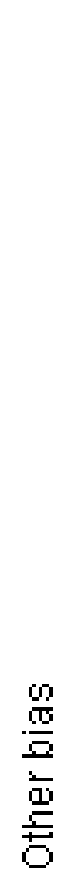 \\
\hline Berti Ceroni 2002 & $?$ & $?$ & $?$ & & & $?$ \\
\hline Datto 2003 & $?$ & $?$ & & & & \\
\hline De Cruppe 2005 & + & + & $?$ & & & $?$ \\
\hline Dobscha 2006 & + & $?$ & & & $?$ & $?$ \\
\hline Drummond 1990 & $?$ & $?$ & & & $?$ & $?$ \\
\hline Hedrick 2003 & $?$ & $?$ & & & $?$ & $?$ \\
\hline Katon 1992 & $?$ & $?$ & & & $?$ & + \\
\hline Katon 1995 & + & $?$ & & & $?$ & $?$ \\
\hline Katon 1999 & + & $?$ & & $?$ & $?$ & $?$ \\
\hline Schrader 2005 & + & $?$ & & & & \\
\hline Van der Felt 2006 & $?$ & $?$ & & & & \\
\hline Worrall 1999 & + & $?$ & $?$ & $?$ & & \\
\hline
\end{tabular}




\section{Allocation}

Six trials (De Cruppe 2005; Dobscha 2006; Katon 1995; Katon 1999; Schrader 2005; Worrall 1999) described how the randomisation sequence was generated, so we rated these a low risk of bias, the remainder did not describe how the randomisation sequence was generated and we therefore rated these an unclear risk. Allocation concealment was only described by De Cruppe 2005 which we therefore rated as a low risk. All other trials did not describe allocation concealment and were therefore rated unclear.

\section{Blinding}

Although a number of trials referred to blinded assessment of outcomes (De Cruppe 2005; Dobscha 2006; Hedrick 2003; Katon 1992; Katon 1995; Katon 1999; Van der Feltz 2006), the measures that were used were self-reported. Therefore in all trials, if consumers were likely to be aware whether they were receiving specialist treatment, we rated them a high risk of performance bias (Datto 2003; Dobscha 2006; Hedrick 2003; Katon 1992; Katon 1995; Katon 1999; Schrader 2005; Van der Feltz 2006).

We considered Drummond 1990 a low risk of performance bias because the interaction between participants and specialists were similar in both groups. We rated the remaining trials as an unclear risk because participants probably did not know if they were in the active group (Berti Ceroni 2002; De Cruppe 2005; Worrall 1999)

\section{Incomplete outcome data}

As there was no loss to follow-up in Katon 1992 and Van der Feltz 2006 they were rated a low risk of attrition bias. Worrall 1999 was rated as unclear because the loss to follow-up was not reported and while Katon 1999 reported using imputed data in analyses because the loss to follow-up was more than $5 \%$ it was also rated an unclear risk. All other trials were rated a high risk of attrition bias because the loss to follow-up was more than $5 \%$.

\section{Selective reporting}

We rated six trials as having high risk of reporting bias: Berti Ceroni 2002 did not report any of the consumer outcomes by group; Datto 2003 only reported categorical outcomes for a subsample who had major depression at baseline; the only consumer outcome reported by De Cruppe 2005 was the use of psychotherapies; Schrader 2005 did not report SF-36 mental health scores; Van der Feltz 2006; did not report SCL-R-90 results as they were not significant; and Worrall 1999 did not report the results for the SCL-90-R even though this was a primary outcome.

The remaining trials were rated an unclear risk of reporting bias because although all primary outcomes appear to have been reported there was no protocol available to check.

\section{Other potential sources of bias}

We rated three trials a high risk of other potential biases. Datto 2003 because significantly more consumers in the standard care group were prescribed antidepressants at baseline (74\% versus $37 \%)$ and there were more women in the intervention group (67\% versus 55\%). Other trials were rated as an unclear risk: Berti Ceroni 2002 because there were more consumers with severe depression allocated to the standard care group (nine versus six6); in Dobscha 2006, more participants in the standard care group had PTSD (44\% versus $35 \%$ ); there were differences between groups in age, time in present accommodation and time until follow-up in Drummond 1990; in Hedrick 2003, the collaborative care group was more likely to have previous depression (59.5\% versus $48.4 \%$ ) and major depression (65\% versus 55\%); in Katon 1995 there were relatively little data to compare groups on baseline characteristics, but there seemed to be more females in the standard care group; and in Katon 1999, there were more females in the standard care group ( $82 \%$ versus $68 \%$ ). In addition, of the six cluster randomised trials (Berti Ceroni 2002; Datto 2003; Dobscha 2006; Schrader 2005; Van der Feltz 2006; Worrall 1999), three (including Berti Ceroni 2002 and Worrall 1999 which randomised clinicians and Datto 2003 which randomised practices), did not appear to account for clustering in the reporting of data and are therefore at risk of unit of analysis error.

We did not identify any other potential sources of bias in De Cruppe 2005, Katon 1992 or Schrader 2005.

\section{Unit of analysis errors}

There were potential unit of analysis errors in several trials. For trials which compared consultation liaison to a control, there appeared to be unit of analysis errors in three trials reporting consumer outcomes because they were randomised by provider (Berti Ceroni 2002; Worrall 1999) or practice (Datto 2003). Another three trials reporting consumer outcomes were also randomised by provider (Dobscha 2006; Schrader 2005) or practice (Van der Feltz 2006) but this was allowed for in the analysis of data. There were also apparent unit of analysis errors for two trials reporting provider outcomes for consultation liaison versus standard care because they were randomised by consumer (De Cruppe 2005) and by practice (Datto 2003). Katon 1992 and Katon 1999 also randomised by consumer and reported the provider outcomes of prescribing and adequate treatment; however the correct sample size for these was consumers. Although corrections for the randomisation of consumers were done in Hedrick 2003, which compared consultation liaison to collaborative care, provider outcomes were prone to unit of analysis bias because corrected data were not reported.

\section{Effects of interventions}

See: Summary of findings for the main comparison Consultation liaison versus standard care for people with mental disorders

\section{Comparison 1: Consultation liaison versus controls}

\section{Primary consumer outcomes}

\section{Improvement in mental health}

More people had improved in the consultation liaison group compared to the standard care group up to three monthsfollowing the start of treatment (two trials, $\mathrm{n}=445, \mathrm{RD} 0.13,95 \% \mathrm{Cl} 0.04$ to 0.22 ; NNTB $8,95 \% \mathrm{Cl} 5$ to $25, \mathrm{I}^{2}=14 \%$ Analysis 1.1 ) but not from three to 12 months, although there was substantial heterogeneity between these two studies (two trials, $\mathrm{n}=678$, RD $0.06,95 \% \mathrm{Cl}$ -0.05 to $0.18,12=57 \%$ Analysis 1.1 ). There were no apparent reasons for the heterogeneity between these studies. Improvement after 12 months was not reported.

\section{Mental disorder symptoms}

There was little or no difference in symptoms from three to 12 months between the consultation liaison and standard care groups 
(three trials, $\mathrm{n}=546$, SMD $-0.15,95 \% \mathrm{Cl}-0.32$ to $-0.03, \mathrm{l}=3 \%$, Analysis 1.2). Katon 1999 also reported depression symptoms at one, three and six months, and Drummond 1990 reported alcohol problems at six months. However, these data were skewed and were therefore not included in the meta-analysis (see Table 1). No trials reported symptoms after 12 months.

\section{Secondary consumer outcomes}

\section{Consumer satisfaction}

People in the consultation liaison group were more likely to be satisfied with treatment up to three months following the start of treatment (one trial, $\mathrm{n}=228$, RD $0.31,95 \% \mathrm{Cl} 0.21$ to 0.40 ; NNTB 3, $95 \% \mathrm{Cl} 2$ to 5, Analysis 1.3) and from three to 12 months following therapy (two trials, $\mathrm{n}=445$, RD $0.12,95 \% \mathrm{Cl} 0.06$ to $0.19, \mathrm{I}^{2}=0 \%$; NNTB 8, $95 \% \mathrm{Cl} 5$ to 17 , Analysis 1.3). Satisfaction was not reported after 12 months. Dobscha 2006 also reported greater satisfaction with care in the consultation liaison group but this was reported as mean scores with no variance (consultation liaison mean: 3.58 , standard care mean: 1.16).

\section{Consumer adherence}

People in the consultation liaison group were more likely to adhere to treatment recommendations from three to 12 months (seven trials, $\mathrm{n}=1251, \mathrm{RD} 0.16,95 \% \mathrm{Cl} 0.08$ to $0.24, \mathrm{I}^{2}=57 \%$; NNTB $6,95 \%$ $\mathrm{Cl} 4$ to 13 , Analysis 1.4) but not up to three months (one trial, $\mathrm{n}=$ 228 , RD $0.08,95 \% \mathrm{Cl}-0.04$ to 0.19 , Analysis 1.4 ) or after 12 months (one trial, $\mathrm{n}=53, \mathrm{RD} 0.03,95 \% \mathrm{Cl}-0.22$ to 0.27 , Analysis 1.4 ). In sensitivity analysis, the substantial heterogeneity at three to 12 months of $57 \%$ was reduced to $0 \%$ by removing data from Katon 1995 with little difference in risk (RD $0.12,95 \% \mathrm{Cl} 0.06$ to 0.17 ). A possible explanation for the markedly greater improvement in the consultation liaison group compared to other studies was because all participants in this study had agreed to antidepressant therapy.

\section{Disability}

Disability scores were lower in the consultation liaison group at six weeks ( $\mathrm{n}=81, \mathrm{MD}-14.10,95 \% \mathrm{Cl}-24.32$ to -3.88 , Analysis 1.5$)$ and six months ( $\mathrm{n}=81, \mathrm{MD}-16.00,95 \% \mathrm{Cl}-25.56$ to -6.44 , Analysis 1.5$)$ in the one trial which compared this outcome in consultation liaison and standard care groups.

\section{General health status}

Drummond 1990 reported data for general health status but as data were skewed (consultation liaison: $n=18$, mean 5.6, SD 6.4; control: $n=18$, mean 5.2, SD 8.3) they were not included in a metaanalysis. Schrader 2005 reported health scores of 36.7 and 37.6 in the consultation liaison and standard care groups respectively but did not report variance.

\section{Healthcare visits}

There was little or no difference in the number of healthcare visits over 12 months reported by Katon 1995 ( $n=217$, MD 0.80, 95\% Cl -0.03 to 1.63, Analysis 1.6). Drummond 1990, Katon 1999; Van der Feltz 2006 and Worrall 1999 also reported healthcare visits but as data were skewed, they were not included in a meta-analysis (see Table 2). Dobscha 2006 also reported more than three visits to the primary care provider (consultation liaison: $39.2 \%$; standard care mean: $49.1 \%$ )

\section{People lost to follow-up}

There was little or no difference between consultation liaison and standard care groups in people lost to follow-up at three months (one trial, $\mathrm{n}=84, \mathrm{RD}=-0.05,95 \% \mathrm{Cl}-0.19$ to 0.09 , Analysis 1.7 ), from three to six months (seven trials, $\mathrm{n}=1544, \mathrm{RD} 0.00,95 \% \mathrm{Cl}-0.03$ to $0.04,12=0 \%$, Analysis 1.7 ) or more than 12 months after treatment (one trial, $\mathrm{n}=67, \mathrm{RD} 0.10,95 \% \mathrm{Cl}-0.12$ to 0.31 , Analysis 1.7 ).

\section{Provider outcomes}

\section{Diagnosis}

There was little or no difference in correct diagnosis rates over six months in the one trial that reported this outcome $(n=137$, RD $-0.02,95 \% \mathrm{Cl}-0.10$ to 0.06 , Analysis 1.8 ).

\section{Received any treatment}

There was little or no difference between groups in the one trial which reported participants who received any type of mental health treatment from three to 12 months $(n=80, R D-0.09,95 \% \mathrm{Cl}-0.31$ to 0.13 , Analysis 1.9).

\section{Received adequate treatment}

Participants in the consultation liaison group were more likely to receive adequate treatment between three and 12 months (three trials, $\mathrm{n}=797, \mathrm{RD} 0.15,95 \% \mathrm{Cl} 0.06$ to 0.24 ; NNTB $7,95 \% \mathrm{Cl} 4$ to 17 , $1^{2}=53 \%$, Analysis 1.10). No studies reported this outcome for other intervals. In a sensitivity analysis the substantial heterogeneity was reduced to $0 \%$ by removing Katon 1999 from the analysis with little change in estimates ( $\mathrm{RD} 0.11,95 \% \mathrm{Cl} 0.04$ to 0.17 ) but there was no apparent reason for this heterogeneity.

\section{Specialist treatment}

There was little or no difference in specialist mental health care from three to 12 months ( $\mathrm{n}=227, \mathrm{RD} 0.05,95 \% \mathrm{Cl}-0.10$ to 0.20 Analysis 1.11) although there was a very high level of heterogeneity between the two studies reporting these data $\left(1^{2}=77 \%\right)$.

\section{Prescribing}

People in the consultation liaison group were more likely to be prescribed pharmacological treatment for a mental disorder than people in the standard care group between three and 12 months (four trials, $\mathrm{n}=796, \mathrm{RD} 0.08,95 \% \mathrm{Cl} 0.02$ to 0.15 ; NNTB $13,95 \% \mathrm{Cl} 7$ to $50, \mathrm{I}^{2}=17 \%$, Analysis 1.12), but not in the one trial that reported prescribing after 12 months $(n=48, R D 0.02,95 \% \mathrm{Cl}-0.25$ to 0.30 , Analysis 1.12).

\section{Primary Care Provider adherence}

There was little or no difference in provider adherence from three to 12 months in the one trial which reported this outcome $(n=53, R D$ $0.18,95 \% \mathrm{Cl}-0.08$ to 0.43 , Analysis 1.13 ). Datto 2003 also reported adherence but as an odds ratio which could not be added to the meta-analysis (OR $3.3095 \% \mathrm{Cl} 0.88$ to 12.36).

\section{Comparison 2: Consultation liaison versus collaborative care}

Only one trial (Hedrick 2003) compared consultation liaison with collaborative care. 


\section{Primary outcomes: consumer}

Improvement in mental health

There was little or no difference between the consultation liaison and collaborative care groups in the number of consumers who had improved at three months $(n=328, R D-0.02,95 \% \mathrm{Cl}-0.10$ to 0.06 , Analysis 2.1) or nine months ( $\mathrm{n}=326, \mathrm{RD}-0.03,95 \% \mathrm{Cl}-0.11$ to 0.05 , Analysis 2.1).

\section{Mental disorder symptoms}

Symptom scores were better in the collaborative care group at three months ( $\mathrm{n}=328$, MD $0.20,95 \% \mathrm{Cl} 0.06$ to 0.34 , Analysis 2.2) and nine months ( $\mathrm{n}=326, \mathrm{MD} 0.16,95 \% \mathrm{Cl} 0.01$ to 0.31 , Analysis 2.2 ).

\section{Secondary outcomes: consumer}

\section{Consumer satisfaction}

There was little or no difference in consumer satisfaction at three (n $=328, \mathrm{RD}-0.02,95 \% \mathrm{Cl}-0.09$ to 0.06 , Analysis 2.3 ) or nine months ( $\mathrm{n}$ $=326, \mathrm{RD} 0.00,95 \% \mathrm{Cl}-0.07$ to 0.08 , Analysis 2.3 ).

\section{Disability}

Disability scores were lower in the collaborative care group at three ( $\mathrm{n}=328, \mathrm{MD} 0.72,95 \% \mathrm{Cl} 0.18$ to 1.26 , Analysis 2.4 ) and nine months $(\mathrm{n}=326, \mathrm{MD} 0.60,95 \% \mathrm{Cl} 0.03$ to 1.17 , Analysis 2.4 ).

\section{General health status}

General health scores were lower in the consultation liaison group at three $(\mathrm{n}=328, \mathrm{MD}-3.35,95 \% \mathrm{Cl}-5.91$ to -0.79 , Analysis 2.5$)$ and nine months ( $\mathrm{n}=326, \mathrm{MD}-3.49,95 \% \mathrm{Cl}-6.28$ to -0.70 , Analysis 2.5$)$.

\section{Healthcare visits}

The mean number of healthcare visits were reported (consultation liaison 8.9; collaborative care 8.5) but because variance was not reported and the sample number was unclear, these data could not be included in a meta-analysis.

\section{People lost to follow-up}

There was little or no difference in loss to follow-up at three $(n=342$, $\mathrm{RD}-0.00,95 \% \mathrm{Cl}-0.06$ to 0.05 , Analysis 2.6 ) or nine months ( $n=342$, $\mathrm{RD}-0.05,95 \% \mathrm{Cl}-0.11$ to 0.01 , Analysis 2.6 ).

\section{Secondary outcomes: provider}

\section{Received adequate treatment}

People in the consultation liaison group were less likely to receive adequate treatment up to nine months $(n=326, R D-0.17,95 \% \mathrm{Cl}$ -0.27 to -0.06 ; NNTB $6,95 \% \mathrm{Cl} 4$ to 17 Analysis 2.7 ).

\section{Prescribing}

People in the consultation liaison group were less likely to receive pharmacological treatment up to nine months ( $n=326, R D-0.18$, $95 \% \mathrm{Cl}-0.27$ to -0.08 ; NNB 6, $95 \% \mathrm{Cl} 4$ to 13 Analysis 2.8).

\section{Cost}

The mean cost for each group was reported (consultation liaison: 6789 US Dollars, $n=186$; collaborative care: 7946 US Dollars, $n=$ 168). Variance was not reported and so this outcome could not be added to a meta-analytic graph.

\section{Publication Bias}

There was not enough data to investigate potential publication bias.

\section{DISCUSSION}

\section{Summary of main results}

The review found that people with a mental disorder were more likely to improve for up to three months when a consultation liaison model was used, compared to standard care. A consultation liaison model also increased consumer satisfaction and adherence. Consultation liaison also appeared to improve the prescription of pharmacological treatment by primary care providers, compared to standard care. However, the quality of these findings were low for all outcomes apart from consumer adherence which was of moderate quality (Summary of findings for the main comparison) There was also some evidence from one trial that the consultation liaison model may not be as effective as a collaborative care with regard to mental disorder symptoms, general health status, disability, and provision of treatment.

\section{Overall completeness and applicability of evidence}

Generalisability of the review findings to all people with mental disorders is limited by the types of participants included in these trials. All primary outcome data came from participants with depressive disorders. Therefore no conclusions can be made regarding the use of consultation liaison with people who have other mental disorders, particularly disorders such as schizophrenia or bipolar disorder. There were also no data which could inform practice with specific groups of people such as children and adolescents or the elderly.

The measures of treatment adequacy were based on the prescription of antidepressants therefore no conclusions can be drawn from this review regarding the use of treatments other than medication for depression.

The length of follow-up in the included trials was generally good with a minimum four months follow-up in one trial and follow-up of 12 months or more in five trials.

Healthcare providers working in, and consumers presenting to general hospital settings were excluded as they represent different populations of healthcare providers and consumers. Therefore, consultation liaison within the hospital setting would be suited to a separate review.

\section{Quality of the evidence}

Despite having thought there would be few, if any RCTs in this area, it was a positive sign that all included trials were RCTs. However, as there was considerable risk of bias in the included trials the quality of evidence was considered low for most outcomes. The difficulty in blinding participants was a particular risk of bias with most of the included trials as most outcomes were self reported. Eight trials were rated as a high risk of performance and detection bias with only one rated as a low risk. Bias due to attrition is also of concern with an overall loss to follow-up of $10 \%$ at three months to nearly $20 \%$ at 12 months or more; eight trials were considered a high risk of attrition bias with two rated as low risk. Selective reporting of data was also a potential bias as six trials were rated a high risk of 
reporting bias and none as low risk. We were unable to investigate the possibility of publication bias because of a lack of data.

In addition, the quality of the evidence is limited by the relatively low number of studies and participants contributing data to any one outcome. When consultation liaison was compared to a control, most outcome data came from one to three trials with 53 to 797 participants. Exceptions were adherence and loss to follow-up where data came from seven trials with up to 1544 participants, and prescribing where data came from four trials with 796 participants. All data comparing consultation liaison to collaborative care came from only one trial with 328 participants.

\section{Potential biases in the review process}

Considerable efforts were made to avoid potential biases in searching for relevant studies, selecting studies, extracting and analysing data, and reporting the review findings. The search covered a wide range of databases and yielded a high number of studies. In addition, reference lists of identified studies and reviews were checked. However, given the large number of identified studies (8191) and differing terminology used to describe consultation liaison, it is possible some studies may have been missed.

Apart from one set of consumer outcomes, data for all included outcomes appear to have been reported but because no protocols were identified for these studies, it is possible that other relevant outcomes may have been collected but not reported.

It is also possible that we were more likely to identify studies which reported positive findings for consultation liaison but because there were too few studies reporting a single primary outcome, we were not able to investigate the possibility of publication bias.

\section{Agreements and disagreements with other studies or reviews}

To date there has not been a systematic review of the effects of primary care consultation liaison on outcomes for people with mental disorders. However, there has been a meta-analysis of the effectiveness of consultation liaison specifically in people with depression (Cape 2010) and one meta-analysis of psychiatric consultation models in primary care (Van der Feltz-Cornelis 2010).

Although the definition of consultation liaison patients used by Cape 2010 (patients seen once or twice by a mental health specialist and advice about management to a GP, but with no treatment actually provided by the mental health professional) differed from the definition we used, four of the five studies included by Cape 2010 were also included in our review. As with our findings, Cape 2010 reported no change in depression symptoms, although we did find an improvement in mental health with consultation liaison. Unlike our review; however, they found no difference in antidepressant use while we found an improvement in prescribing and consumer adherence. This lack of an effect of consultation liaison in Cape 2010 may have been due to the smaller number of studies. Four of the studies in our review were also included in the ten studies included by Van der Feltz-Cornelis 2010, which compared collaborative care and consultation liaison to care as usual. This review found a moderate improvement in a single meta-analysis including both collaborative care and consultation liaison, and pooling data across a range of outcomes including symptom reduction, function, treatment adherence, general health, healthcare use and cost (Van der Feltz-Cornelis 2010).

As there are no formally recognised definitions of primary carebased mental health care, five of the 12 studies included in our review were also identified in the 79 studies included in the review of Collaborative care for depression and anxiety problems by Archer 2012. This review defined Collaborative Care as a multi-professional approach, structured management plan, scheduled patient follow-up, and enhanced inter-professional communication (Archer 2012). As with our review, Archer 2012 found a significant improvement in people's symptoms, medication usage and satisfaction.

Our findings are also similar to the Cochrane review by Bower 2000 which found that onsite mental health workers improved the prescribing behaviour of primary care providers.

\section{AUTHORS' CONCLUSIONS}

\section{Implications for practice}

The review found that consultation liaison improves mental health outcomes for consumers, particularly those with depression, for up to three months and improves consumer satisfaction and adherence up to 12 months. Primary care providers were also more likely to provide adequate treatment and prescribe pharmacological therapy for up to 12 months. There was also limited evidence that the consultation liaison model may not be as effective as collaborative care in terms of mental disorder symptoms, general health status, lower disability, and provision of treatment. More evidence is needed to determine the effectiveness of consultation liaison for people with mental disorders other than depression.

\section{Implications for research}

Given the limitations of the available evidence there is a considerable need for further RCTs of consultation liaison in the primary care setting. There is also a need for more trials comparing different models of delivering mental healthcare in the primary care setting. Future trials should take particular care to address potential biases, particularly the blinding of participants. It is also important that trials address the CONSORT criteria for RCTs (Moher 2001).

None of the identified trials included participants with schizophrenia or bipolar disorder, therefore trials which include people who may have quite different mental health care needs to people with depression are needed. Also, given the differing mental health needs of adolescent and older people, trials reporting separate data for these age groups are required.

Given the wide range of elements, frequency and modes of contact between consumers and providers in the consultation liaison models used in these trials, studies of a more standardised yet feasible model are to be encouraged. Also, given the difficulty in differentiating primary care-based models of mental health care, broader efforts to agree and formally recognise definitions should be made.

Future trials need to measure the consumer outcomes of improvement in mental health and mental disorder symptoms. Other outcomes such as general health, quality of life, satisfaction 
and adverse events should also be reported. With regard to provider outcomes, satisfaction, cost, and the adequacy of treatment, including non-pharmacological treatments, should be reported. In addition, validated scales and measures should be used for all outcomes. So that these trials can be added to meta-analytic updates, all data should be reported or made available and use the most commonly identified measures in this review. In particular, separate data for specific types of mental disorders and different age groups (i.e. children and adolescents and the elderly) should be made available.

\section{ACKNOWLEDGEMENTS}

We would like to thank Emma Tavender, Managing Editor of the Australian satellite of the Effective Practice and Organisation of Care Group, for her assistance with this review. 


\section{R E F E R E N C E S}

\section{References to studies included in this review}

\section{Berti Ceroni 2002 \{published data only\}}

Ceroni GB, Rucci P, Berardi D, Ceroni FB, Katon W. Case review vs. usual care in primary care patients with depression: a pilot study. General Hospital Psychiatry 2002;24(2):71-80. [MEDLINE: 11869740]

\section{Datto 2003 \{published data only\}}

Datto CJ, Thompson R, Horowitz D, Disbot M, Oslin DW. The pilot study of a telephone disease management program for depression. General Hospital Psychiatry 2003;25(3):169-77. [MEDLINE: 12748029]

\section{De Cruppe 2005 \{published data only\}}

De Cruppe W, Hennch C, Buchholz C, Muller A, Eich W, Herzog W. Communication between psychosomatic C-L consultants and general practitioners in a German health care system. General Hospital Psychiatry 2005;27(1):63-72. [MEDLINE: 15694220]

Dobscha 2006 \{published data only\}

Dobscha SK, Corson K, Hickam DH, Perrin NA, Kraemer D, Gerrity MS. Depression decision support in primary care: a cluster randomized trial. Annals of Internal Medicine 2006;145(7):477-87. [MEDLINE: 17015865]

\section{Drummond 1990 \{published data only\}}

* Drummond DC, Thom B, Brown C, Edwards G, Mullan M J. Specialist versus general practitioner treatment of problem drinkers. Lancet 1990;336(8720):915-8. [MEDLINE: 1976937]

Thom C, Brown C, Drummond C, Edwards G, Mullen M. The use of services for alcohol problems: general practitioner and specialist alcohol clinic. British Journal of Addiction 1992;87:613-24. [MEDLINE: 1317237]

\section{Hedrick 2003 \{published data only\}}

* Hedrick SC, Chaney EF, Felker B, Liu CF, Hasenberg N, Heagerty $\mathrm{P}$, et al. Effectiveness of collaborative care depression treatment in Veterans' Affairs primary care. Journal of General Internal Medicine 2003;18(1):9-16. [MEDLINE: 12534758]

Liu, CF, Hedrick, SC, Chaney, EF, Heagerty, P, Felker, B, Hasenberg, N, et al. Cost-effectiveness of collaborative care for depression in a primary care veteran population. Psychiatric Services 2003;54(5):698-704. [MEDLINE: 12719501]

\section{Katon 1992 \{published data only\}}

* Katon W, Von Korff M, Lin E, Bush T, Russo J, Lipscomb P, et al. A randomized trial of psychiatric consultation with distressed high utilizers. General Hospital Psychiatry 1992;14:86-98. [MEDLINE: 1592254]

Katon W, von Korff M, Lin E, Bush T, Ormel J. Adequacy and duration of antidepressant treatment in primary care. Medical care 1992;30(1):67-76. [MEDLINE: 1729588]

\section{Katon 1995 \{published data only\}}

Bush T, Rutter C, Simon G, Von Korff M, Katon WJ, Walker EA, et al. Who benefits from more structured depression treatment?
International Journal of Psychiatry in Medicine: International Journal of Psychiatry in Medicine 2004;34(3):247-58. [MEDLINE: 15666959]

Katon W. Collaborative care models for the treatment of depression. American Journal of Managed Care 1999;5(13 Suppl):s794-s810. [MEDLINE: 10621070]

Katon W, Von Korff M, Lin E, Simon G, Walker E, Bush T, et al. Collaborative management to achieve depression treatment guidelines. Journal of Clinical Psychiatry 1997;58:20-3. [MEDLINE: 9054905]

* Katon W, Von Korff M, Lin E, Walker E, Simon GE, Bush T, et al. Collaborative management to achieve treatment guidelines. Impact on depression in primary care. JAMA 1995;273(13):1026-31. [MEDLINE: 7897786]

Lin EH, Simon GE, Katon WJ, Russo JE, Von Korff M, Bush TM, et al. Can enhanced acute-phase treatment of depression improve long-term outcomes? A report of randomized trials in primary care. American Journal of Psychiatry 1999;156(4):643-5. [MEDLINE: 10200750]

Lin EHB, Katon WJ, Simon GE, Von Korff M, Bush TM, Ruuter CM, et al. Achieving guidelines for the treatment of depression in primary care: is physician education enough?. Medical Care 1997;35(8):831-42. [MEDLINE: 9268255]

Von Korff M, Katon W, Bush T, Lin EH, Simon GE, Saunders K, et al. Treatment costs, cost offset, and cost-effectiveness of collaborative management of depression. Psychosocial Medicine 1998;60(2):143-9. [MEDLINE: 9560861]

\section{Katon 1999 \{published data only\}}

Katon W, Russo J, Von Korff M, Lin E, Simon G, Bush T, et al. Long-term effects of a collaborative care intervention in persistently depressed primary care patients. Journal of General Internal Medicine 2002;17(10):741-8. [MEDLINE: 12390549]

* Katon W, Von Korff M, Lin E, Simon G, Walker E, Unutzer J, et al. Stepped collaborative care for primary care patients with persistent symptoms of depression: a randomized trial. Archives of General Psychiatry 1999;56(12):1109-15. [MEDLINE: 10591288]

Simon GE, Manning WG, Katzelnick DJ, Pearson SD, Henk HJ, Helstad CS. Cost-effectiveness of systematic depression treatment for high utilizers of general medical care. American Journal of Psychiatry 2001;58(2):181-7. [MEDLINE: 11177120]

Walker EA, Katon WJ, Russo J, Von Korff M, Lin E, Simon G, et al. Predictors of outcome in a primary care depression trial. Journal of General Internal Medicine 2000;15(12):859-67. [MEDLINE: 11119182]

\section{Schrader 2005 \{published data only\}}

Schrader G, Cheok F, Hordacre AL, Marker J, Wade V. Effect of psychiatry liaison with general practitioners on depression severity in recently hospitalised cardiac patients: a randomised controlled trial. Medical Journal of Australia 2005;182(6):272-6. [MEDLINE: 15777141] 
Van der Feltz 2006 \{published data only\}

Van der Feltz-Cornelis CM, Van OP, Ader HJ, Van Dyck R. Randomised controlled trial of a collaborative care model with psychiatric consultation for persistent medically unexplained symptoms in general practice. Psychotherapy and Psychosomatics 2006;75(5):282-9. [MEDLINE: 16899964]

\section{Worrall 1999 \{published data only\}}

Worrall G, Angel J, Chaulk P, Clarke C, Robbins M. Effectiveness of an educational strategy to improve family physicians' detection and management of depression: a randomized controlled trial. Canadian Medical Association Journal 1999;161(1):37-40. [MEDLINE: 10420862]

\section{References to studies excluded from this review}

Arora 2011 \{published data only\}

Arora S, Kalishman S, Dion D, Som D, Thornton K, Bankhurst A, et al. Partnering urban academic medical centers and rural primary care clinicians to provide complex chronic disease care. Health Affairs 2011;30(6):1176-84. [MEDLINE: 21596757]

\section{Baker 2001 \{published data only\}}

Baker R, Reddish S, Robertson N, Hearnshaw H, Jones B. Randomised controlled trial of tailored strategies to implement guidelines for the management of patients with depression in general practice. British Journal of General Practice 2001;51(470):737-41. [MEDLINE: 11593835]

\section{Bauer 2011 \{published data only\}}

Bauer AM, Azzone V, Goldman HH, Alexander L, Unutzer J, Coleman-Beattie B, et al. Implementation of collaborative depression management at community-based primary care clinics: an evaluation. Psychiatric Services 2011;62(9):1047-53. [MEDLINE: 21885583]

\section{Bogner 2012 \{published data only\}}

Bogner HR, Morales KH, De Vries HF, Cappola AR. Integrated management of type 2 diabetes mellitus and depression treatment to improve medication adherence: a randomized controlled trial. Annals of Family Medicine 2012;10(1):15-22. [MEDLINE: 22230826]

\section{Carr 1997 \{published data only\}}

Carr VJ, Donovan P. Psychiatry in General Practice: a pilot scheme using the liaison-attachment model. Medical Journal of Australia 1992;156:379-382. [MEDLINE: 1545744]

* Carr VJ, Faehrmann C, Lewin TJ, Walton JM, Reid AA. Determining the effect that consultation-liaison psychiatry in primary care has on family physicians' psychiatric knowledge and practice. Psychosomatics 1997;38(3):217-29. [MEDLINE: 9136250]

Carr VJ, Lewin TJ. Supplementary outcome data on treatment for psychological morbidity in general practice: some cautionary remarks. Australian and New Zealand Journal of Psychiatry 1999;33(5):764-6. [MEDLINE: 10545005]

Carr VJ, Lewin TJ, Reid AL, Walton JM, Faehrmann C. An evaluation of the effectiveness of a consultation-liaison psychiatry service in general practice. Australian and New Zealand Journal of Psychiatry 1997;31:714-25. [MEDLINE: 9400878]

Carr VJ, Lewin TJ, Walton JM, Faehrmann C, Reid AL. Consultation-liaison psychiatry in general practice. Australian and New Zealand Journal of Psychiatry 1997;31(1):85-94. [MEDLINE: 9088491]

\section{Chung 2011 \{published data only\}}

Chung H, Klein MC, Silverman D, Corson-Rikert J, Davidson E, Ellis $P$, et al. A pilot for improving depression care on college campuses: results of the College Breakthrough SeriesDepression (CBS-D) project. Journal of American College Health 2011;59(7):628-39. [MEDLINE: 21823958]

\section{Dietrich 2004 \{published data only\}}

Dietrich AJ, Oxman TE, Williams JW, Schulberg HC, Bruce ML, Lee PW, et al. Re-engineering systems for the treatment of depression in primary care: Cluster randomised controlled trial. BMJ 2004;329(7466):618-22. [MEDLINE: 15345600]

\section{Harvey 2012 \{published data only\}}

Harvey ST, Fisher LJ, Green VM. Evaluating the clinical efficacy of a primary care-focused, nurse-led, consultation liaison model for perinatal mental health. Journal of Mental Health Nursing 2012;21(1):75-81. [MEDLINE: 21895906]

\section{Horner 2005 \{published data only\}}

Horner D, Asher K. General practitioners and mental health staff sharing patient care: working model. Australasian Psychiatry 2005;13(2):176-80. [MEDLINE: 15948917]

\section{Liu 2007 \{published data only\}}

Liu SI, Huang HC, Yeh ZT, Hwang LC, Tjung JJ, Huang CR, et al. Controlled trial of problem-solving therapy and consultationliaison for common mental disorders in general medical settings in Taiwan. General Hospital Psychiatry 2007;29(5):402-8.

\section{Llewellyn-Jones 1999 \{published data only\}}

Llewellyn-Jones RH, Baikie KA, Smithers H, Cohen J, Snowdon J, Tennant CC. Multifaceted shared care intervention for late life depression in residential care: randomised controlled trial. BMJ 1999;319(7211):676-82. [MEDLINE: 10480824]

\section{Menchetti 2007 \{published data only\}}

Menchetti M, Sighinolfi C, Di MV, Peloso P, Nespeca C, Bandieri PV, et al. Effectiveness of collaborative care for depression in Italy. A randomized controlled trial. General Hospital Psychiatry 2013;36(6):579-86.

\section{Serrano 2011 \{published data only\}}

Serrano N, Monden K. The effect of behavioral health consultation on the care of depression by primary care clinicians. WMJ 2011;110(3):113-8. [MEDLINE: 21748995]

\section{Sherbourne 2001 \{published data only\}}

Sherbourne CD, Wells KB, Duan N, Miranda J, Unutzer J, Jaycox $L$, et al. Long-term effectiveness of disseminating quality 
improvement for depression in primary care. Archives of General Psychiatry 2001;58(7):696-703. [MEDLINE: 11448378]

\section{Sinnema 2011 \{published data only\}}

Sinnema H, Franx G, Volker D, Majo C, Terluin B, Wensing M, et al. Randomised controlled trial of tailored interventions to improve the management of anxiety and depressive disorders in primary care. Implementation Science 2011;6:75. [MEDLINE: 21777463]

\section{Stiefel 2008 \{published data only\}}

Stiefel F, Zdrojewski C, Bel Hadj F, Boffa D, Dorogi Y, So A, et al. Effects of a multifaceted psychiatric intervention targeted for the complex medically ill: a randomized controlled trial. Psychosomatics 2008;77(4):247-56. [MEDLINE: 18443391]

\section{Su 2011 \{published data only\}}

Su JA, Tsai CS, Hung TH, Chou SY. Change in accuracy of recognizing psychiatric disorders by non-psychiatric physicians: five-year data from a psychiatric consultation-liaison service. Psychiatry and Clinical Neurosciences 2011;65(7):618-23. [MEDLINE: 22176280]

\section{Tello-Bernabe 2011 \{published data only\}}

Tello-Bernabe E, Sanz-Cuesta T, del Cura-Gonzalez I, de Santiago-Hernando ML, Jurado-Sueiro M, FernandezGiron M, et al. Effectiveness of a clinical practice guideline implementation strategy for patients with anxiety disorders in primary care: cluster randomized trial. Implementation Science 2011;6:123. [MEDLINE: 22132861]

Wells 1999 \{published data only\}

Wells KB. The design of Partners in Care: evaluating the costeffectiveness of improving care for depression in primary care. Social Psychiatry and Psychiatric Epidemiology 1999;34(1):20-9. [MEDLINE: 10073117]

\section{Wiener 2006 \{published data only\}}

Wiener A, Rodwell H. Evaluation of a CAMHS in primary care service for general practice. Child and Adolescent Mental Health 2006;11(3):150-5.

\section{Additional references}

\section{Andrews 2001}

Andrews G, Issakidis C, Carter G. Shortfall in mental health service utilisation. British Journal of Psychiatry 2001;179:417-25.

\section{Archer 2012}

Archer J, Bower P, Gilbody S, Lovell K, Richards D, Gask L, Dickens C, Coventry P. Collaborative care for depression and anxiety problems. Cochrane Database of Systematic Reviews 2012, Issue 10. [DOI: 10.1002/14651858.CD006525.pub2]

\section{Bambling 2007}

Bambling M, Kavanagh D, Lewis G, King R, King D, Sturk H, et al. Challenges faced by general practitioners and allied mental health services in providing mental health services in rural Queensland. Australian Journal of Rural Health 2007;15(2):126-30. [1038-5282]

\section{Berardi 2002}

Berardi D, Menchetti M, Dragani A, Fava C, Leggieri G, Ferrari G. The Bologna Primary Care Liaison Service: first year evaluation. Community Mental Health Journal 2002;38(6):439-45.

[0010-3853]

\section{Bourgeois 2005}

Bourgeois JA, Wegelin JA, Servis ME, Hales RE. Psychiatric diagnoses of 901 inpatients seen by consultation-liaison psychiatrists at an academic medical center in a managed care environment. Psychosomatics 2005;46(1):47-57. [0033-3182]

\section{Bower 2000}

Bower P, Sibbald B. On-site mental health workers in primary care: effects on professional practice. Cochrane Database of Systematic Reviews 2000, Issue 3. [DOI: 10.1002/14651858.CD000532]

\section{Bower 2005}

Bower P, Gilbody S. Managing common mental health disorders in primary care: conceptual models and evidence base. BMJ 2005;330:839-42.

\section{Broome 2005}

Broome MR, Woolley JB, Johns LC, Valmaggia LR, Tabraham P, Gafoor R, et al. Outreach and support in south London (OASIS): implementation of a clinical service for prodromal psychosis and the at risk mental state. European Psychiatry: the Journal of the Association of European Psychiatrists 2005;20(5-6):372-8. [0924-9338]

\section{Cape 2010}

Cape J, Whittington C, Bower P. What is the role of consultationliaison psychiatry in the management of depression in primary care? A systematic review and meta-analysis. General Hospital Psychiatry 2010;32(3):246-54.

\section{Chew-Graham 2007}

Chew-Graham CA, Lovell K, Roberts C, Baldwin R, Morley M, Burns A, et al. A randomised controlled trial to test the feasibility of a collaborative care model for the management of depression in older people. British Journal of General Practice 2007;57(538):364-70. [0960-1643]

\section{Copty 2005}

Copty M, Whitford DL. Mental health in general practice: assessment of current state and future needs. Irish Journal of Psychological Medicine 2005;22(3):83-6. [0790-9667]

\section{Deeks 2011}

Deeks JJ, Higgins JPT, Altman DG (editors). Chapter 9: Analysing data and undertaking meta-analyses. In: Higgins JPT, Green S (editors). Cochrane Handbook for Systematic Reviews of Interventions Version 5.1.0 (updated March 2011). The Cochrane Collaboration, 2011. Available from www.cochranehandbook.org.

\section{Emmanuel 2002}

Emmanuel JS, McGee A, Ukoumunne OC, Tyrer P. A randomised controlled trial of enhanced key-worker liaison psychiatry in 
general practice. Social Psychiatry \& Psychiatric Epidemiology 2002;37(6):261-6. [0933-7954]

\section{EPOC 2013a}

Effective Practice, Organisation of Care (EPOC). What study designs should be included in an EPOC review? EPOC Resources for review authors. Oslo: Norwegian Knowledge Centre for the Health Services; 2013. Available at: http://epoc.cochrane.org/ epoc-specific-resources-review-authors.

\section{EPOC 2013b}

Effective Practice, Organisation of Care (EPOC). Data extraction and management. EPOC Resources for review authors. Oslo: Norwegian Knowledge Centre for the Health Services; 2013. Available at: http://epoc.cochrane.org/epoc-specific-resourcesreview-authors.

\section{EPOC 2014}

Effective Practice, Organisation of Care (EPOC). How to report the search process in EPOC protocols, reviews, and updates. EPOC Resources for review authors. Oslo: Norwegian Knowledge Centre for the Health Services; 2014. Available at: http://epoc.cochrane.org/epoc-specific-resources-reviewauthors.

\section{Gilbody 2003}

Gilbody S, Whitty P, Grimshaw J, Thomas R. Educational and organizational interventions to improve the management of depression in primary care: a systematic review. JAMA 2003;289(23):3145-51. [0098-7484]

\section{Gunn 2009}

Gunn WB, Blount A. Primary care mental health: a new frontier for psychology. Journal of Clinical Psychology 2009;65(3):235-52. [0021-9762]

\section{Harmon 2000}

Harmon K, Carr VJ, Lewin TJ. Comparison of integrated and consultation-liaison models for providing mental health care in general practice in New South Wales, Australia. Journal of Advanced Nursing 2000;32(6):1459-66. [0309-2402]

\section{Hickie 2007}

Hickie IB, Fogarty AS, Davenport TA, Luscombe GM, Burns J. Responding to experiences of young people with common mental health problems attending Australian general practice. Medical Journal of Australia 2007;187(Suppl 7):S47-52.

\section{Higgins 2003}

Higgins JPT, Thompson SG, Deeks JJ, Altman DG. Measuring inconsistency in meta-analyses. BMJ 2003;327(7414):557-60.

\section{Higgins 2011}

Higgins JPT, Altman DG, Sterne JAC (editors). Chapter 8: Assessing risk of bias in included studies. In: Higgins JPT, Green S (editors). Cochrane Handbook for Systematic Reviews of Interventions Version 5.1.0 (updated March 2011). The Cochrane Collaboration, 2011. Available from www.cochranehandbook.org. Chichester: Wiley Blackwell.

\section{Hilty 2006}

Hilty DM, Yellowlees PM, Cobb HC, Bourgeois JA, Neufeld JD, Nesbitt TS. Models of telepsychiatric consultation-liaison service to rural primary care. Psychosomatics 2006;47(2):152-7. [0033-3182]

\section{Huyse 2000}

Huyse FJ, Herzog T, Lobo A, Malt UF, Opmeer BC, Stein B, et al. European consultation-liaison services and their user populations: the European Consultation-Liaison Work group Collaborative Study. Psychosomatics 2000;41(4):330-8. [0033-3182]

\section{Ilchef 2006}

Ilchef R. Diamonds in the coalface: new research in consultation-liaison psychiatry. Current Opinion in Psychiatry 2006;19(2):175-9. [0951-7367]

\section{Katon 2001}

Katon W, Von Korff M, Lin E, Simon G. Rethinking practitioner roles in chronic illness: the specialist, primary care physician and the practice nurse. General Hospital Psychiatry 2001;23(3):138-44.

\section{Kessler 2012}

Kessler R. Mental health care treatment initiation when mental health services are incorporated into primary care practice. Journal of the American Board of Family Medicine 2012;25(2):255-9.

\section{Kisely 2007}

Kisely S, Campbell LA. Taking consultation-liaison psychiatry into primary care. International Journal of Psychiatry in Medicine 2007;37(4):383-91.

\section{Kohn 2004}

Kohn R, Saxena S, Levav I, Saraceno B. The treatment gap in mental health care. Bulletin of the World Health Organization 2004;82:858-66.

\section{Marttunen 2000}

Marttunen M, Pelkonen M. Psychiatric risk factors for adolescent suicide - a review. Psychiatria Fennica 2000;31:110-25.

\section{McNamara 2008}

McNamara P, Bryant J, Forster J, Sharrock J, Happell B. Exploratory study of mental health consultation-liaison nursing in Australia: Part 2. Preparation, support and role satisfaction. International Journal of Mental Health Nursing 2008;17(3):189-96.

\section{Mitchell 2002}

Mitchell G, Del Mar C, Francis D. Does primary medical practitioner involvement with a specialist team improve patient outcomes? A systematic review. British Journal of General Practice 2002;52(484):934-9. [0960-1643]

\section{Moher 2001}

Moher D, Schulz KF, Altman DG. The CONSORT statement: revised recommendations for improving the quality of reports 
of parallel-group randomized trials. CONSORT group JAMA 2001;285(15):1987-91.

\section{Parker 2008}

Parker AG, Hetrick SE, Purcell R, Gillies D. Consultation liaison in primary practice for mental health problems. Cochrane Database of Systematic Reviews 2008, Issue 2. [DOI: 10.1002/14651858.CD007193]

\section{Parslow 2000}

Parslow RA, Jorm AF. Who uses mental health services in Australia? An analysis of data from the National Survey of Mental Health and Wellbeing. Australian \& New Zealand Journal of Psychiatry 2000;34(6):997-1008.

\section{Patel 2007}

Patel V, Flisher AJ, Hetrick S, McGorry P. Mental health of young people: a global public-health challenge. The Lancet 2007;369:1302-13.

\section{Reilly 2012}

Reilly S, Planner C, Hann M, Reeves D, Nazareth I, Lester H. The role of primary care in service provision for people with severe mental illness in the United Kingdom. PLOS ONE 2012;7(5):e36468.

\section{Reilly 2013}

Reilly S, Planner C, Gask L, Hann M, Knowles S, Druss B, et al. Collaborative care approaches for people with severe mental illness. Cochrane Database of Systematic Reviews 2013, Issue 11. [DOI: 10.1002/14651858.CD009531.pub2]

\section{RevMan 2014 [Computer program]}

The Nordic Cochrane Centre, The Cochrane Collaboration. Review Manager (RevMan). Version 5.3. Copenhagen: The Nordic Cochrane Centre, The Cochrane Collaboration, 2014.

\section{Rodrigo 2013}

Rodrigo A, Foo L, Majoor J. Have Primary Mental Health Teams lived up to their expectations?. Australasian Psychiatry 2013;21(2):127-30.

\section{Ruddy 2005}

Ruddy R, House A. Meta-review of high-quality systematic reviews of interventions in key areas of liaison psychiatry. British Journal of Psychiatry 2005;187:109-20. [0007-1250]

\section{Sarries 2008}

Sarries AG, De Jalon Aramayo EG, Gonzalez NL, Urra EL. Analysis of the patients referred from primary care to mental health center [Analisis de las derivaciones desde atencion primaria a salud mental]. Anales de Psiquiatria 2008;24(2):83-8.

\section{Sved Williams 2006}

Sved Williams A, Dodding J, Wilson I, Fuller J, Wade V. Consultation-liaison to general practitioners coming of age: the South Australian psychiatrists' experience. Australasian Psychiatry 2006;14(2):206-11. [1039-8562]

\section{Sved-Williams 2010}

Sved-Williams A, Poulton J. Primary care mental health consultation-liaison: a connecting system for private psychiatrists and general practitioners. Australasian Psychiatry 2010;18(2):125-9.

\section{Tovey 2004}

Tovey A, Harvey L. A nurse-led service to identify and treat depression in primary care. Professional Nurse 2004;19(8):424-5. [0266-8130]

\section{Trude 2003}

Trude S, Stoddard JJ. Referral gridlock: primary care physicians and mental health services. Journal of General Internal Medicine 2003;18(6):442-9.

\section{Van der Feltz-Cornelis 2010}

Van der Feltz-Cornelis CM, Van Os TW, Van Marwijk HW, Leentjens AF. Effect of psychiatric consultation models in primary care. A systematic review and meta-analysis of randomized clinical trials. Journal of Psychosomatic Research 2010;68(6):521-33.

\section{Van Heeringen 2000}

Van Heeringen K, Hawton K, Williams JMG. Pathways to suicide: an integrative approach. In: Hawton K, Heering KV editor(s). Suicide and Attempted Suicide. Chichester: John Wiley \& Sons LTD, 2000.

\section{Van Rijswijk 2007}

Van Rijswijk E, Borghuis M, van de Lisdonk E, Zitman F, van Weel $C$. Treatment of mental health problems in general practice: a survey of psychotropics prescribed and other treatments provided. International Journal of Clinical Pharmacology and Therapeutics 2007;45(1):23-9.

\section{Vythilingum 2011}

Vythilingum B, Chiliza B. Consultation liaison psychiatry in Africa - essential service or unaffordable luxury?. African Journal of Psychiatry 2011;14(4):257.

\section{Wang 2005}

Wang PS, Berglund P, Olfson M, Pincus HA, Wells KB, Kessler RC. Failure and delay in initial treatment contact after first onset of mental disorders in the National Comorbidity Survey Replication. Archives of General Psychiatry 2005;62(6):603-13.

\section{WHO 2001}

World Health Organization (WHO). The World Health Report 2001 - Mental Health: New Understanding, New Hope. Geneva: WHO, 2001.

\section{Younes 2008}

Younes N, Passerieux C, Hardy-Bayle MC, Falissard B, Gasquet I. Long term GP opinions and involvement after a consultationliaison intervention for mental health problems. BMC Family Practice 2008;9:41.

* Indicates the major publication for the study 
CHARACTERISTICS OF STUDIES

Characteristics of included studies [ordered by study ID]

Berti Ceroni 2002

\begin{tabular}{|c|c|}
\hline Methods & Cluster-randomised controlled trial of consultation liaison compared to standard care \\
\hline \multirow[t]{5}{*}{ Participants } & $\begin{array}{l}\text { Consumers ( } n=92) \text { : People attending primary care practices diagnosed by Composite International Di- } \\
\text { agnostic Interview (CIDI) for DSM-IV major depression, minor depression (at least three major depres- } \\
\text { sion symptoms including anhedonia or depressed mood) or subsyndromal depression (at least two } \\
\text { symptoms excluding anhedonia and depressed mood). Their mean age was } 44.6 \text { years, } 80 \% \text { were fe- } \\
\text { male }(n=64) \text {. Major depression } 15 \text {, minor } 38 \text { and subsyndromal } 27\end{array}$ \\
\hline & $\begin{array}{l}\text { Excluded: Older than } 65 \text { years, life-threatening illness, psychotic disorders, cognitive impairment or on- } \\
\text { going treatment with a mental health specialist. }\end{array}$ \\
\hline & Primary care providers ( $n=30)$ : GPs with an established practice of at least ten years. \\
\hline & $\begin{array}{l}\text { Mental health specialists }(n=2) \text { : one psychiatrist from a local community mental health service and one } \\
\text { experienced in primary care psychiatry. }\end{array}$ \\
\hline & Setting: general health care settings in rural and urban areas, Bologna, Italy. \\
\hline
\end{tabular}

Interventions

1. Consultation Liaison $(n=44)$.

Mental health specialist/consumer: interaction not reported.

Mental health specialist/primary care provider: primary care providers and two psychiatrists met in 12 biweekly groups of two hours where diagnoses and planning for therapies were discussed. Each consumer was discussed at least three times.

Primary care provider/consumer: interaction not reported.

2. Standard care $(n=36)$.

Treatment as usual although the primary care provider received feedback on diagnosis.

\section{Consumer}

Improvement: remission of diagnosis (CIDI) at 12 months.

Symptoms: Hamilton Depression Rating Scale, Hamilton Anxiety Rating Scale, Medical Outcomes Study Short Form - 36 at 12 months.

General Health: General Health Questionnaire (GHQ-12) at 3 and 12 months.

\section{Provider}

Treatment: received any treatment over 12 months.

Prescribing: received pharmacotherapy over 12 months.

Notes

\section{Risk of bias}

\begin{tabular}{lll}
\hline Bias & Authors' judgement & Support for judgement \\
\hline $\begin{array}{l}\text { Random sequence genera- } \\
\text { tion (selection bias) }\end{array}$ & Unclear risk & $\begin{array}{l}\text { Primary care providers were block randomised but how this was done was not } \\
\text { described. }\end{array}$ \\
\hline
\end{tabular}


Berti Ceroni 2002 (Continued)

Allocation concealment $\quad$ Unclear risk $\quad$ Not reported.
(selection bias)

\begin{tabular}{|c|c|c|}
\hline $\begin{array}{l}\text { Blinding (performance } \\
\text { bias and detection bias) } \\
\text { All outcomes }\end{array}$ & Unclear risk & $\begin{array}{l}\text { Primary care providers would have been aware which groups they were in so } \\
\text { this may have affected treatment patterns. It is not clear whether consumers } \\
\text { would have been aware if they were in the active group. }\end{array}$ \\
\hline
\end{tabular}

\begin{tabular}{|c|c|c|}
\hline $\begin{array}{l}\text { Incomplete outcome data } \\
\text { (attrition bias) } \\
\text { All outcomes }\end{array}$ & High risk & $\begin{array}{l}\text { Data was only reported for those available at } 12 \text { months follow-up, loss to fol- } \\
\text { low-up } 13 \% \text {. }\end{array}$ \\
\hline
\end{tabular}

\begin{tabular}{lll}
\hline $\begin{array}{l}\text { Selective reporting (re- } \\
\text { porting bias) }\end{array}$ & High risk & None of the consumer outcomes were reported by group. \\
\hline Other bias & Unclear risk & $\begin{array}{l}\text { There were more consumers with severe depression in the standard care } \\
\text { group }(9 \text { vs } 6) \text { at baseline. Cluster randomisation does not seem to have been } \\
\text { accounted for in the analysis. }\end{array}$ \\
\hline
\end{tabular}

\section{Datto 2003}

\begin{tabular}{|c|c|}
\hline Methods & Cluster-randomised controlled trial of telephone disease management compared to standard care. \\
\hline Participants & $\begin{array}{l}\text { Consumers }(n=84) \text { : Primary care consumers with symptoms suggestive of depression who agreed to be } \\
\text { monitored by telephone. The mean age was } 46.9 \text { years, } 60.8 \% \text { female, } 80 \% \text { white. The mean score on } \\
\text { the Centre for Epidemiological Studies Depression Scale }(C E S-D) \text { was } 32.2 ; 84.8 \% \text { were diagnosed with } \\
\text { major depression, } 55.5 \% \text { prescribed antidepressants and } 16.5 \% \text { referred for mental health treatment. }\end{array}$ \\
\hline & $\begin{array}{l}\text { Excluded: Significant suicide risk, current substance abuse problems, psychotic symptoms, bipolar af- } \\
\text { fective disorder. }\end{array}$ \\
\hline
\end{tabular}

Primary care providers $(n=74)$ : primary care providers working at study practices, 46 internal medicine and 24 family practice doctors, and 4 nurse practitioners.

Mental health specialists $(n=1)$ : one nurse who was trained and experienced in mental health and received weekly supervision from a health system psychiatrist.

Setting: 35 primary care practices, 13 urban and 22 suburban.

Interventions $\quad$ 1. Telephone Disease Management $(n=42)$

Mental health specialist/Consumer: follow up telephone assessments and education every three weeks. Topics included depression as a treatable condition, treatment options and side effects, coping skills, risk factors, suicide prevention and reinforcing follow-up with primary care provider. Hard copy educational material was also provided.

Mental health specialist/primary care provider: primary care provider provided with written individual consumer feedback after each assessment, including depression scores and clinical interpretation. General treatment recommendations were provided, with reference to a depression treatment algorithm based on AHRQ guidelines. Also asked clinician about depressive symptomatology, diagnostic criteria, and need for treatment modifications. Contact with psychiatrist also available if necessary.

Primary care provider/consumer: interaction not reported.

2. Standard care $(n=42)$.

Assessed at 16 weeks.

Outcomes 1. Consumer


Datto 2003 (Continued)

Improvement: remitted depression defined by a CES-D $<11$ at 16 weeks.

Symptoms: CES-D (20 item); Medical Outcomes Study Short Form -12 at 16 weeks.

2. Primary care provider

Adherence: asked consumers whether primary care providers had made treatment recommendations over 12 weeks.

Notes

Improvement and provider adherence were reported as odds ratios for a subsample of participants.

\section{Risk of bias}

\begin{tabular}{lll}
\hline Bias & Authors' judgement & Support for judgement \\
\hline $\begin{array}{l}\text { Random sequence genera- } \\
\text { tion (selection bias) }\end{array}$ & Unclear risk & Randomised by primary care practice. \\
\hline $\begin{array}{l}\text { Allocation concealment } \\
\text { (selection bias) }\end{array}$ & Unclear risk & Not reported. \\
\hline $\begin{array}{l}\text { Blinding (performance } \\
\text { bias and detection bias) } \\
\text { All outcomes }\end{array}$ & High risk & Probable that participants knew they were in an active group. \\
\hline $\begin{array}{l}\text { Incomplete outcome data } \\
\text { (attrition bias) } \\
\text { All outcomes }\end{array}$ & High risk & Data was reported for those available at follow-up, loss to follow-up 14\%. \\
\hline $\begin{array}{l}\text { Selective reporting (re- } \\
\text { porting bias) }\end{array}$ & High risk & $\begin{array}{l}\text { All categorical outcomes were only reported for a subsample who had major } \\
\text { depression at baseline. }\end{array}$ \\
\hline $\begin{array}{l}\text { Other bias } \\
\text { Significantly more consumers in the standard care group were prescribed an- } \\
\text { tidepressants at baseline (74\% vs 37\%) and there were more women in the in- } \\
\text { tervention group (67\% vs 55\%). Cluster randomisation does not seem to have } \\
\text { been accounted for in the analysis. }\end{array}$
\end{tabular}

\section{De Cruppe 2005}

\begin{tabular}{|c|c|}
\hline Methods & Randomised controlled trial of consultation liaison compared to standard care. \\
\hline \multirow[t]{5}{*}{ Participants } & $\begin{array}{l}\text { Consumers }(n=67) \text { : consumers referred to a hospital-based psychosomatic consultation liaison ser- } \\
\text { vice. Their mean age was } 45 \text { years, } 42 \% \text { were male. Somatoform disorders } 21 \text {, common psychiatric dis- } \\
\text { orders } 22 \text {, and adjustment disorder or stress reaction } 24 \text {. }\end{array}$ \\
\hline & $\begin{array}{l}\text { Excluded: organic mental disorders; substance- and abuse-related disorders, schizophrenia, schizotyp- } \\
\text { al or delusional disorders, pre-terminal illness or limited German. }\end{array}$ \\
\hline & $\begin{array}{l}\text { Primary care providers ( } n \text { not reported): general practitioners of a consumer randomised to the inter- } \\
\text { vention group, } 62.4 \% \text { had received certification for psychosomatic primary care. }\end{array}$ \\
\hline & $\begin{array}{l}\text { Mental health specialists }(n=5) \text { : psychosomatic consultants trained in internal medicine and psy- } \\
\text { chotherapy with one year training. }\end{array}$ \\
\hline & Setting: GP practices in Germany 1998-9. \\
\hline
\end{tabular}

Interventions

1. Consultation Liaison $(n=33)$ 
Mental health specialist/consumer: initial assessment through hospital psychosomatic consultation liaison service and recommendation for further psychosocial care and therapy.

Mental health specialist/primary care provider: one phone-call (10 min) and one written report. Both incorporated diagnosis, symptom-related psychosocial findings and therapy recommendations.

Primary care provider/consumer: recommendations were made to primary care providers to hold symptom-based conversations with the client integrating psychosocial aspects every four to six weeks.

2. Standard care $(n=34)$

Mental health specialist/consumer: initial assessment through hospital psychosomatic consultation liaison service and recommendation for further psychosocial care and therapy (as for consultation liaison).

1. Consumer
Symptoms: Beschwerden Liste (general and somatic symptoms, 24 item), Allgemeine Depressionskala
(Depressive symptoms, 20 item), State-Trait Anxiety Inventory (20 item), WHO Global Assessment of So-
cial Functioning (five-point scale) at 6 and 42 months.

Adherence: used recommended psychotherapy treatments at 6 and 42 months.

2. Provider

Adherence: followed through with $\mathrm{CL}$ recommendations over 6 months.

Notes

As provider sample sizes were not reported, these were assumed to be the same as consumers for provider adherence.

\section{Risk of bias}

\begin{tabular}{lll}
\hline Bias & Authors' judgement & Support for judgement \\
\hline $\begin{array}{l}\text { Random sequence genera- } \\
\text { tion (selection bias) }\end{array}$ & Low risk & An independent statistician block randomised consumers by diagnosis. \\
\hline $\begin{array}{l}\text { Allocation concealment } \\
\text { (selection bias) }\end{array}$ & Low risk & See sequence generation. \\
\hline $\begin{array}{l}\text { Blinding (performance } \\
\text { bias and detection bias) } \\
\text { All outcomes }\end{array}$ & Unclear risk & $\begin{array}{l}\text { Independent statistician was responsible for psychometric tests but responses } \\
\text { were self-reported; however, participants probably did not know whether they } \\
\text { were in the active group. }\end{array}$ \\
\hline
\end{tabular}

\section{Incomplete outcome data High risk} (attrition bias)

All outcomes

\section{Data was reported for those available at follow-up, loss to follow-up at 6 months $21 \%$, 42 months $28 \%$.}

\begin{tabular}{|c|c|c|}
\hline $\begin{array}{l}\text { Selective reporting (re- } \\
\text { porting bias) }\end{array}$ & High risk & $\begin{array}{l}\text { The only consumer outcome reported was use of psychotherapies. Primary } \\
\text { care provider adherence was reported but sample sizes were not reported. }\end{array}$ \\
\hline
\end{tabular}

Other bias Unclear risk No other bias identified.

\section{Dobscha 2006}

Methods Cluster-randomised trial of a decision support intervention compared to standard care


Dobscha 2006 (Continued)

Participants
Consumers $(n=375)$ : consumers of participating clinicians with Patient Health Questionnaire (PHQ)-9 depression scores of 10 to 25 at screening and between 10 to 20 or a score of at least 1 on the Hopkins Symptom checklist (SCL-20) at enrolment. Major depression 49\%, dysthymia 47\%, moderate-great pain $68 \%$, alcohol disorder $17 \%$, panic disorder $14 \%$, other anxiety disorder $25 \%$, PTSD $39 \%$, taking antidepressant at study entry $41 \%$. Their mean age 56.8 years, 349 were male; white 177 , non-white 10 , not recorded 188.

Excluded: received specialist mental health treatment in previous six months, dementia, psychotic or bipolar disorder terminal illness, and people referred for urgent care because of PHQ-9 scores of 25 or more and/or active dangerous ideation.

Primary care providers $(n=41)$ : full and part time physicians (28), physician assistants or nurse practitioners (13). Mean age 45.1 years; female 21. Mean time since training 15.1 years.

Mental health specialists $(n=2)$ : One psychiatrist 4 hours per week and one nurse care manager 8 hours per week in the intervention group. An on-site mental health consultation team was also available to both groups.

Setting: five Veterans Affairs medical clinics (3 urban, 2 rural), Portland USA, 2002-3.
Interventions
1. Depression decision support $(n=189)$

Mental health specialist/consumer: the Depression Support Team nurse called the consumer 1 to 2 weeks after enrolment to discuss education, barriers, adherence, and communicating with the primary care provider. Consumers were also mailed educational materials and invited to a two-hour depression education programme. For $76 \%$ of consumers this was only contact with mental health specialists; psychiatrists met with $13 \%$ and rang $1 \%$; education sessions attended by $8 \%$

Mental health specialist/primary care provider: all primary care providers were also offered two fourhour training sessions in the recognition and management of depression (communication, skills and knowledge). A treatment progress report based on monthly file review by the decision support team for each consumer was mailed to the primary care provider every three months. The review considered appointments, medications, symptom severity, PTSD and alcohol screening. If the primary care provider did not respond to an initial PHQ-9 score of 15 or more, or the consumer did not improve over time, the primary care provider was contacted by the team to discuss treatment, offer psychiatric consultation (with the primary care provider or consumer), or facilitate referral to ongoing speciality care. The Depression Support Team communicated with primary care providers or their nurses an average of 2.2 times.

Primary care provider/consumer: interaction not reported.

2. Standard care $(n=186)$

Mental health specialist/primary care provider: prior to the study, all primary care providers were offered two four-hour training sessions in the recognition and management of depression (as were intervention primary care providers). An onsite mental health consultation team was also available. Providers received notification that the consumer was enrolled in the study and their baseline and follow-up PHQ-9 scores were made available in patient charts.

Mental health specialist/consumer: none aside from depression measurement at baseline, 1, 3, 6, 9 and 12 months.

\section{Consumer}

Symptoms: SCL-20 at 6 and 12 months, Patient Health Questionnaire (PHQ-9) scores at 1, 3, 6, 9 and 12 months.

Health status: health-related Quality of Life Short Form for Veterans (SF-36V) scores at 6 and 12 months.

Satisfaction: rated poor to excellent on a five-point Likert scale at 6 and 12 months.

Adherence: attended at least three mental health appointments. 
Healthcare visits: attended three or more primary care appointments.

\section{Provider}

Diagnosis: consumers assessed for depression over 12 months.

Prescribing: prescribed antidepressants.

Adherence: at least one follow-up depression-related action.

Adequate treatment: minimally effective dose for at least 90 days.

\section{Notes}

SCL-20 means and standard errors estimated from graph, PHQ-9 scores but not variance were also graphed.

Diagnosis and provider adherence reported for a subsample not receiving antidepressants at the beginning of the study.

\section{Risk of bias}

\begin{tabular}{lll}
\hline Bias & Authors' judgement & Support for judgement \\
\hline $\begin{array}{l}\text { Random sequence genera- } \\
\text { tion (selection bias) }\end{array}$ & Low risk & $\begin{array}{l}\text { Stratified randomisation 'using a random-number generator' by clinician to } \\
\text { ensure distribution across type of clinician, clinic site and caseload. }\end{array}$ \\
\hline $\begin{array}{l}\text { Allocation concealment } \\
\text { (selection bias) }\end{array}$ & Unclear risk & Not reported. \\
\hline $\begin{array}{l}\text { Blinding (performance } \\
\text { bias and detection bias) } \\
\text { All outcomes }\end{array}$ & High risk & $\begin{array}{l}\text { Data was collected by a blinded research assistant via phone or posted } \\
\text { questionnaires, however data were self-reported and both consumers and } \\
\text { providers are likely to have been aware whether they were in the active group. }\end{array}$ \\
\hline $\begin{array}{l}\text { Incomplete outcome data } \\
\text { (attrition bias) } \\
\text { All outcomes }\end{array}$ & High risk & $\begin{array}{l}\text { Data were reported for those available at follow-up, loss to follow-up at } 6 \\
\text { months 16\%, 12 months 15\%. }\end{array}$ \\
\hline $\begin{array}{l}\text { Selective reporting (re- } \\
\text { porting bias) }\end{array}$ & Unclear risk & $\begin{array}{l}\text { SF-36V scores were not reported, diagnosis, referrals and healthcare visits re- } \\
\text { ported for subsample. }\end{array}$ \\
\hline \begin{tabular}{l} 
Other bias \\
\hline
\end{tabular} & Unclear risk & \begin{tabular}{l} 
More participants in the standard care group had PTSD (44\% vs 35\%). \\
\hline
\end{tabular}
\end{tabular}

Drummond 1990

\begin{tabular}{ll}
\hline Methods $\quad$ Randomised controlled trial of consultation liaison compared to standard care. \\
\hline
\end{tabular}

\section{Participants}

Consumers $(n=40)$ : problem drinkers attending an alcohol clinic in the UK. The mean age was 39 years and $75 \%$ were male. Based on the General Health Questionnaire $45 \%$ were considered severe cases.

Excluded: not stated.

Primary care providers: GPs of consumers attending the clinic.

Mental health specialists $(n=4)$ : alcohol addiction specialists including three psychiatrists and one clinical nurse specialist.

Setting: GP practices in the UK.
Interventions
1. Consultation Liaison $(n=20)$ 
Drummond 1990 (Continued)

Mental health specialist/consumer: all consumers received a full psychiatric and physical assessment, counselled and given advice about their drinking problem and returned to their GP with assurances that the specialist would remain in contact with their GP.

Mental health specialist/primary care provider: specialists visited the GP to discuss management of the consumer and provided a booklet of guidelines on the management of alcohol problems. The mental health specialist offered further advice and support to the GP, initiated further contact by phone to check on progress or difficulties, and provided a contact phone number.

Primary care provider/consumer: interaction not reported.

2. Standard care $(n=20)$

Mental health specialist/consumer: people in the standard care group also received a full psychiatric and physical assessment, and counselling and advice about their drinking problem (as with the intervention group). They continued to receive routine outpatient clinic care through the alcohol clinic and, if necessary, admission to hospital.

1. Consumer
Symptoms: Alcohol Problems Questionnaire (APQ, 23 items) at six months.
General Health: General Health Questionnaire at six months.
Adherence: complete abstinence over six months.
Healthcare visits: attended GP during six months.
2. Provider
No provider outcomes were reported.

Notes

Risk of bias

\begin{tabular}{lll} 
Bias & Authors' judgement & Support for judgement \\
\hline $\begin{array}{l}\text { Random sequence genera- } \\
\text { tion (selection bias) }\end{array}$ & Unclear risk & Randomised by consumer, stratified on two-level measure of dependence. \\
\hline $\begin{array}{l}\text { Allocation concealment } \\
\text { (selection bias) }\end{array}$ & Unclear risk & Not reported. \\
\hline $\begin{array}{l}\text { Blinding (performance } \\
\text { bias and detection bias) } \\
\text { All outcomes }\end{array}$ & Low risk & $\begin{array}{l}\text { Follow-up conducted by 'research workers who were not blinded' but respons- } \\
\text { es were self-reported; however, as the interaction between consumers and } \\
\text { specialists was similar it is unlikely whether participants knew they were in an } \\
\text { active or standard care group. }\end{array}$ \\
\hline
\end{tabular}

Incomplete outcome data High risk Data were reported for those available at follow-up, loss to follow-up $8 \%$.
(attrition bias)

All outcomes

\begin{tabular}{|c|c|c|}
\hline $\begin{array}{l}\text { Selective reporting (re- } \\
\text { porting bias) }\end{array}$ & Unclear risk & $\begin{array}{l}\text { The reported APQ score was derived from } 23 \text { items 'applicable to all subjects' } \\
\text { rather than all } 46 \text { items. }\end{array}$ \\
\hline
\end{tabular}

\begin{tabular}{|c|c|c|}
\hline Other bias & Unclear risk & $\begin{array}{l}\text { There were differences between groups in age, time in present accommoda- } \\
\text { tion and time till follow-up. }\end{array}$ \\
\hline
\end{tabular}


Hedrick 2003

Methods

Participants
Randomised trial of consultation liaison compared to collaborative care.

Consumers $(n=354)$ : consumers who had been identified as having depression or dysthymia in two other studies, through a check-in survey, or by referral from their primary care provider. The mean age was 57.2 years, $95.5 \%$ were male, $79.7 \%$ were white, $53.6 \%$ had had previous depression, $59.7 \%$ had major depression and $60.7 \%$ had both depression and dysthymia.

Excluded: consumers with recent or scheduled mental health clinic appointments, requiring treatment for substance use or PTSD, suicidality, psychosis or other condition requiring immediate treatment.

Primary care providers $(n=67)$ : doctors (19 physicians, 38 residents, 10 fellows) and 22 nurse practitioners working for the General Internal Medicine Clinic. All were provided with three hours education on depression assessment, treatment and resources.

Mental health specialists ( $n>10)$ : CL team included a full-time psychiatry resident, psychiatrist consultant, clinical psychologists and interns, four social workers and interns.

Setting: Veteran's Affairs clinics, 1998-9 USA.

\section{Consultation Liaison $(n=186)$}

Mental health specialist/consumer: mental health specialists provided treatment directly to consumers in the primary care setting if appropriate or they were referred to speciality mental health clinics.

Mental health specialist/primary care provider: mental health specialist clinicians informed primary care provider of consumer diagnosis and facilitated referral to psychiatry residents, psychologist and/or social workers within the clinic. Primary care providers consulted with, or referred to Mental health specialists 'as deemed necessary'.

Consumer/Primary care provider: primary care provider responsible for initiating treatment and co-ordinating consumers' overall care. Primary care providers also able to refer to psychologists and social workers working at clinic.

2. Collaborative care $(n=168)$

Collaborative care team $(n>5)$ included a clinical psychologist, psychiatrist, social workers and "psychology technician".

Mental health specialist/consumer: treatment options included medication, six sessions of group CBT, and referral to speciality care. The social worker or students contacted consumers on a 'regular schedule' to encourage adherence, address treatment barriers and assess response. All consumers received a video and workbook.

Mental health specialist/primary care provider: the collaborative care mental health team informed the primary care provider of the consumer's diagnosis, provided a treatment plan, consulted on any disagreements over treatment, monitored primary care provider adherence to the plan, reviewed treatment results and communicated with the primary care provider via electronic progress notes. Primary care providers were also able to refer to psychologists and social workers working at the clinic.

\section{Consumer}

Improvement: 50\% reduction in SCL-20 score.

Symptoms: Hopkins SCL-20 depression scale, Veterans Short Form (SF)-36 mental component summary at three and nine months.

Satisfaction: Consumer satisfaction scale (five items) at three and nine months.

Diability: Sheehan Disability Scale (three items) at three and nine months. 
Prescribing: consumers prescribed antidepressants over nine months, consumers prescribed minimum therapeutic dose of antidepressants over nine months.

Cost: Total cost per consumer over nine months.

Notes

Note: the SCL-20 average item score was reported.

The number of consumers that no longer had SCL-20 cutoff scores for major depression of more than

1.75 were also reported but because this was a subset of all consumers $50 \%$ change from baseline

scores were used for improvement.

\section{Risk of bias}

\begin{tabular}{lll}
\hline Bias & Authors' judgement & Support for judgement \\
\hline $\begin{array}{l}\text { Random sequence genera- } \\
\text { tion (selection bias) }\end{array}$ & Unclear risk & $\begin{array}{l}\text { Consumers were randomised by the General Internal Medicine Clinic, se- } \\
\text { quence generation not described. }\end{array}$ \\
\hline $\begin{array}{l}\text { Allocation concealment } \\
\text { (selection bias) }\end{array}$ & Unclear risk & Not reported. \\
\hline $\begin{array}{l}\text { Blinding (performance } \\
\text { bias and detection bias) } \\
\text { All outcomes }\end{array}$ & High risk & $\begin{array}{l}\text { Consumer outcome measures were administered by graduate students who } \\
\text { were not informed of a participant's group membership; however, outcomes } \\
\text { were self-reported and participants in the CC group were probably aware they } \\
\text { were receiving specialist treatment. }\end{array}$ \\
\hline $\begin{array}{l}\text { Incomplete outcome data } \\
\text { (attrition bias) }\end{array}$ & High risk & $\begin{array}{l}\text { Data were reported for those available at follow-up, loss to follow-up at three } \\
\text { months 7\%, nine months } 8 \% .\end{array}$ \\
\hline $\begin{array}{l}\text { Selective reporting (re- } \\
\text { porting bias) }\end{array}$ & Unclear risk & $\begin{array}{l}\text { The decision to report the number of consumers prescribed antidepressants } \\
\text { (but not the number receiving therapeutic doses) may have been post hoc. }\end{array}$ \\
\hline $\begin{array}{l}\text { Other bias } \\
\text { Thes }\end{array}$ & Unclear risk & $\begin{array}{l}\text { The collaborative care group were more likely to have previous depression } \\
\text { (59.5\% vs 48.4\%) and to have major depression (65\% vs } 55 \%) .\end{array}$ \\
\hline
\end{tabular}

Katon 1992

Methods Randomised controlled trial of consultation liaison compared to standard care.

\section{Participants}

Consumers $(n=251)$ : people aged 18 to 75 years who were high utilisers of primary care and identified with anxiety, depression, or somatisation by the SCL-90-R. Their mean age was 47 years, $39 \%$ were male, $24 \%$ currently had major depression, and $68 \%$ had a lifetime history of major depression.

Excluded: people with current alcohol abuse, psychotic symptoms, serious suicidality, dementia, limited English, or plan to discontinue health insurance.

Primary care providers $(n=18)$ : board-certified family physicians and internists.

Mental health specialists $(n=2)$ : psychiatrists.

Setting: two primary care clinics in Washington state, US.

Interventions $\quad$ Consultation Liaison $(n=124)$

Mental health specialist/consumer: the psychiatrist provided a one hour assessment interview during which the Mental Health Diagnostic Interview Schedule was administered. Psychiatric diagnoses over the past month were made according to DSM-III-R criteria. A half-hour interview was then conducted 
Katon 1992 (Continued)

by the psychiatrist with the consumer and primary care provider present. During this interview the psychiatrist reviewed the consumer's psychiatric status and social developmental history and a treatment plan was formulated by all three participants.

Mental health specialist/primary care provider: the psychiatrist and primary care provider jointly formulated a treatment plan with the consumer during the 30-minute joint interview. There was one additional case conference between the psychiatrist and GP to review the management of each consumer. The primary care provider was provided with a written psychiatric consultation, treatment protocol and an article on treatment for the specific disorder. The psychiatrist reviewed information from the medical charts, primary care provider and consumers and immediately after consultation filled out a form listing the identified problems and treatment needs. In $10 \%$ of interviews both psychiatrists were present to ensure uniformity.

Primary care provider/consumer: interaction not reported.

2. Standard care $(n=127)$

1. Consumer
Consumer adherence: filled one or more prescriptions for antidepressants.
2. Provider
Prescribing: prescribed antidepressants over 12 months.
Adequate treatment: prescribed adequate dosage of antidepressants for at least 90 days.

Notes

Risk of bias

\begin{tabular}{|c|c|c|}
\hline Bias & Authors' judgement & Support for judgement \\
\hline $\begin{array}{l}\text { Random sequence genera- } \\
\text { tion (selection bias) }\end{array}$ & Unclear risk & Randomised by consumer. \\
\hline $\begin{array}{l}\text { Allocation concealment } \\
\text { (selection bias) }\end{array}$ & Unclear risk & Not stated. \\
\hline $\begin{array}{l}\text { Blinding (performance } \\
\text { bias and detection bias) } \\
\text { All outcomes }\end{array}$ & High risk & $\begin{array}{l}\text { 'Chart reviewers were blind to whether participants were in the standard care } \\
\text { or intervention group' but consumers in the consultation liaison group would } \\
\text { have known they were receiving specialist care. }\end{array}$ \\
\hline $\begin{array}{l}\text { Incomplete outcome data } \\
\text { (attrition bias) } \\
\text { All outcomes }\end{array}$ & Low risk & Data was available for all participants. \\
\hline $\begin{array}{l}\text { Selective reporting (re- } \\
\text { porting bias) }\end{array}$ & Unclear risk & All outcomes appear to have been reported but protocol was not available. \\
\hline Other bias & Low risk & None identified. \\
\hline
\end{tabular}

Katon 1995

Methods $\quad$ Randomised controlled trial of consultation liaison compared to standard care.

Participants

Consumers $(n=217)$ : primary care consumers aged 18 to 80 years who met criteria for definite or probable major depression (at least 0.75 on the SCL-20 score for depression) and had agreed to antidepres- 
Katon 1995 (Continued)

sant therapy. Their mean age was 48 years and 23\% were male, 91 had major depression and 126 had minor depression.

Excluded: people with current alcohol abuse, psychotic symptoms, serious suicidality, dementia, limited English, or plan to discontinue health insurance.

Primary care providers $(n=22)$ : board certified family physicians.

Mental health specialists $(n=2)$ : study psychiatrists.

Setting: a large primary care clinic in Washington state, USA.

\begin{abstract}
Interventions $\quad$ Consultation Liaison $(n=108)$
Mental health specialist/consumer: consumers were given psychoeducational material prior to the first visit including a booklet on the biology and medications for depression, a booklet on CBT for depression, a 20-minute videotape with four doctor-consumer vignettes, and a questionnaire designed to motivate consumers' active involvement in care to take back to the primary care provider. Consumers alternated visits with the primary care provider (visits one and three) and mental health specialist (visits two and four) over four to six weeks. The psychiatrist did not do any formal psychotherapy but helped the primary care provider and consumer with a new medication if there had been side-effects. Consumers could also refer themselves or be referred by the primary care provider to a designated mental health clinic.
\end{abstract}

Mental health specialist/primary care provider: primary care providers participated in a half day didactic on antidepressant and behavioural treatment of depression. Monthly case conferences and case-bycase consultations were tailored to primary care providers' queries.

Primary care provider/consumer: interaction not reported.

2. Standard care $(n=109)$

Consumers received treatment for depression from their primary care provider and, as with the $\mathrm{CL}$ group, could refer themselves or be referred by the primary care provider to a designated mental health clinic.

Outcomes $\quad$ 1. Consumer

Improved: more than 50\% decrease from baseline SCL-90 at 4 months.

Symptoms: SCL-90 (self-report) at 1, 4, 7 months but were reported in a graph.

Adherence: automated pharmacy data over 90 days.

Satisfaction: five-point ordinal scale at four months.

Healthcare visits: over 12 months.

2. Provider

No provider outcomes were reported.

\title{
Risk of bias
}

\begin{tabular}{lll}
\hline Bias & Authors' judgement & Support for judgement \\
\hline $\begin{array}{l}\text { Random sequence genera- } \\
\text { tion (selection bias) }\end{array}$ & Low risk & $\begin{array}{l}\text { Stratified randomisation of consumers based on severe or moderate depres- } \\
\text { sion was computer-generated. }\end{array}$ \\
\hline $\begin{array}{l}\text { Allocation concealment } \\
\text { (selection bias) }\end{array}$ & Unclear risk & Not reported. \\
\hline \hline
\end{tabular}




\section{Katon 1995 (Continued)}

Blinding (performance bias and detection bias) All outcomes

High risk

Consumers were assessed by 'telephone interview survey team blinded to the consumers' randomisation status'; however, outcomes were self-reported and participants would have been aware they were receiving specialist treatment.

$\begin{array}{ll}\begin{array}{l}\text { Incomplete outcome data } \\ \text { (attrition bias) }\end{array} & \text { High risk } \\ \text { Datla were reported for those available at follow-up, loss to follow-up at one } \\ \text { month } 8 \% \text {, four months } 11 \% \text {, seven months } 15 \% .\end{array}$

All outcomes month $8 \%$, four months $11 \%$, seven months $15 \%$.

Selective reporting (re- $\quad$ Unclear risk $\quad$ IDS scores were not reported by group.
porting bias)

Other bias Unclear risk Insufficient information, appeared to be more females in standard care group.

Katon 1999

Methods Randomised controlled trial of consultation liaison versus standard care.

Participants

Consumers $(n=228)$ : consumers aged 18 to 80 years receiving a new prescription for antidepressants, and identified at risk for persistent depression by four or more major depressive symptoms on the Structured Clinical Interview for DSM-III-R and a score of at least one on the SCL-20, or a score of 1.5 or more on the SCL-20. Their mean age was 47 years and $25 \%$ were males, $80 \%$ had recurrent depression (at least three episodes), 55\% had dysthymia and $10 \%$ had panic disorder.

Excluded: alcohol misuse, pregnancy or nursing, seeing a psychiatrist, using lithium or an antipsychotic, limited English, or plan to discontinue health insurance.

Primary care providers ( $n=73$ ): board-certified family physicians.

Mental health specialists (n not known): psychiatrists.

Setting: four large primary care clinics in Washington, USA.

Interventions $\quad$ Consultation Liaison $(n=114)$

Mental health specialist/consumer: two sessions were scheduled with the psychiatrist over four weeks with a brief phone call in between visits to review progress. The psychiatrist reviewed the course of the current episode; individual, family and psychosocial history; and current medication. Additional visits could be provided based on clinical response to treatment. Participants were also given a book and videotape about depression and being an active participant in their care with the primary care provider

Mental health specialist/primary care provider: physicians received immediate verbal consultation about the consumer's progress and typed physician notes within one week. The psychiatrist reviewed medication compliance and alerted the Primary care provider of premature discontinuation.

Primary care provider/consumer: interaction not reported.

2. Standard care $(n=114)$

Consumer/primary care provider: treatment typically involved prescription of medication over the first three months plus the option of referral to a mental health service.

\section{Consumer}

Improvement: 0 to 1 symptoms on the 9-symptom Structured Clinical Interview for DSM-IV at three and six months.

Symptoms: SCL-90 at one, three, and six months. 
Katon 1999 (Continued)

Adherence: self-reported adherence to antidepressant therapy for 25 of the previous 30 days at one, three, and six months.

Satisfaction: with treatment for depression on a five-point ordinal scale at three and six months.

Healthcare visits: at three and six months.

\section{Provider}

Adequate treatment: prescribed therapeutic dose of antidepressant for at least 90 days - identified from computerised pharmacy records.

Notes Symptom scores were estimated from graphs but data were skewed.

\section{Risk of bias}

Bias Authors' judgement Support for judgement

Random sequence genera- Low risk $\quad$ Computer-generated block randomisation of consumers was used.
tion (selection bias)

tion (selection bias)

Allocation concealment $\quad$ Unclear risk Not described.
(selection bias)

\begin{tabular}{|c|c|c|}
\hline $\begin{array}{l}\text { Blinding (performance } \\
\text { bias and detection bias) } \\
\text { All outcomes }\end{array}$ & High risk & $\begin{array}{l}\text { Consumer outcomes were collected by telephone interviewers blind to ran- } \\
\text { domisation status; however, these were self-reported and consumers would } \\
\text { have been aware they were receiving specialist treatment. }\end{array}$ \\
\hline
\end{tabular}

\begin{tabular}{|c|c|c|}
\hline $\begin{array}{l}\text { Incomplete outcome data } \\
\text { (attrition bias) }\end{array}$ & Unclear risk & $\begin{array}{l}\text { Imputed data were used for analyses but loss to follow-up at one month was } \\
8 \% \text {, three months } 15 \% \text {, and six months } 16 \% \text {. }\end{array}$ \\
\hline
\end{tabular}

All outcomes

\begin{tabular}{lll}
\hline $\begin{array}{l}\text { Selective reporting (re- } \\
\text { porting bias) }\end{array}$ & Unclear risk & All outcomes appear to have been reported but protocol was not available. \\
\hline Other bias & Unclear risk & There were more females in the standard care group (82\% vs $68 \%)$. \\
\hline
\end{tabular}

Schrader 2005

\begin{tabular}{|c|c|}
\hline Methods & Cluster-randomised controlled trial of consultation liaison compared to standard care. \\
\hline \multirow[t]{5}{*}{ Participants } & $\begin{array}{l}\text { Consumers }(n=669) \text { : consumers hospitalised for a range of cardiac conditions and identified as de- } \\
\text { pressed (CES-D score of } 16 \text { or more). They were aged } 18 \text { to } 84 \text { years, } 62 \% \text { were male, and } 45 \% \text { had mod- } \\
\text { erate to severe depression. }\end{array}$ \\
\hline & Exclusions: severe cognitive or physical impairment, participants in other trials, limited English. \\
\hline & Primary care providers $(n=480)$ : GPs. \\
\hline & $\begin{array}{l}\text { Mental health specialists (n not known): psychiatric registrars, psychiatrist and cardiac rehabilitation } \\
\text { nurse. }\end{array}$ \\
\hline & $\begin{array}{l}\text { Setting: consumers were enrolled from four urban hospitals in Adelaide, Australia 2000-2001 but con- } \\
\text { sultation liaison care was delivered in conjunction with the consumer's GP. }\end{array}$ \\
\hline \multirow[t]{2}{*}{ Interventions } & 1. Consultation Liaison $(n=331)$ \\
\hline & $\begin{array}{l}\text { Mental health specialist/consumer: consumers were referred to the psychiatric } C L \text { unit while in hospital } \\
\text { for a consultation of 20-30 minutes with the psychiatric registrar and cardiac rehabilitation nurse. }\end{array}$ \\
\hline
\end{tabular}


Mental health specialist/primary care provider: GPs were invited to a 15 to 30 minute phone case conference with the attending psychiatric registrar and cardiac rehabilitation nurse. If this was not possible, the GP was offered a 5 to 10 minute phone call with a psychiatrist who had not seen the consumer for management suggestions. The consumer's depression scores and guide for the recognition and treatment of depression (medication and CBT) was sent to all participating GPs. The percentage of GPs participating in the case conference was $24 \%$, receiving a call from the psychiatrist was $40 \%$, and just received the consumer's scores and treatment guide was $36 \%$.

Primary care provider/consumer: interaction not reported.

2. Standard care $(n=338)$

Consumers in the standard care group received usual cardiac and non-cardiac care in the hospital and community.

\section{Consumer}

Improved: no longer categorised as depressed according to CES-D scores at 12 months.

Health: SF-36 physical health subscale at 12 months.

2. Provider

No provider outcomes were reported.

Notes

\section{Risk of bias}

\begin{tabular}{lll}
\hline Bias & Authors' judgement & Support for judgement \\
\hline $\begin{array}{l}\text { Random sequence genera- } \\
\text { tion (selection bias) }\end{array}$ & Low risk & 'Centrally randomised' by GP. \\
\hline $\begin{array}{l}\text { Allocation concealment } \\
\text { (selection bias) }\end{array}$ & Unclear risk & Not described. \\
\hline $\begin{array}{l}\text { Blinding (performance } \\
\text { bias and detection bias) }\end{array}$ & High risk & $\begin{array}{l}\text { Blinding was not described but consumers were probably aware they were in } \\
\text { the active group. }\end{array}$ \\
\hline $\begin{array}{l}\text { Incomplete outcome data } \\
\begin{array}{l}\text { (attrition bias) } \\
\text { All outcomes }\end{array}\end{array}$ & High risk & Loss to follow-up was very high (33\%). \\
\hline $\begin{array}{l}\text { Selective reporting (re- } \\
\text { porting bias) }\end{array}$ & High risk & Did not report SF-36 mental health scores. \\
\hline \begin{tabular}{l} 
Other bias \\
\hline
\end{tabular} & Low risk & None identified. \\
\hline
\end{tabular}

\section{Van der Feltz 2006}

Methods Cluster-randomised trial of consultation liaison compared to standard care.

Participants

Consumers $(n=81)$ : consumers from GP practices who wanted to continue diagnostic procedures despite persistent symptoms which remained unexplained by previous specialist diagnostic tests. Their mean age was 44 years, 68 were caucasian and 62 were female. Seventy were given a comorbid psychi- 
Van der Feltz 2006 (Continued)

atric diagnosis: 20 with generalised anxiety disorder, eight with anxiety disorder, seven panic disorder, 15 depression, and 20 with personality disorder.

Excluded: psychosis, suicidality, dementia, alcohol dependency, current psychiatric treatment, younger than 18 or unable to complete questionnaire.

Primary care providers ( $n=58)$ : GPs.

Mental health specialist $(n=1)$ : a consultant psychiatrist.

Setting: 36 GP practices in the Netherlands.

Interventions

1. Consultation Liaison $(n=58)$

Mental health specialist/consumer: during the one hour consultation where the GP was present the psychiatrist aimed to identify a comorbid psychiatric diagnosis requiring medication as well as disorders requiring $\mathrm{CBT}$ or other psychotherapeutic interventions. Consumers without psychiatric diagnoses received explanations that may explain their symptoms and were advised to start psychotherapy. The consumer was given copies of the psychiatrist's recommendations.

Mental health specialist/primary care provider: GPs were given training in case management and CBT techniques over three to nine three-hour sessions. GPs also received case management advice and were given copies of the psychiatrist's recommendations.

2. Primary care provider/consumer: interaction not reported.

Standard care $(n=23)$.

Mental health specialist/primary care provider: GPs also received training but no consultation.

1. Consumer
Symptoms: SCL-90-R at six weeks and six months.
Disability: Sickness Impact Profile at six weeks and six months.
Healthcare visits: visits to doctors and other health care services over six months.
2. Provider
No provider outcomes were reported.

Notes

\section{Risk of bias}

\begin{tabular}{lll}
\hline Bias & Authors' judgement & Support for judgement \\
\hline $\begin{array}{l}\text { Random sequence genera- } \\
\text { tion (selection bias) }\end{array}$ & Unclear risk & Practices were randomly assigned by a research assistant. \\
\hline $\begin{array}{l}\text { Allocation concealment } \\
\text { (selection bias) }\end{array}$ & Unclear risk & Not described. \\
\hline $\begin{array}{l}\text { Blinding (performance } \\
\text { bias and detection bias) } \\
\text { All outcomes }\end{array}$ & High risk & $\begin{array}{l}\text { Outcomes were recorded by a blinded research assistant but they were self-re- } \\
\text { ported and participants would have been aware they were receiving specialist } \\
\text { treatment. }\end{array}$ \\
\hline $\begin{array}{l}\text { Incomplete outcome data } \\
\text { (attrition bias) }\end{array}$ & Low risk & No loss to follow-up. \\
All outcomes & & \\
\hline
\end{tabular}


Van der Feltz 2006 (Continued)

\begin{tabular}{|c|c|c|}
\hline $\begin{array}{l}\text { Selective reporting (re- } \\
\text { porting bias) }\end{array}$ & High risk & $\begin{array}{l}\text { The SCL-90-R results were not reported because 'changes -- were not signifi- } \\
\text { cant'. }\end{array}$ \\
\hline
\end{tabular}

Other bias High risk

Although practices were randomly allocated the much higher number of consumers in the intervention group ( 58 vs 23 ) may indicate biases in the detection of disorders.

\section{Worrall 1999}

\begin{tabular}{|c|c|}
\hline Methods & Cluster-randomised controlled trial of consultation liaison compared to guidelines only. \\
\hline Participants & $\begin{array}{l}\text { Consumers ( } n=147) \text { : consumers with newly diagnosed depression. } \\
\text { Excluded: } \text { not described. } \\
\text { Primary care providers }(n=42) \text { : family physicians (only one per practice was included). } \\
\text { Mental health specialists }(n=2) \text { : a psychiatrist and academic family physician. } \\
\text { Setting: } 42 \text { General practices in Canada in } 1997 \text {. }\end{array}$ \\
\hline Interventions & $\begin{array}{l}\text { 1. Consultation Liaison ( } \mathrm{n}=91 \text { ) } \\
\text { Mental health specialist/consumer: no interaction reported. } \\
\text { Mental health specialist/primary care provider: GPs attended three hour workshops delivered by a psy- } \\
\text { chiatrist and academic family physician. The workshop covered the epidemiology and explanation of } \\
\text { clinical practice guidelines developed by the Canadian Medical Association for depression and included } \\
\text { case discussions. GPs could discuss their own cases with reference to diagnosis and treatment difficul- } \\
\text { ties. A psychiatrist was available for advice on patient management at a specific time each week. } \\
\text { 2. Guidelines only }(n=56)\end{array}$ \\
\hline
\end{tabular}

1. Consumer
Symptoms: CES-D at six months.
Adherence: took antidepressant for six months.
Healthcare visits: to primary care physician over six months.
2. Provider
Diagnosis: correct DSM-IV diagnoses over six months.
Prescribing: prescribed antidepressants at first visit.
Specialist treatment: referrals to mental health professionals over six months.

Notes

\section{Risk of bias}

Bias Authors' judgement Support for judgement

'Physicians were assigned to the intervention or standard care group by the use of random number tables' 
Worrall 1999 (Continued)

$\begin{aligned} & \text { Allocation concealment } \\ & \text { (selection bias) }\end{aligned}$
Unclear risk Not described.

Blinding (performance

bias and detection bias)

All outcomes
Unclear risk

Blinding was not described; however, consumer participants were probably not aware of whether they were in the active or standard care group as there was no direct interaction with a mental health specialist reported. Primary care providers would have been aware which group they had been allocated to.

\begin{tabular}{lll}
\hline $\begin{array}{l}\text { Incomplete outcome data } \\
\text { (attrition bias) } \\
\text { All outcomes }\end{array}$ & Unclear risk & $\begin{array}{l}\text { Participant numbers for all outcomes may be incorrect as the loss to follow-up } \\
\text { was not reported and 'not all patients completed the CES-D at } 6 \text { months'. }\end{array}$ \\
\hline $\begin{array}{l}\text { Selective reporting (re- } \\
\text { porting bias) }\end{array}$ & High risk & The results for the SCL-90-R, which was a primary outcome, were not reported. \\
\hline Other bias & High risk & $\begin{array}{l}\text { Although physicians were randomly allocated, the higher number of con- } \\
\text { sumers in the intervention group (91 vs 56) may indicate biases in the detec- } \\
\text { tion of depression. Cluster randomisation does not seem to have been ac- } \\
\text { counted for in the analysis. }\end{array}$ \\
\hline
\end{tabular}

APQ: Alcohol Problems Questionnaire

CBT: Cognitive Behavioural therapy

CES-D: Centre for Epidemiological Studies Depression Scale

CIDI: Composite International Diagnostic Interview

DSM: Diagnostic and Statistical Manual of Mental Disorders

GHQ: General Health Questionnaire

GP: General practitioner

IDS: Inventory for Depressive Symptomatology

PHQ: Patient Health Questionnaire

PTSD: Posttraumatic Stress Disorder

SCL: Hopkins Symptoms checklist

SF-36V: Short Form for Veterans

WHO: World Health Organization

Characteristics of excluded studies [ordered by study ID]

\begin{tabular}{ll}
\hline Study & Reason for exclusion \\
\hline Arora 2011 & Implementation of a telemedicine project, not mental health-specific. \\
\hline Baker 2001 & Guideline implementation study. \\
\hline Bauer 2011 & Study of collaborative care. \\
\hline Bogner 2012 & Study of collaborative care. \\
\hline Carr 1997 & Controlled before and after study, did not have two intervention and two control sites. \\
\hline Chung 2011 & Quality Improvement programme based on training and discussion lists. \\
\hline Dietrich 2004 & Study of collaborative care. \\
\hline Harvey 2012 & Pre-post study with one measure at each interval. \\
\hline
\end{tabular}




\begin{tabular}{|c|c|}
\hline Study & Reason for exclusion \\
\hline Horner 2005 & Study of collaborative care. \\
\hline Liu 2007 & Patients were being managed in general medical clinic in a general hospital. \\
\hline Llewellyn-Jones 1999 & Shared care intervention. \\
\hline Menchetti 2007 & $\begin{array}{l}\text { Whether treatment was delivered by primary care providers, the consultant } \\
\text { psychiatrist, community mental health centre, or a combination of these was based on a treat- } \\
\text { ment algorithm. }\end{array}$ \\
\hline Serrano 2011 & Study of collaborative care. \\
\hline Sherbourne 2001 & Trial of recommendations to use psychotherapy or medications compared to standard care. \\
\hline Sinnema 2011 & Study of interventions to improve guideline implementation. \\
\hline Stiefel 2008 & Patient participants had a complex medical illness not a mental disorder. \\
\hline Su 2011 & Chart review of consultation liaison service in a general hospital. \\
\hline Tello-Bernabe 2011 & Implementation of Clinical Practice Guidelines. \\
\hline Wells 1999 & $\begin{array}{l}\text { Interaction between mental health specialist and primary care provider was educational not con- } \\
\text { sultative. }\end{array}$ \\
\hline Wiener 2006 & Before and after study of consultation liaison utilisation and satisfaction. \\
\hline
\end{tabular}

\section{DATA AND ANALYSES}

\section{Comparison 1. Consultation liaison versus control}

\begin{tabular}{|c|c|c|c|c|}
\hline $\begin{array}{l}\text { Outcome or subgroup } \\
\text { title }\end{array}$ & No. of studies & $\begin{array}{l}\text { No. of partici- } \\
\text { pants }\end{array}$ & Statistical method & Effect size \\
\hline 1 Improvement & 3 & & Risk Difference (M-H, Random, 95\% Cl) & Subtotals only \\
\hline 1.1 up to 3 months & 2 & 445 & Risk Difference (M-H, Random, 95\% Cl) & $0.13[0.04,0.22]$ \\
\hline 1.2 from 3 to 12 months & 2 & 678 & Risk Difference (M-H, Random, 95\% Cl) & $0.06[-0.05,0.18]$ \\
\hline 2 Symptoms & 3 & & $\begin{array}{l}\text { Std. Mean Difference (IV, Random, 95\% } \\
\mathrm{CI} \text { ) }\end{array}$ & Subtotals only \\
\hline 2.1 from 3 to 12 months & 3 & 546 & $\begin{array}{l}\text { Std. Mean Difference (IV, Random, 95\% } \\
\text { CI) }\end{array}$ & $-0.15[-0.32,0.03]$ \\
\hline 3 Consumer satisfaction & 2 & & Risk Difference (M-H, Random, 95\% Cl) & Subtotals only \\
\hline 3.1 up to 3 months & 1 & 228 & Risk Difference (M-H, Random, 95\% Cl) & $0.31[0.21,0.40]$ \\
\hline 3.2 from 3 to 12 months & 2 & 445 & Risk Difference (M-H, Random, 95\% Cl) & $0.12[0.06,0.19]$ \\
\hline
\end{tabular}




\begin{tabular}{|c|c|c|c|c|}
\hline $\begin{array}{l}\text { Outcome or subgroup } \\
\text { title }\end{array}$ & No. of studies & $\begin{array}{l}\text { No. of partici- } \\
\text { pants }\end{array}$ & Statistical method & Effect size \\
\hline 4 Consumer adherence & 7 & & Risk Difference (M-H, Random, 95\% Cl) & Subtotals only \\
\hline 4.1 up to 3 months & 1 & 228 & Risk Difference (M-H, Random, 95\% Cl) & $0.08[-0.04,0.19]$ \\
\hline 4.2 from 3 to 12 months & 7 & 1251 & Risk Difference (M-H, Random, 95\% Cl) & $0.16[0.08,0.24]$ \\
\hline 4.3 more than 12 months & 1 & 53 & Risk Difference (M-H, Random, 95\% Cl) & $0.03[-0.22,0.27]$ \\
\hline 5 Disability & 1 & & Mean Difference (IV, Random, 95\% CI) & Totals not selected \\
\hline 5.1 up to 3 months & 1 & & Mean Difference (IV, Random, 95\% Cl) & $0.0[0.0,0.0]$ \\
\hline 5.2 from 3 to 12 months & 1 & & Mean Difference (IV, Random, 95\% CI) & $0.0[0.0,0.0]$ \\
\hline 6 Healthcare visits & 1 & & Mean Difference (IV, Random, 95\% CI) & Totals not selected \\
\hline 6.1 from 3 to 12 months & 1 & & Mean Difference (IV, Random, 95\% CI) & $0.0[0.0,0.0]$ \\
\hline 7 People lost to follow-up & 7 & & Risk Difference (M-H, Random, 95\% Cl) & Subtotals only \\
\hline 7.1 up to 3 months & 1 & 84 & Risk Difference (M-H, Random, 95\% Cl) & $-0.05[-0.19,0.09]$ \\
\hline 7.2 from 3 to 12 months & 7 & 1544 & Risk Difference (M-H, Random, 95\% Cl) & $0.00[-0.03,0.04]$ \\
\hline 7.3 more than 12 months & 1 & 67 & Risk Difference (M-H, Random, 95\% Cl) & $0.10[-0.12,0.31]$ \\
\hline 8 Diagnosis & 1 & & Risk Difference (M-H, Random, 95\% Cl) & Totals not selected \\
\hline 8.1 from 3 to 12 months & 1 & & Risk Difference (M-H, Random, 95\% Cl) & $0.0[0.0,0.0]$ \\
\hline 9 Received any treatment & 1 & & Risk Difference (M-H, Random, 95\% Cl) & Totals not selected \\
\hline 9.1 from 3 to 12 months & 1 & & Risk Difference (M-H, Random, 95\% Cl) & $0.0[0.0,0.0]$ \\
\hline $\begin{array}{l}10 \text { Received adequate } \\
\text { treatment }\end{array}$ & 3 & & Risk Difference (M-H, Random, 95\% Cl) & Subtotals only \\
\hline 10.1 from 3 to 12 months & 3 & 797 & Risk Difference (M-H, Random, 95\% Cl) & $0.15[0.06,0.24]$ \\
\hline 11 Specialist treatment & 2 & & Risk Difference (M-H, Random, 95\% Cl) & Subtotals only \\
\hline 11.1 from 3 to 12 months & 2 & 227 & Risk Difference (M-H, Random, 95\% Cl) & $0.05[-0.10,0.20]$ \\
\hline 12 Prescribing & 5 & & Risk Difference (M-H, Random, 95\% Cl) & Subtotals only \\
\hline 12.1 from 3 to 12 months & 4 & 796 & Risk Difference (M-H, Random, 95\% Cl) & $0.08[0.02,0.15]$ \\
\hline $\begin{array}{l}12.2 \text { more than } 12 \\
\text { months }\end{array}$ & 1 & 48 & Risk Difference (M-H, Random, 95\% Cl) & $0.02[-0.25,0.30]$ \\
\hline $\begin{array}{l}13 \text { Primary care provider } \\
\text { adherence }\end{array}$ & 1 & & Risk Difference (M-H, Random, 95\% Cl) & Totals not selected \\
\hline 13.1 from 3 to 12 months & 1 & & Risk Difference (M-H, Random, 95\% Cl) & $0.0[0.0,0.0]$ \\
\hline
\end{tabular}


Analysis 1.1. Comparison 1 Consultation liaison versus control, Outcome 1 Improvement.

\begin{tabular}{|c|c|c|c|c|c|}
\hline Study or subgroup & $\begin{array}{c}\text { Consulta- } \\
\text { tion Liaison } \\
n / N\end{array}$ & $\begin{array}{l}\text { Control } \\
\mathrm{n} / \mathrm{N}\end{array}$ & $\begin{array}{c}\text { Risk Difference } \\
\text { M-H, Random, 95\% Cl }\end{array}$ & Weight & $\begin{array}{c}\text { Risk Difference } \\
\text { M-H, Random, 95\% Cl }\end{array}$ \\
\hline \multicolumn{6}{|l|}{ 1.1.1 up to 3 months } \\
\hline Katon 1995 & $72 / 108$ & $64 / 109$ & $\mathbf{m}$ & $46.61 \%$ & $0.08[-0.05,0.21]$ \\
\hline Katon 1999 & $46 / 114$ & $26 / 114$ & $\rightarrow-$ & $53.39 \%$ & $0.18[0.06,0.29]$ \\
\hline Subtotal $(95 \% \mathrm{Cl})$ & 222 & 223 & & $100 \%$ & $0.13[0.04,0.22]$ \\
\hline \multicolumn{6}{|c|}{ Total events: 118 (Consultation Liaison), 90 (Control) } \\
\hline \multicolumn{6}{|c|}{ Heterogeneity: $\mathrm{Tau}^{2}=0 ; \mathrm{Chi}^{2}=1.16, \mathrm{df}=1(\mathrm{P}=0.28) ; \mathrm{I}^{2}=14 \%$} \\
\hline \multicolumn{6}{|c|}{ Test for overall effect: $Z=2.73(P=0.01)$} \\
\hline \multicolumn{6}{|c|}{ 1.1.2 from 3 to 12 months } \\
\hline Katon 1999 & $50 / 114$ & $35 / 114$ & 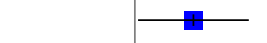 & $43.47 \%$ & $0.13[0.01,0.26]$ \\
\hline Schrader 2005 & $86 / 213$ & $93 / 237$ & & $56.53 \%$ & $0.01[-0.08,0.1]$ \\
\hline Subtotal $(95 \% \mathrm{Cl})$ & 327 & 351 & & $100 \%$ & $0.06[-0.05,0.18]$ \\
\hline \multicolumn{6}{|c|}{ Total events: 136 (Consultation Liaison), 128 (Control) } \\
\hline \multicolumn{6}{|c|}{ Heterogeneity: $\mathrm{Tau}^{2}=0 ; \mathrm{Chi}^{2}=2.35, \mathrm{df}=1(\mathrm{P}=0.13) ; \mathrm{I}^{2}=57.39 \%$} \\
\hline \multicolumn{6}{|c|}{ Test for overall effect: $Z=1.07(P=0.29)$} \\
\hline Test for subgroup dif & $77, d f=1(P=0.38)$, & & & & \\
\hline
\end{tabular}

Analysis 1.2. Comparison 1 Consultation liaison versus control, Outcome 2 Symptoms.

\begin{tabular}{|c|c|c|c|c|c|c|c|}
\hline \multirow[t]{2}{*}{ Study or subgroup } & \multicolumn{2}{|c|}{$\begin{array}{l}\text { Consulta- } \\
\text { tion Liaison }\end{array}$} & \multicolumn{2}{|c|}{ Control } & \multirow{2}{*}{$\begin{array}{l}\text { Std. Mean Difference } \\
\text { Random, } 95 \% \mathrm{Cl}\end{array}$} & \multirow[t]{2}{*}{ Weight } & \multirow{2}{*}{$\begin{array}{l}\text { Std. Mean Difference } \\
\text { Random, } 95 \% \mathrm{Cl}\end{array}$} \\
\hline & $\mathbf{N}$ & Mean(SD) & $\mathbf{N}$ & $\operatorname{Mean}(S D)$ & & & \\
\hline \multicolumn{8}{|c|}{ 1.2.1 from 3 to 12 months } \\
\hline Datto 2003 & 35 & $14.8(11.2)$ & 37 & $19.3(10.3)$ & & $13.68 \%$ & $-0.41[-0.88,0.05]$ \\
\hline Dobscha 2006 & 163 & $1.5(0.6)$ & 164 & $1.6(0.7)$ & & $59.92 \%$ & $-0.06[-0.27,0.16]$ \\
\hline Worrall 1999 & 91 & $19.4(13.6)$ & 56 & $22.2(11.7)$ & $\longrightarrow$ & $26.4 \%$ & $-0.22[-0.55,0.12]$ \\
\hline \multicolumn{8}{|c|}{ Heterogeneity: $\mathrm{Tau}^{2}=0 ; \mathrm{Chi}^{2}=2.07, \mathrm{df}=2(\mathrm{P}=0.36) ; \mathrm{I}^{2}=3.4 \%$} \\
\hline \multicolumn{8}{|c|}{ Test for overall effect: $Z=1.67(P=0.1)$} \\
\hline & & & & Favours $\mathrm{CL} \quad-2$ & -1 & Favours & \\
\hline
\end{tabular}

Analysis 1.3. Comparison 1 Consultation liaison versus control, Outcome 3 Consumer satisfaction.

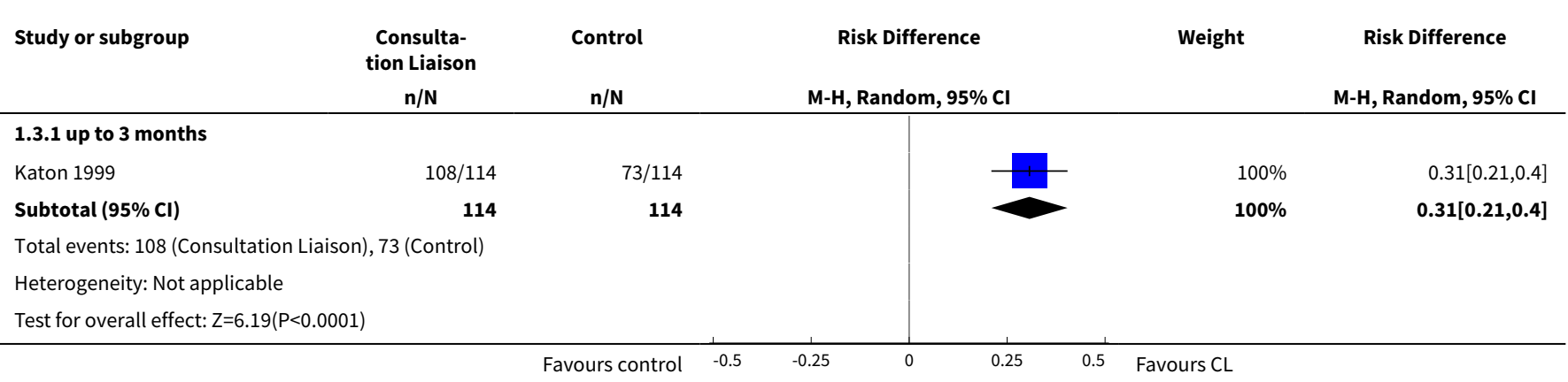




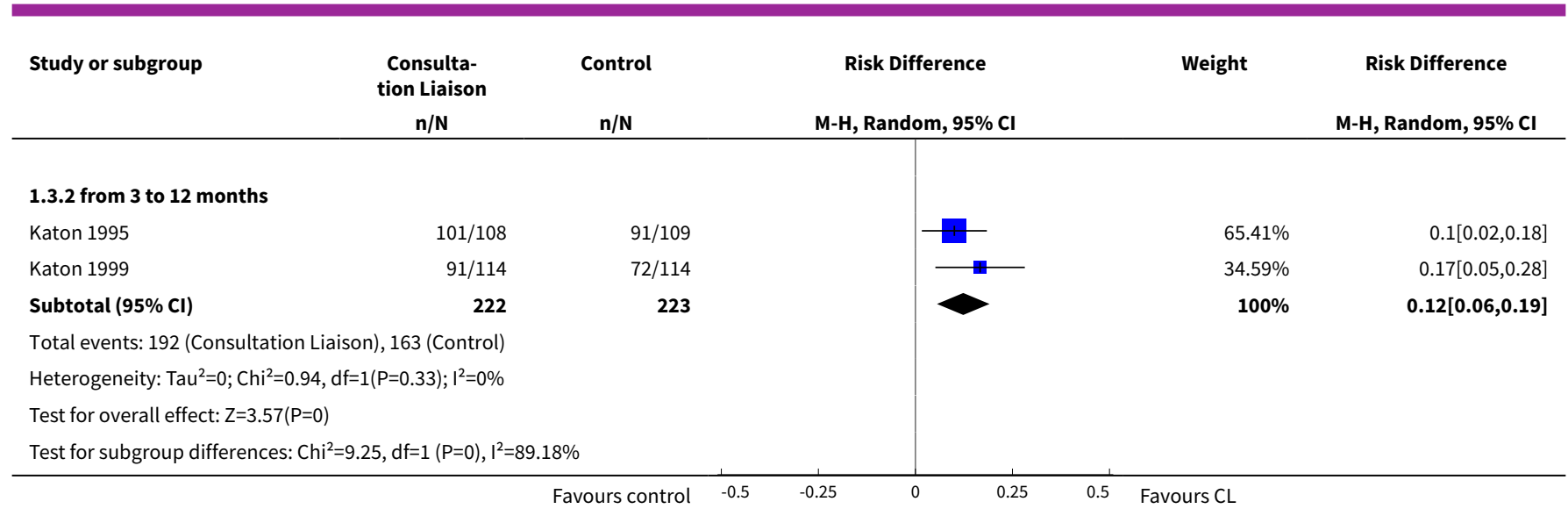

Analysis 1.4. Comparison 1 Consultation liaison versus control, Outcome 4 Consumer adherence.

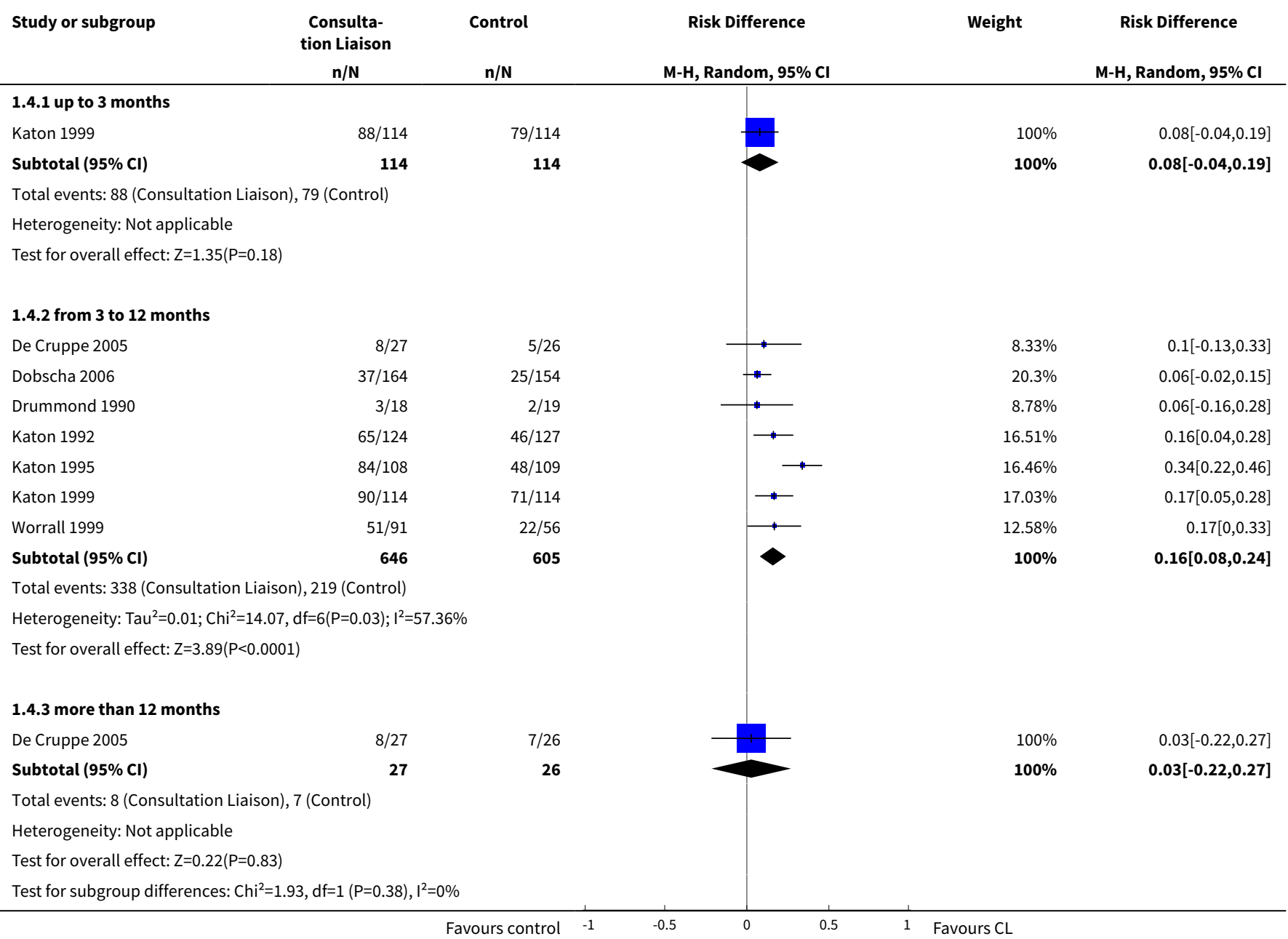


Analysis 1.5. Comparison 1 Consultation liaison versus control, Outcome 5 Disability.

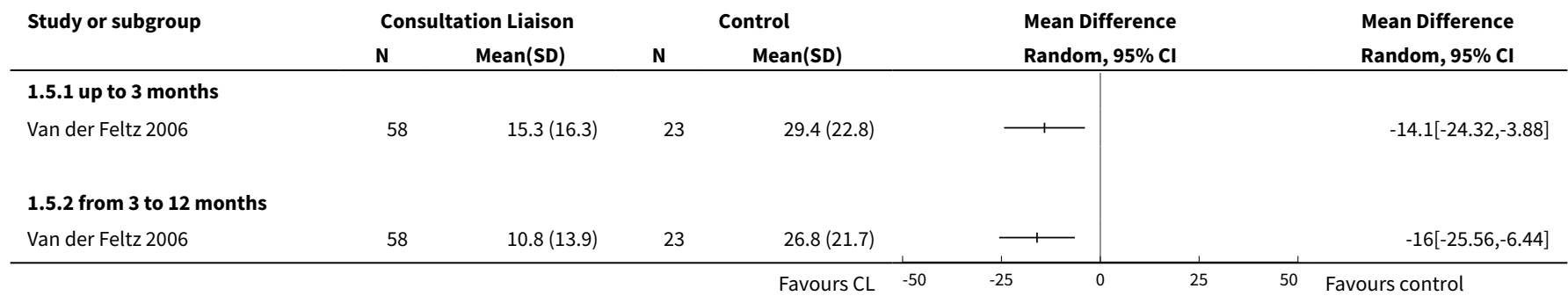

Analysis 1.6. Comparison 1 Consultation liaison versus control, Outcome 6 Healthcare visits.

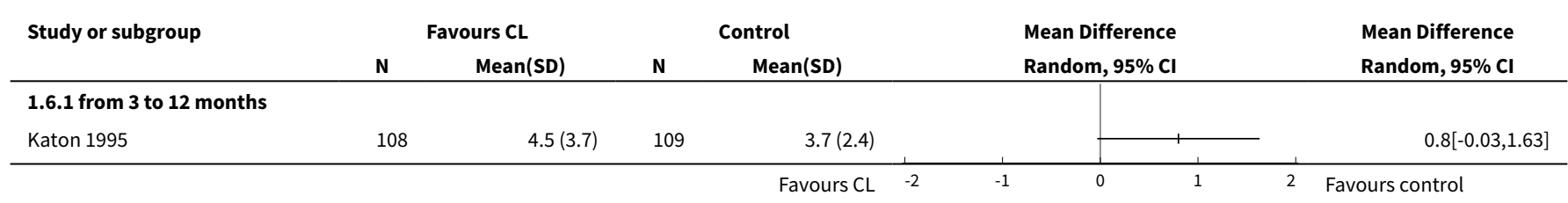

Analysis 1.7. Comparison 1 Consultation liaison versus control, Outcome 7 People lost to follow-up.

\begin{tabular}{|c|c|c|c|c|c|}
\hline Study or subgroup & $\begin{array}{c}\text { Consulta- } \\
\text { tion Liaison } \\
\mathbf{n} / \mathbf{N} \\
\end{array}$ & Control & M-H, Random, 95\% Cl & Weight & $\begin{array}{c}\text { Risk Difference } \\
\text { M-H, Random, } 95 \% \mathrm{Cl}\end{array}$ \\
\hline \multicolumn{6}{|l|}{ 1.7.1 up to 3 months } \\
\hline Datto 2003 & $4 / 42$ & $6 / 42$ & & $100 \%$ & $-0.05[-0.19,0.09]$ \\
\hline Subtotal $(95 \% \mathrm{Cl})$ & 42 & 42 & & $100 \%$ & $-0.05[-0.19,0.09]$ \\
\hline \multicolumn{6}{|c|}{ Total events: 4 (Consultation Liaison), 6 (Control) } \\
\hline \multicolumn{6}{|c|}{ Test for overall effect: $Z=0.68(P=0.5)$} \\
\hline \multicolumn{6}{|c|}{ 1.7.2 from 3 to 12 months } \\
\hline Datto 2003 & $7 / 42$ & $6 / 42$ & & $5.06 \%$ & $0.02[-0.13,0.18]$ \\
\hline De Cruppe 2005 & $6 / 33$ & $8 / 34$ & $\longrightarrow$ & $3.21 \%$ & $-0.05[-0.25,0.14]$ \\
\hline Dobscha 2006 & $26 / 189$ & $33 / 186$ & & $22.28 \%$ & $-0.04[-0.11,0.03]$ \\
\hline Katon 1999 & $27 / 114$ & $34 / 114$ & $\rightarrow$ & $9.2 \%$ & $-0.06[-0.18,0.05]$ \\
\hline Schrader 2005 & $118 / 331$ & $101 / 338$ & & $23.97 \%$ & $0.06[-0.01,0.13]$ \\
\hline Van der Feltz 2006 & $0 / 58$ & $0 / 23$ & & $31.71 \%$ & $0[-0.06,0.06]$ \\
\hline Subtotal $(95 \% \mathrm{Cl})$ & 787 & 757 & & $100 \%$ & $0[-0.03,0.04]$ \\
\hline \multicolumn{6}{|c|}{ Total events: 186 (Consultation Liaison), 183 (Control) } \\
\hline \multicolumn{6}{|c|}{ Heterogeneity: $\mathrm{Tau}^{2}=0 ; \mathrm{Chi}^{2}=5.6, \mathrm{df}=6(\mathrm{P}=0.47) ; \mathrm{I}^{2}=0 \%$} \\
\hline \multicolumn{6}{|c|}{ Test for overall effect: $Z=0.06(P=0.95)$} \\
\hline \multicolumn{6}{|c|}{ 1.7.3 more than 12 months } \\
\hline De Cruppe 2005 & $11 / 33$ & $8 / 34$ & - & $100 \%$ & $0.1[-0.12,0.31]$ \\
\hline Subtotal $(95 \% \mathrm{Cl})$ & 33 & 34 & & $100 \%$ & $0.1[-0.12,0.31]$ \\
\hline \multicolumn{6}{|c|}{ Total events: 11 (Consultation Liaison), 8 (Control) } \\
\hline Heterogeneity: Not a & & & & & \\
\hline
\end{tabular}




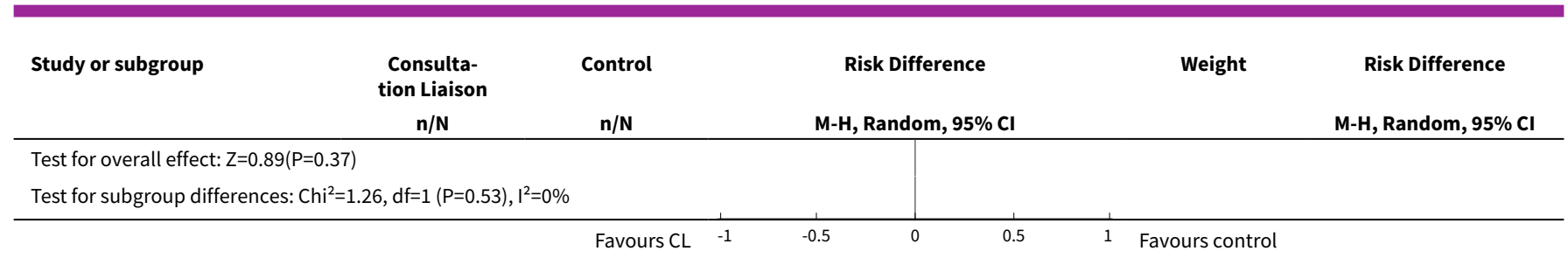

Analysis 1.8. Comparison 1 Consultation liaison versus control, Outcome 8 Diagnosis.

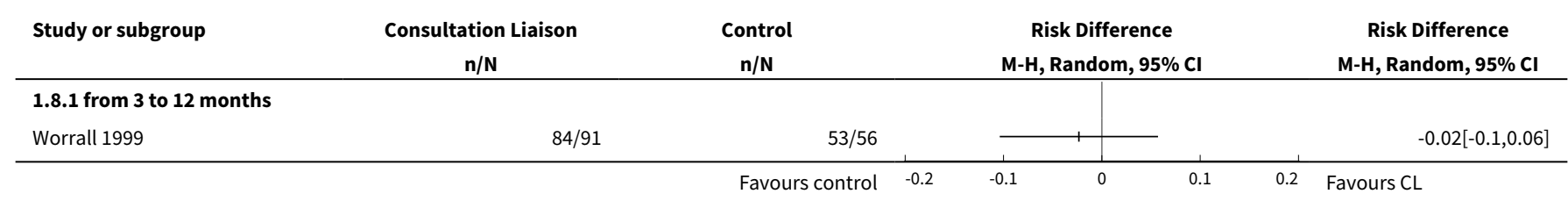

Analysis 1.9. Comparison 1 Consultation liaison versus control, Outcome 9 Received any treatment.

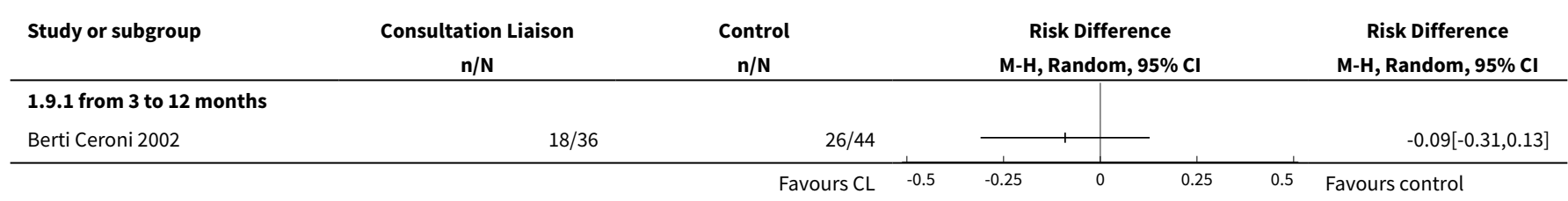

Analysis 1.10. Comparison 1 Consultation liaison versus control, Outcome 10 Received adequate treatment.

\begin{tabular}{|c|c|c|c|c|c|}
\hline \multirow[t]{2}{*}{ Study or subgroup } & $\begin{array}{l}\text { Consulta- } \\
\text { tion Liaison }\end{array}$ & Control & Risk Difference & Weight & Risk Difference \\
\hline & $n / N$ & $n / N$ & M-H, Random, $95 \% \mathrm{Cl}$ & & M-H, Random, 95\% C \\
\hline
\end{tabular}

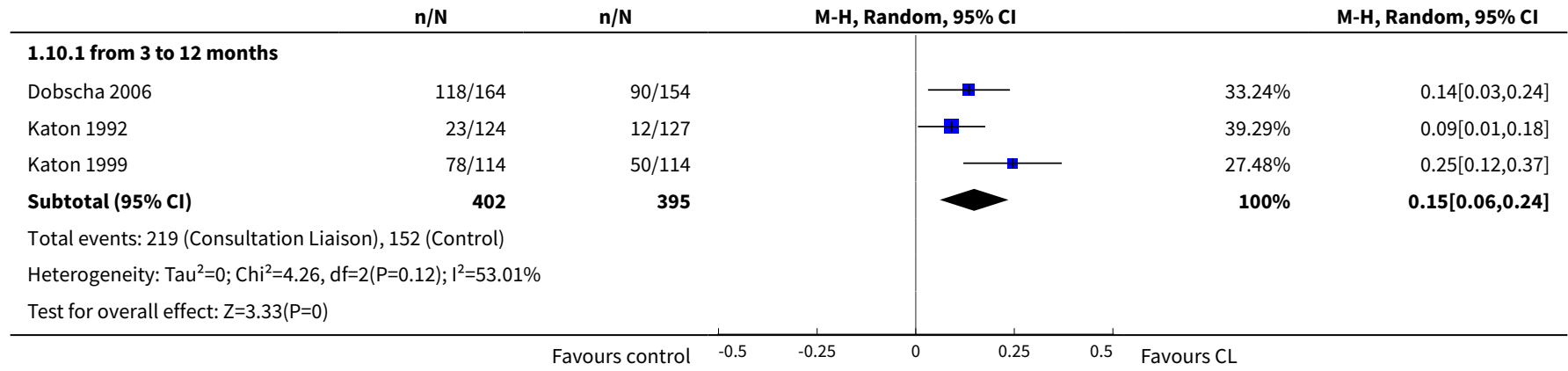

Analysis 1.11. Comparison 1 Consultation liaison versus control, Outcome 11 Specialist treatment.

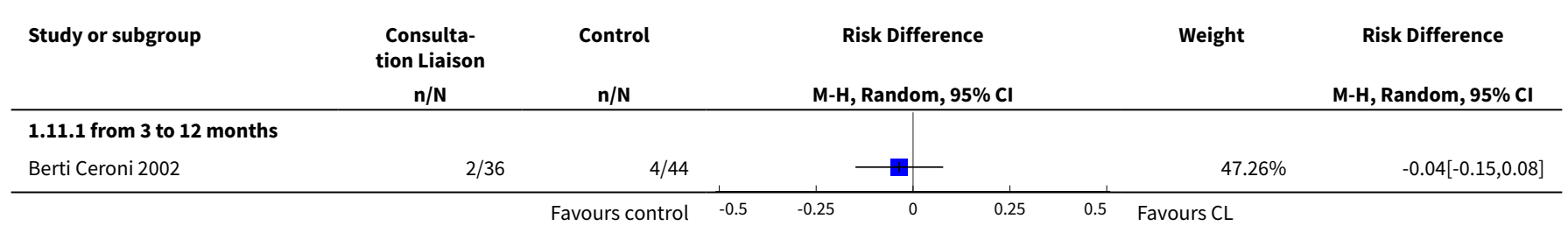




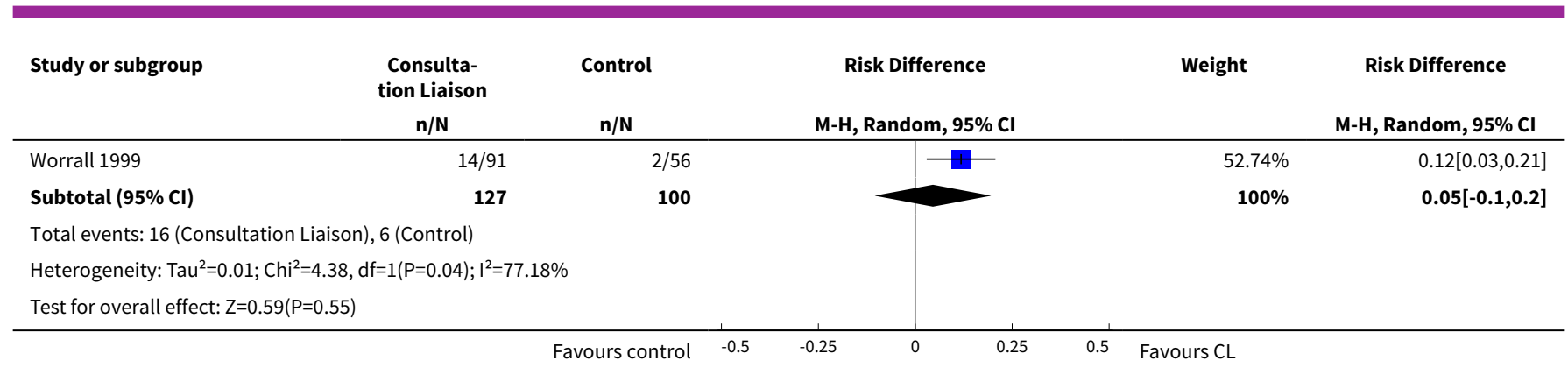

\section{Analysis 1.12. Comparison 1 Consultation liaison versus control, Outcome 12 Prescribing.}

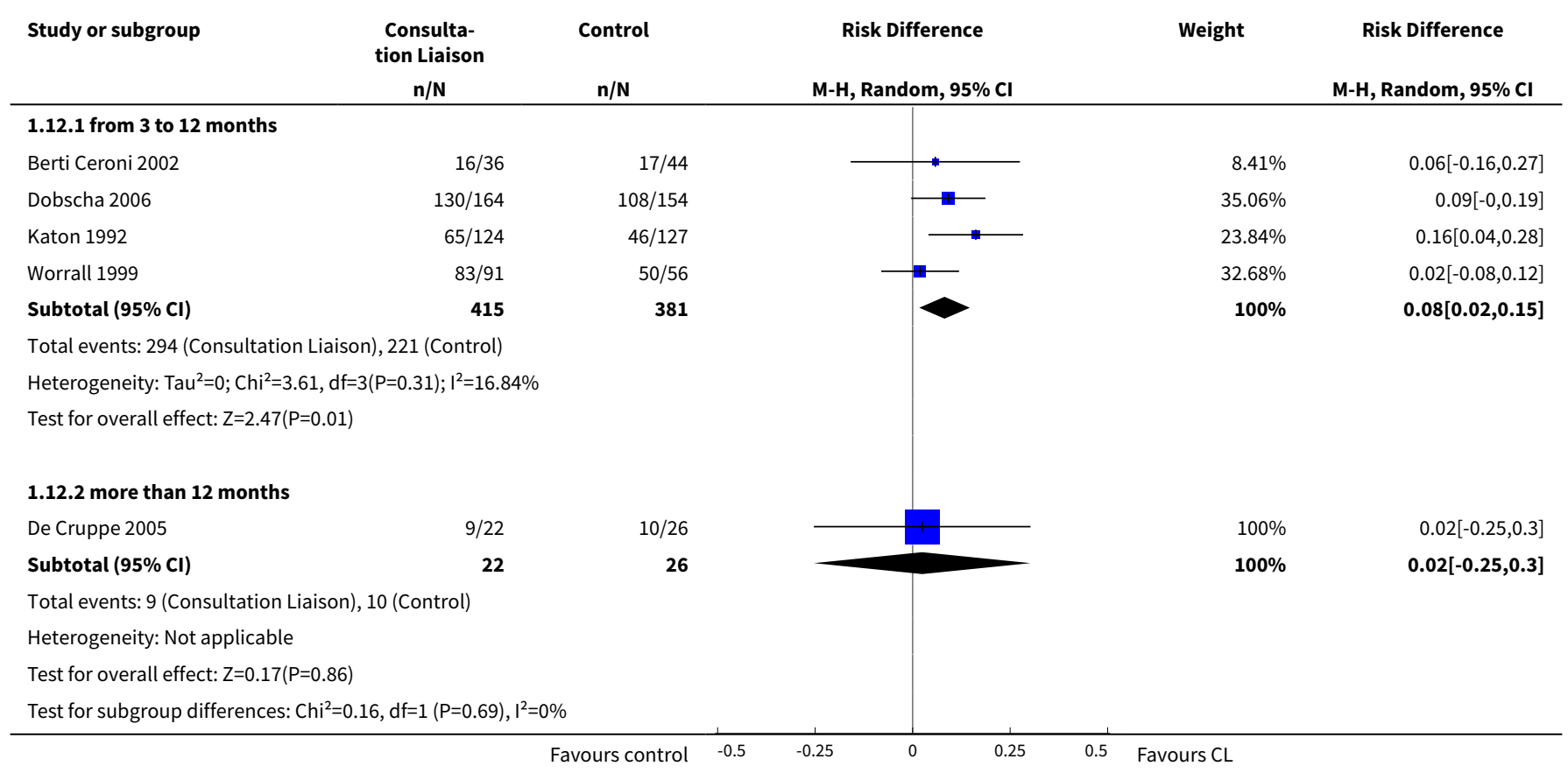

Analysis 1.13. Comparison 1 Consultation liaison versus control, Outcome 13 Primary care provider adherence.

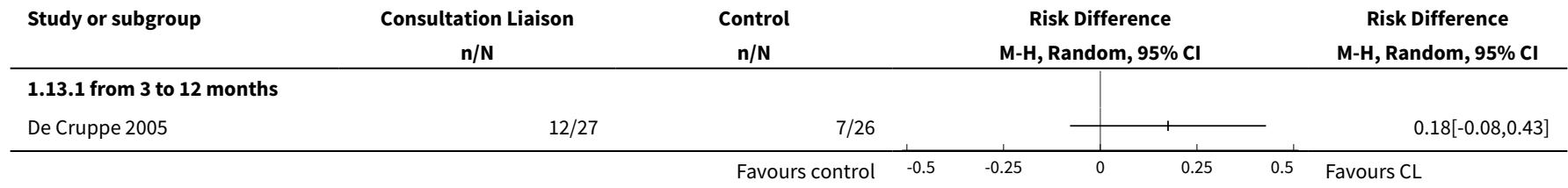

\section{Comparison 2. Consultation liaison versus collaborative care}

\begin{tabular}{lllll}
\hline $\begin{array}{l}\text { Outcome or subgroup } \\
\text { title }\end{array}$ & No. of studies & $\begin{array}{l}\text { No. of partici- } \\
\text { pants }\end{array}$ & Statistical method & Effect size \\
\hline 1 Improvement & 1 & Risk Difference (M-H, Fixed, 95\% Cl) & Totals not selected \\
\hline
\end{tabular}




\begin{tabular}{|c|c|c|c|c|}
\hline $\begin{array}{l}\text { Outcome or subgroup } \\
\text { title }\end{array}$ & No. of studies & $\begin{array}{l}\text { No. of partici- } \\
\text { pants }\end{array}$ & Statistical method & Effect size \\
\hline 1.1 up to 3 months & 1 & & Risk Difference (M-H, Fixed, 95\% Cl) & $0.0[0.0,0.0]$ \\
\hline 1.2 from 3 to 12 months & 1 & & Risk Difference (M-H, Fixed, 95\% Cl) & $0.0[0.0,0.0]$ \\
\hline 2 Symptoms & 1 & & Mean Difference (IV, Fixed, 95\% CI) & Totals not selected \\
\hline 2.1 up to 3 months & 1 & & Mean Difference (IV, Fixed, 95\% CI) & $0.0[0.0,0.0]$ \\
\hline 2.2 from 3 to 12 months & 1 & & Mean Difference (IV, Fixed, 95\% CI) & $0.0[0.0,0.0]$ \\
\hline 3 Consumer satisfaction & 1 & & Risk Difference (M-H, Fixed, 95\% Cl) & Totals not selected \\
\hline 3.1 up to 3 months & 1 & & Risk Difference (M-H, Fixed, 95\% Cl) & $0.0[0.0,0.0]$ \\
\hline 3.2 from 3 to 12 months & 1 & & Risk Difference (M-H, Fixed, 95\% Cl) & $0.0[0.0,0.0]$ \\
\hline 4 Disability & 1 & & Mean Difference (IV, Fixed, 95\% CI) & Totals not selected \\
\hline 4.1 up to 3 months & 1 & & Mean Difference (IV, Fixed, 95\% CI) & $0.0[0.0,0.0]$ \\
\hline 4.2 from 3 to 12 months & 1 & & Mean Difference (IV, Fixed, 95\% CI) & $0.0[0.0,0.0]$ \\
\hline 5 General health & 1 & & Mean Difference (IV, Fixed, 95\% CI) & Totals not selected \\
\hline 5.1 up to 3 months & 1 & & Mean Difference (IV, Fixed, 95\% CI) & $0.0[0.0,0.0]$ \\
\hline 5.2 from 3 to 12 months & 1 & & Mean Difference (IV, Fixed, 95\% CI) & $0.0[0.0,0.0]$ \\
\hline 6 Loss to follow-up & 1 & & Risk Difference (M-H, Fixed, 95\% Cl) & Totals not selected \\
\hline 6.1 up to 3 months & 1 & & Risk Difference (M-H, Fixed, 95\% Cl) & $0.0[0.0,0.0]$ \\
\hline 6.2 from 3 to 12 months & 1 & & Risk Difference (M-H, Fixed, 95\% Cl) & $0.0[0.0,0.0]$ \\
\hline $\begin{array}{l}7 \text { Received adequate } \\
\text { treatment }\end{array}$ & 1 & & Risk Difference (M-H, Fixed, 95\% Cl) & Totals not selected \\
\hline 7.1 from 3 to 12 months & 1 & & Risk Difference (M-H, Fixed, 95\% Cl) & $0.0[0.0,0.0]$ \\
\hline 8 Prescribing & 1 & & Risk Difference (M-H, Fixed, 95\% Cl) & Totals not selected \\
\hline 8.1 from 3 to 12 months & 1 & & Risk Difference (M-H, Fixed, 95\% Cl) & $0.0[0.0,0.0]$ \\
\hline
\end{tabular}

Analysis 2.1. Comparison 2 Consultation liaison versus collaborative care, Outcome 1 Improvement.

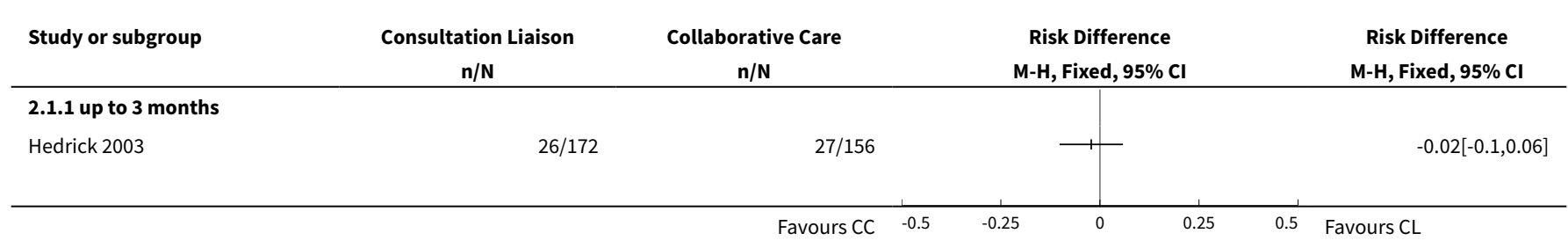




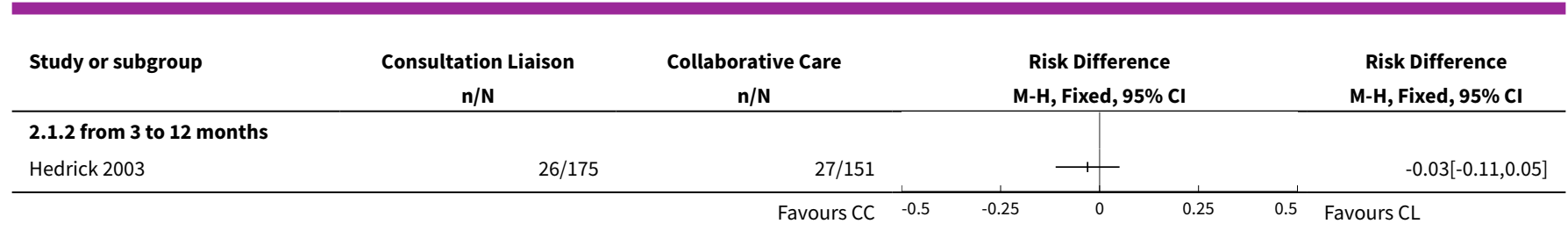

Analysis 2.2. Comparison 2 Consultation liaison versus collaborative care, Outcome 2 Symptoms.

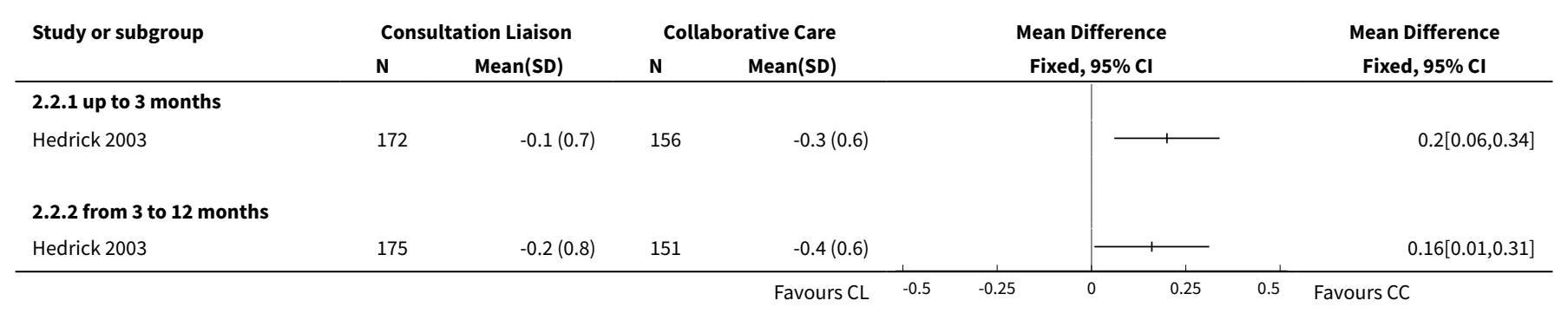

Analysis 2.3. Comparison 2 Consultation liaison versus collaborative care, Outcome 3 Consumer satisfaction.

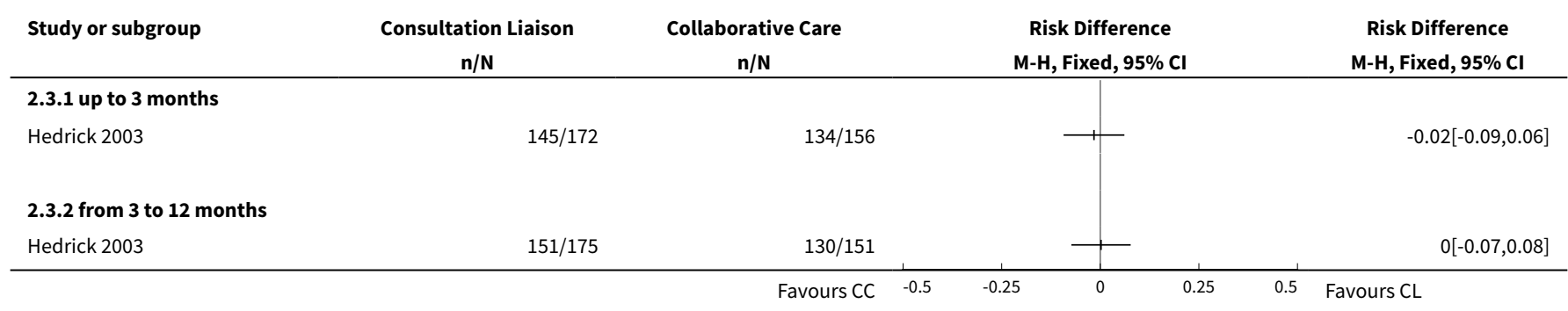

Analysis 2.4. Comparison 2 Consultation liaison versus collaborative care, Outcome 4 Disability.

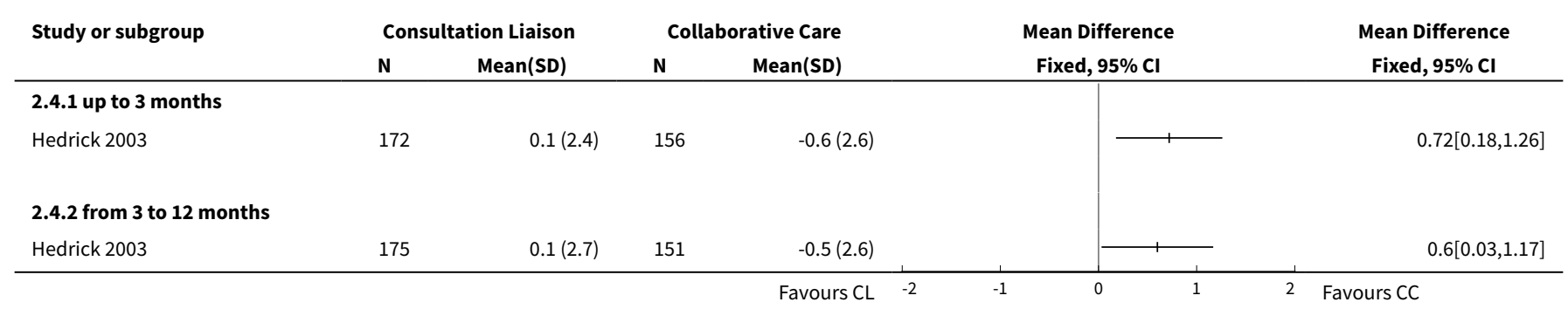

Analysis 2.5. Comparison 2 Consultation liaison versus collaborative care, Outcome 5 General health.

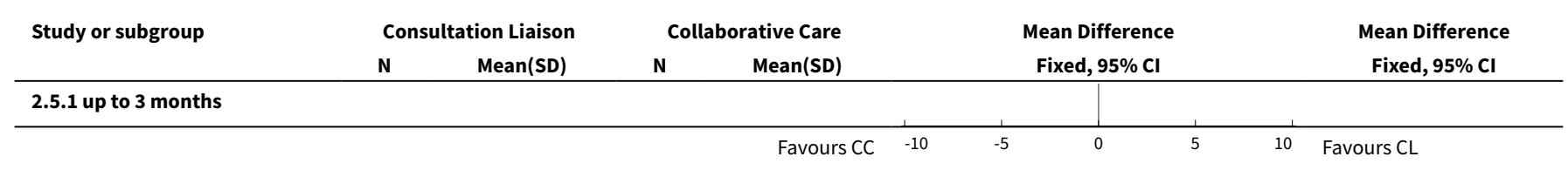




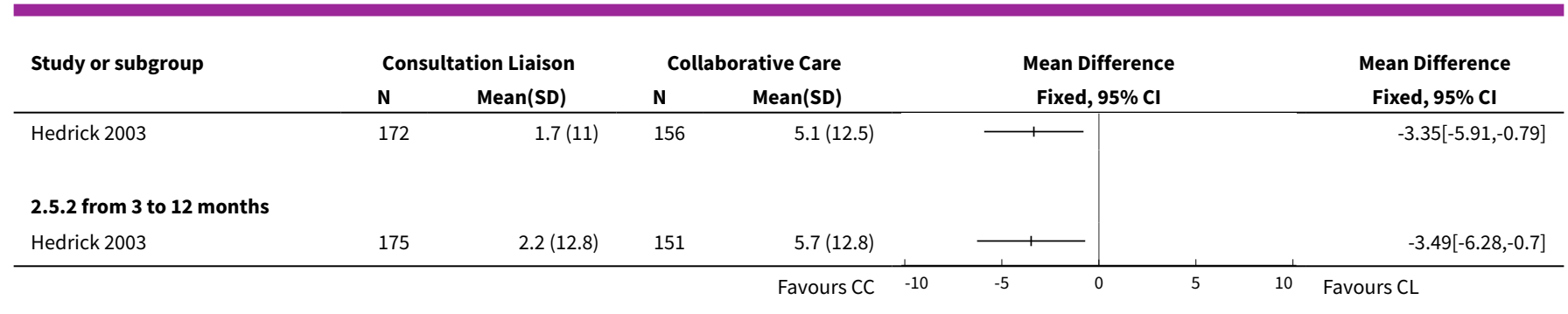

Analysis 2.6. Comparison 2 Consultation liaison versus collaborative care, Outcome 6 Loss to follow-up.

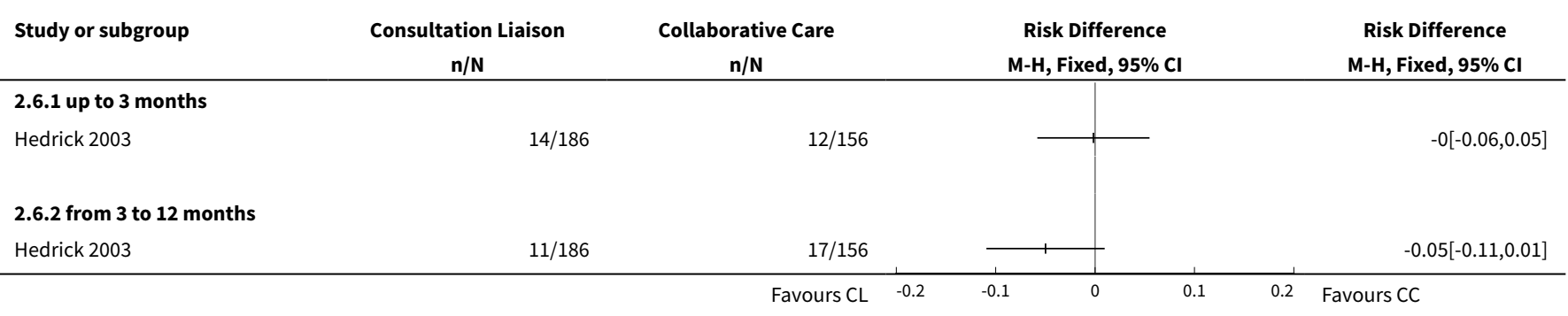

Analysis 2.7. Comparison 2 Consultation liaison versus collaborative care, Outcome 7 Received adequate treatment.

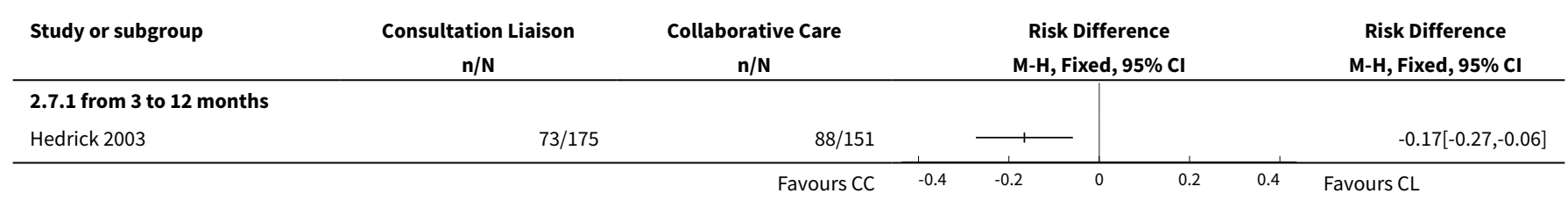

Analysis 2.8. Comparison 2 Consultation liaison versus collaborative care, Outcome 8 Prescribing.

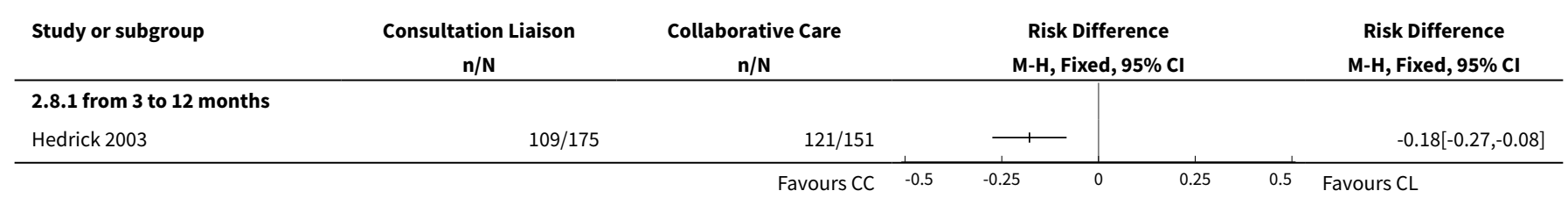

\section{ADDITIONAL TABLES}

Table 1. Symptoms - skewed data

\begin{tabular}{llllll}
\hline Study & Interval & group & sample & mean & SD \\
\hline $\begin{array}{l}\text { Drummond } \\
1990\end{array}$ & 6 months & Consultation liaison & 18 & 4.6 & 4.7 \\
\cline { 2 - 5 } & & Control & 19 & 5.4 & 7.0 \\
\hline \hline
\end{tabular}


Table 1. Symptoms - skewed data (Continued)

\begin{tabular}{|c|c|c|c|c|c|}
\hline \multirow[t]{6}{*}{ Katon 1999} & \multirow[t]{2}{*}{1 month } & Consultation liaison & 114 & 1.35 & 1.6 \\
\hline & & Control & 114 & 1.5 & 1.5 \\
\hline & \multirow[t]{2}{*}{3 months } & Consultation liaison & 114 & 1.05 & 1.6 \\
\hline & & Control & 114 & 1.35 & 1.5 \\
\hline & \multirow[t]{2}{*}{6 weeks } & Consultation liaison & 114 & 1.15 & 1.6 \\
\hline & & Control & 114 & 1.3 & 1.4 \\
\hline
\end{tabular}

Table 2. Healthcare visits - skewed data

\begin{tabular}{|c|c|c|c|c|c|}
\hline Study & Interval & group & sample $n$ & mean & SD \\
\hline \multirow{2}{*}{$\begin{array}{l}\text { Drummond } \\
1990\end{array}$} & 6 months & Consultation liaison & 18 & 4.6 & 6.4 \\
\hline & & Control & 19 & 1.8 & 1.8 \\
\hline \multirow[t]{4}{*}{ Katon 1999} & 6 weeks & Consultation liaison & 114 & 1.6 & 1.8 \\
\hline & & Control & 114 & 1.8 & 1.8 \\
\hline & 6 months & Consultation liaison & 114 & 3.4 & 4.3 \\
\hline & & Control & 114 & 3.3 & 3.1 \\
\hline \multirow{4}{*}{$\begin{array}{l}\text { Van der Feltz } \\
2006\end{array}$} & 6 weeks & Consultation liaison & 58 & 44.3 & 59.3 \\
\hline & & Control & 23 & 89.2 & 145.1 \\
\hline & 6 months & Consultation liaison & 58 & 32.7 & 25.6 \\
\hline & & Control & 23 & 133.9 & 219.4 \\
\hline \multirow[t]{2}{*}{ Worrall 1999} & 6 months & Consultation liaison & 91 & 3.6 & 7.7 \\
\hline & & Control & 56 & 4.2 & 7.6 \\
\hline
\end{tabular}

\section{AP PE N DICES}

\section{Appendix 1. MEDLINE search strategy}

1 consultation liaison.ti,ab. [this term is most often associated with a psychiatric model] (1153)

2 ((depression or mental or psych\$) adj3 (collaborativ\$ or liaison?)).ti,ab. (2495)

3 (psychiatr\$ and (general practitioner? or family doctor? or family practitioner? or family doctor? or GP)).ti. (347)

4 (psychiatr\$ adj4 (general practitioner? or family doctor? or family practitioner? or family doctor? or GP)).ab. (646)

5 ((psychiatri\$ or mental health or depression or depressed) and (general practice? or (primary adj2 care))).ti. (3253)

6 ((psychiatri\$ or mental health or depression or depressed) adj6 (general practice? or (primary adj2 care))).ab. (4550)

7 or/1-6 [Keyword Set] (9490)

8 community psychiatry/ or community mental health services/ (17831) 
9 (community adj3 (psychiatr\$ or mental health)).ti,ab. (7707)

10 or/8-9 [Community Psychiatry] (21868)

11 telepsychiatry.ti,ab. (322)

12 tele-psychiatry.ti,ab. (2)

14 mental health services/ or exp counseling/ or social work, psychiatric/ (60799)

15 psychotherapy/or behavior therapy/or cognitive therapy/ (77856)

16 behavioral medicine/ or psychiatry/or adolescent psychiatry/or biological psychiatry/or child psychiatry/or community psychiatry/or ethnopsychology/or geriatric psychiatry/or neuropsychiatry/or orthopsychiatry/or psychoanalysis/or psychosomatic medicine/ (54791) 17 exp mental disorders/ (957894)

18 (mental\$ adj2 (health or ill or illness\$ or disorder?)).ti,ab. or (bipolar or depression or schitzophr\$ or psychotic or anorex\$ or bulimi? or suicid\$).ti. or depressive.ti,ab. (275857)

19 (((mood or anxiety or eating) adj2 disorder?) or (PTSD or post-traumatic stress or bulimi\$ or anorexi\$)).ti,ab. (78418)

20 or/14-19 [Mental health/disorders/practitioners/therapies] (1191783)

21 Primary health care/ (55187)

22 Family practice/ or General Practice/ or Primary Care Nursing/ (65614)

23 General Practitioners/ or Physicians, Family/ or Physicians, Primary Care/ (18284)

24 ((general or family) adj2 (practice? or practitioner? or physician? or doctor?)).ti,ab. or GP.ti. (95569)

25 (primary adj2 (care or health care or healthcare or medical care or patient care)).ti,ab. (89077)

26 or/21-25 [Primary Care/Practitioners] (214638)

27 (randomized controlled trial or controlled clinical trial).pt. or randomized.ab. or placebo.ab. or clinical trials as topic.sh. or randomly.ab. or trial.ti. (930250)

28 exp animals/ not humans.sh. (4051829)

2927 not 28 [Cochrane RCT Filter 6.4.d Sens/Precision Maximizing] (859939)

30 (collaborativ\$ or target?ed or multidisciplin\$ or multi-disciplin\$ or interdisciplin\$ or inter-disciplin\$ or multi-facet\$ or multifacet\$ or coordinated or co-ordinated or coordinating or co-ordinating or shared care).ti. (57268)

3120 and 26 and 29 [Mental Disorders/practitioners \& Primary Care \& RCT] (4145)

32 (20 and 30 and 29) not 31 [Mental Disorders/practitioners \& Collaborative kw \& RCT] (414)

33 (and/7,29) not (or/31-32) [Keyword \& RCT] (152)

34 ((or/10,13) and (or/26,30) and 29) not (or/31-33) [Telepsych/Community psych \& PC or collab kw--RCT] (2)

3531 or 32 or 33 or $34(4713)$

36 remove duplicates from 35 (3984)

37 review.pt. or ((literature or evidence or systematic) adj3 review).ti. or metaanalys\$.ti,hw. or meta-analys\$.ti,hw. (1983039)

3836 and 37 [export as Review set] (352)

3936 not 38 [Export 2013 ML1.2 results all years deduping will be done in Reference Manager] (3632)

\section{WHAT'S NEW}

\begin{tabular}{lll}
\hline Date & Event & Description \\
\hline 12 December 2016 & Amended & $\begin{array}{l}\text { Changes to Summary of Findings Table without a change of con- } \\
\text { clusions }\end{array}$ \\
\hline
\end{tabular}

\section{CONTRIBUTIONSOF AUTHORS}

Donna Gillies - co-ordinated the review, study selection, data extraction, data entry and analysis, wrote the review.

Penny Buykx - study selection, data extraction, wrote the review.

Alex Parker - study selection, data extraction, wrote the protocol.

Sarah Hetrick - study selection, data extraction, wrote the protocol. 


\section{DECLARATIONS OF INTEREST}

Donna Gillies - none known. Penny Buykx - none known.

Alex Parker - none known.

Sarah Hetrick - none known.

\section{SOURCES OF SUPPORT}

\section{Internal sources}

- Western Sydney Local Health District - Mental Health, Parramatta, Australia.

- Monash University School of Rural Health, Bendigo, Australia.

- University of Melbourne, Melbourne, Australia.

\section{External sources}

- No sources of support supplied

\section{DIFFERENCES BETWEEN PROTOCOLANDREVIEW}

The protocol stated that "For CBA studies there needs to be contemporaneous data collection and a control group that is comparable on key characteristics"; however, these criteria were updated in line with the EPOC data checklist that there had to be at least two intervention and control sites for the study to be included.

In the protocol it was stated that:

- we would handsearch those high-yield journals and conference proceedings which have not already been handsearched on behalf of the Cochrane Collaboration;

- we would contact authors of relevant papers regarding any further published or unpublished work;

- we would contact authors of other reviews in the field of effective professional practice regarding relevant studies of which they may be aware; and

- we would search ISI Web of Science for papers which cite studies included in the review.

However, given the comprehensive search strategy that was available to us these were not done.

The author team and title have changed since the publication of the protocol (Parker 2008).

We had originally stated that we would calculate odds ratios for binary data; however, based on feedback from Peer Reviewers and the criteria for choosing methods of data synthesis described above, we used Risk Difference instead.

\section{IN DEX TERMS}

\section{Medical Subject Headings (MeSH)}

*Mental Health; Community Mental Health Services [*organization \& administration]; Depression [diagnosis] [therapy]; Mental Disorders [diagnosis] [*therapy]; Patient Care Team [*organization \& administration]; Patient Participation; Physician-Patient Relations; Primary Health Care [ ${ }^{*}$ organization \& administration]; Randomized Controlled Trials as Topic; Referral and Consultation [organization \& administration]

\section{MeSH check words}

Humans 